FLÁVIO URSCHEI

\title{
PROTOCOLO PARA A CONSTRUÇÃO DE OVERLAYS PARA DISTRIBUIÇÃO DE STREAMINGS EM REDES P2P
}


FLÁVIO URSCHEI

\section{PROTOCOLO PARA A CONSTRUÇÃO DE OVERLAYS PARA DISTRIBUIÇÃO DE STREAMINGS EM REDES P2P}

Dissertação apresentada à Escola

Politécnica da Universidade de

São Paulo para obtenção do

título de Mestre em Engenharia

São Paulo 
FLÁVIO URSCHEI

\title{
PROTOCOLO PARA A CONSTRUÇÃO DE OVERLAYS PARA DISTRIBUIÇÃO DE STREAMINGS EM REDES P2P
}

\author{
Dissertação apresentada à Escola \\ Politécnica da Universidade de \\ São Paulo para obtenção do \\ título de Mestre em Engenharia
}

Área de Concentração:

Sistemas Digitais

Orientadora:

Profa. Dra. Tereza Cristina Melo de Brito Carvalho 


\section{Urschei, Flávio}

Protocolo para a construção de overlays para distribuição de streamings em redes P2P / F. Urschei. -- São Paulo, 2009.

$96 \mathrm{p}$.

Dissertação (Mestrado) - Escola Politécnica da Universidade de São Paulo. Departamento de Engenharia de Computação e Sistemas Digitais.

1. Redes de computadores 2. Vídeo (Transmissão) 3. Siste mas distribuídos 4. Comunicações digitais I. Universidade de São Paulo. Escola Politécnica. Departamento de Engenharia de Computação e Sistemas Digitais II. t. 


\section{DEDICATÓRIA}

Dedico este trabalho aos meus pais. 


\section{AGRADECIMENTOS}

Primeiramente a Deus, por me dar força, saúde e coragem para enfrentar os três anos do curso de mestrado da Escola Politécnica da Universidade de São Paulo.

À professora Tereza Cristina Melo de Brito Carvalho por me orientar e ajudar naquilo que fosse preciso para o desenvolvimento dessa pesquisa.

Ao Frank Schaffa, membro do IBM Research, em Hawthorne, nos Estados Unidos, por me orientar durante todo o desenvolvimento dessa pesquisa, principalmente durante o período que estive lá.

À FAPESP - Fundação de Amparo à Pesquisa do Estado de São Paulo e à empresa Ericsson por viabilizarem os projetos de pesquisa durante o período em que estive no LARC.

Aos amigos Marcio A. L. Silva, Joelle Quaini, Diego Gallo e Marcos Tork que trabalharam comigo no LARC - Laboratório de Arquitetura e Redes de Computadores, apoiando-me no desenvolvimento de diversas atividades fundamentais para o desenvolvimento dessa pesquisa.

Ao meu pai, Pedro, e à minha mãe, Eneci, por me apoiarem, hoje e sempre. Sem eles, sei que não conseguiria chegar onde estou hoje.

À minha futura esposa, Carolina A. Sousa, por sempre me incentivar e apoiar na realização e conclusão do trabalho.

Tenho certeza que agradeci a uma pequena parte das pessoas a quem devo muito. Peço desculpas àquelas que omiti. 


\section{EPIGRAFE}

A diferença entre o sonho e a realidade é a quantidade certa de tempo e trabalho.

(Willian Douglas) 


\section{RESUMO}

O desenvolvimento da Internet motivou o surgimento de inúmeras aplicações que utilizam sua infra-estrutura. Dentre elas destacam-se as aplicações P2P para a transmissão de streamings de voz/vídeo. Essas aplicações exigem que determinados requisitos como largura de banda, latência, variação de atraso, escalabilidade, disponibilidade, entre outros, sejam satisfeitos para que possa haver qualidade no serviço provido (QoS - Quality of Service). Satisfazer a todos esses requisitos torna-se um grande desafio quando é utilizada a infra-estrutura da Internet para transmissão. Deste modo, impulsionado pelo grande atrativo que existe no paradigma $\mathrm{P} 2 \mathrm{P}$, assim como todos os desafios por trás dessa abordagem, o objetivo principal deste trabalho é a proposta de um protocolo para a construção de overlays para a distribuição de streamings de vídeo em redes P2P. O protocolo proposto visa garantir que o overlay a ser empregado na distribuição de streamings seja construído, levando-se em consideração as características da rede física (nesse trabalho, a Internet) sob o mesmo. A idéia fundamental deste protocolo é organizar os pares de forma dinâmica, agrupando aqueles que estão mais próximos em termos de latência. $O$ segundo objetivo a ser alcançado neste trabalho é a validação do protocolo por meio de experimentos (prova de conceito) realizados com o PlanetLab, de modo a validar os mecanismos propostos.

Palavras-chave: Redes overlay. P2P streaming. Distribuição de vídeo. Sistemas distribuídos. 


\begin{abstract}
The Internet development has leveraged several kinds of application that depends on its infrastructure, such as P2P applications to voice/video streaming transmission. These applications have a plenty of requirements, such as bandwidth, latency, jitter, scalability, availability, and so on, that should be fulfilled in order to achieve the required level of Quality of Service (QoS). When it is used the Internet infrastructure to transmission, it is a great challenge fulfill all these requirements. In this manner, the main goal of this work is to propose a protocol to build an overlay to distribute video streaming in $\mathrm{P} 2 \mathrm{P}$ networks, taking into account the network characteristics. The fundamental idea of this protocol is dynamically organize the peers, gathering these peers considering the latency between them. Another goal of this work is the protocol assessment by means of experiments (proof of concept) performed in PlanetLab, in order to verify the proposed mechanisms.
\end{abstract}

Keywords: Network computing. Video distribution. Streaming over peers. Distributed systems. 


\section{LISTA DE ILUSTRAÇÕES}

Figura 2.1 - Taxonomia de arquiteturas para a distribuição de vídeo em larga escala (broadcast). Adaptado de (JIANGCHUAN et al., 2008).

Figura 2.2 - Representação do buffer do BitTorrent (POUWELSE et al., 2005) (a) e CoolStreaming (b), onde os segmentos sombreados são os que estão disponíveis no buffer. Extraído de (XINYAN et al., 2005).

Figura 2.3 - mTreebone - Saída e falha de um nó. Extraído de (WANG; XIONG; LIU, 2007). 35

Figura 4.1 - Aspecto geral da organização do overlay. 50

Figura 4.2 - Diagrama de troca de mensagens. 53

Figura 4.3 - Máquinas de estados para a Fonte (a) e para os Controladores Designados (b). 54

Figura 4.4 - Máquina de estados para um novo nó Nx. 55

Figura 4.5 - Máquinas de estados para o Servidor de Aplicação (a), para os Controladores Ordinários (b) e para os Nós de Referência (c). 57

Figura 4.6 - Armazenamento de Coordenadas. 60

Figura 5.1 - Estimativa das coordenadas quando há solução para as equações. ...74

Figura 5.2 - Estimativa das coordenadas quando há solução parcial para as equações. 75

Figura 5.3 - Estimativa das coordenadas quando não há solução para as equações. 


\section{LISTA DE GRÁFICOS}

Gráfico 5.1 - Resultado da análise das distâncias (latências) entre os Nós de Referência nos diferentes períodos.

Gráfico 5.2 - Porcentagem de casos em que foi possível estimas as coordenadas cenário RF_PROXIMOS_NOS_PROXIMOS.

Gráfico 5.3 - Comportamento do erro de estimativa das coordenadas $(\varepsilon)$ - Cenário RF_PROXIMOS_NOS_PROXIMOS.

Gráfico 5.4 - Porcentagem de casos em que foi possível estimas as coordenadas cenário RF_PROXIMOS_NOS_EUA.

Gráfico 5.5 - Porcentagem de casos em que foi possível estimas as coordenadas cenário RF_PROXIMOS_NOS_LONGE.

Gráfico 5.6 - Comportamento do erro de estimativa das coordenadas $(\varepsilon)$ - Cenário RF_PROXIMOS_NOS_EUA.

Gráfico 5.7 - Comportamento do erro de estimativa das coordenadas $(\varepsilon)$ - Cenário RF_PROXIMOS_NOS_LONGE.

Gráfico 5.8 - Porcentagem de casos em que foi possível estimas as coordenadas cenário RF_EUA_NOS_PROXIMOS

Gráfico 5.9 - Porcentagem de casos em que foi possível estimas as coordenadas cenário RF_LONGE_NOS_PROXIMOS.

Gráfico 5.10 - Comportamento do erro de estimativa das coordenadas $(\varepsilon)$ - Cenário RF_EUA_NOS_PROXIMOS.

Gráfico 5.11 - Comportamento do erro de estimativa das coordenadas $(\varepsilon)$ - Cenário RF_LONGE_NOS_PROXIMOS.

Gráfico 5.12 - Porcentagem de casos em que foi possível estimas as coordenadas cenário RF_EUA_NOS_EUA.

Gráfico 5.13 - Porcentagem de casos em que foi possível estimas as coordenadas cenário RF_EUA_NOS_LONGE. 
Gráfico 5.14 - Porcentagem de casos em que foi possível estimas as coordenadas cenário RF_LONGE_NOS_EUA.

Gráfico 5.15 - Porcentagem de casos em que foi possível estimas as coordenadas cenário RF_LONGE_NOS_LONGE.

Gráfico 5.16 - Comportamento do erro de estimativa das coordenadas $(\varepsilon)$ - Cenário RF_EUA_NOS_EUA.

Gráfico 5.17 - Comportamento do erro de estimativa das coordenadas $(\varepsilon)$ - Cenário RF_EUA_NOS_LONGE. 86

Gráfico 5.18 - Comportamento do erro de estimativa das coordenadas $(\varepsilon)$ - Cenário RF_LONGE_NOS_EUA. 86

Gráfico 5.19 - Comportamento do erro de estimativa das coordenadas $(\varepsilon)$ - Cenário RF_LONGE_NOS_LONGE. 87

Gráfico 5.20 - Distribuição cumulativa de probabilidades para o erro estimado. 88 


\section{LISTA DE TABELAS}

Tabela 2.1 - Sumário comparativo das abordagens para distribuição de streaming de vídeo.

Tabela 3.1 - Índice de desempenho médio para a seleção do melhor par dentro de um conjunto de 10 candidatos (baseado em (NG et al., 2003)) 40

Tabela 5.1 - Conjunto de nós próximos. 62

Tabela 5.2 - Conjunto de nós nos Estados Unidos. 63

Tabela 5.3 - Conjunto de nós espalhados pelo mundo. 63

Tabela 5.4 - Sumário dos resultados na geração dos Nós de Referência. 66

Tabela 5.5 - Sumário dos resultados na geração dos Nós de Referência por período de execução.

Tabela 5.6 - Sumário dos cenários experimentais avaliados. 72 


\section{LISTA DE ABREVIATURAS E SIGLAS}

\{Ci\} Lista de Controladores Candidatos

ACK ACKnowledgement

AS Application Server (Servidor de Aplicação)

C Controladores

CDN Content Delivery Networks

Ci Controlador Candidato

Cj Controlador Designado

G Group (Agrupamento de Nós)

ICMP Internet Control Message Protocol

ID Índice de Desempenho

IP Internet Protocol

IR Índice de Recursos

L Landmark nodes (Nós de Referência)

LCT Local Coordinate Table

LT Latency Threshold

MDC Multiple Description Coding

MTU Maximum Transmission Unit

N Nós Ordinários

NAT Network Address Translation 
OSI

Open Systems Interconnection

P2P

Peer-to-Peer

QoS

Quality of Service

QRC

Quadrant Representative Controller

RTT

Round-Trip Time

$\mathrm{S} / \mathrm{C}_{0}$

Source/Controllero (Fonte/Primeiro Controlador)

TCP

Transmission Control Protocol 


\section{SUMÁRIO}

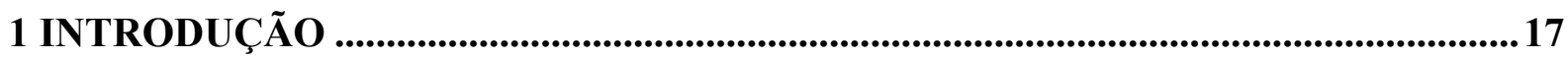

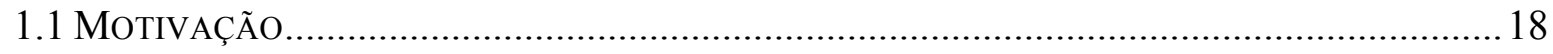

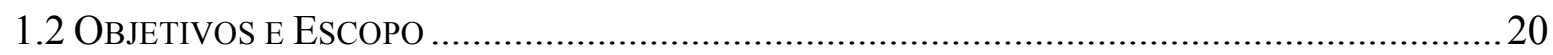

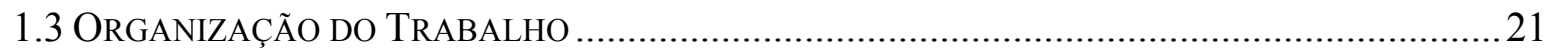

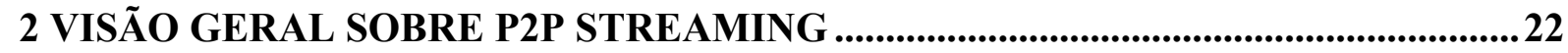

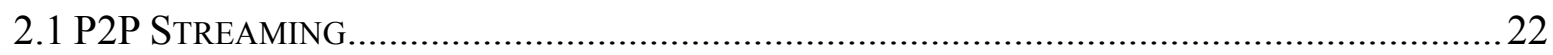

2.2 TAXONOMia PARA A Distribuição DE VÍDEO EM LARGa EsCALA (BROADCAST)..........23

2.3 Métodos de Distribuição de Vídeo em Redes P2P ...................................................25

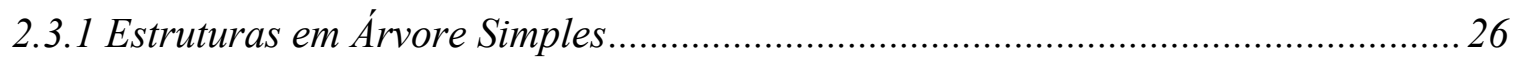

2.3.2 Estruturas em Múltiplas Árvores ........................................................................... 27

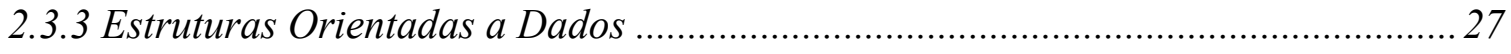

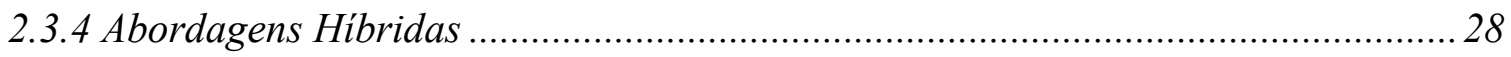

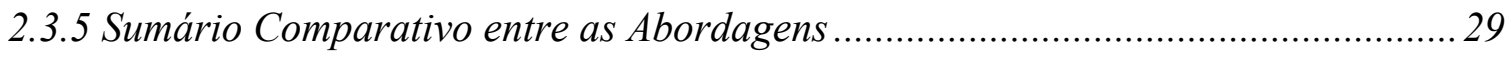

2.4 Exemplos de Soluções Existentes Para Streaming de Vídeo em Redes P2P ........31

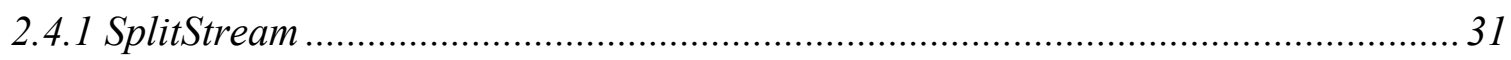

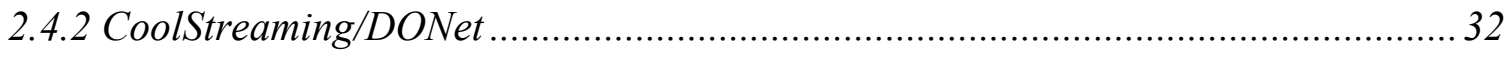

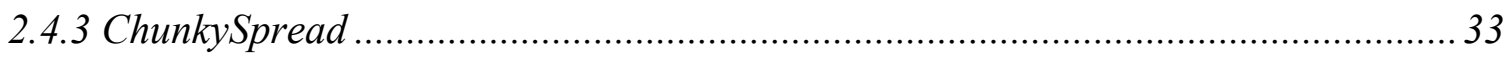

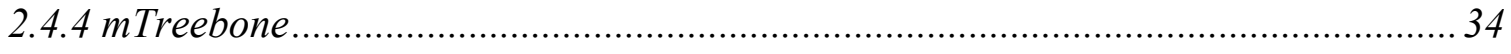

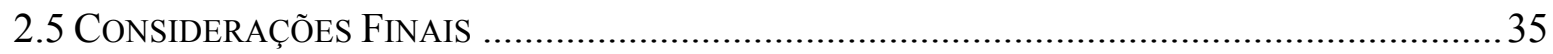

3 TÉCNICAS PARA A CONSTRUÇÃO DE OVERLAYS ................................................36

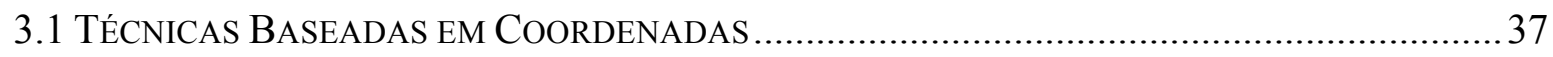

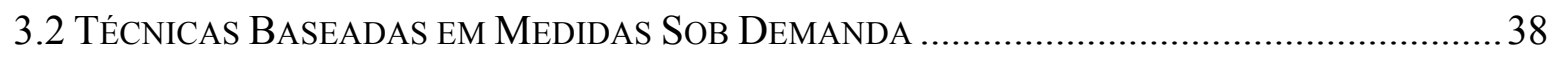

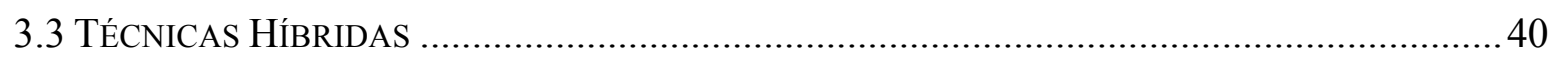

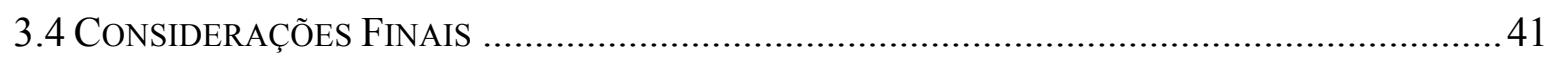

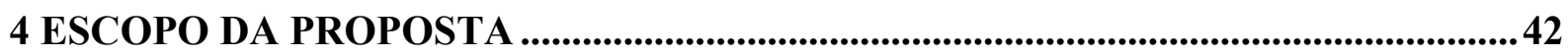

4.1 ESPECIFICAÇÃo de REQUisitos Do PROTOCOLO ........................................................ 42

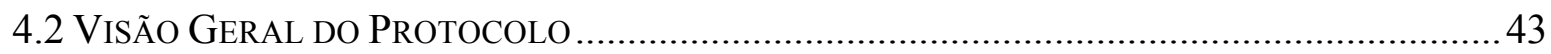

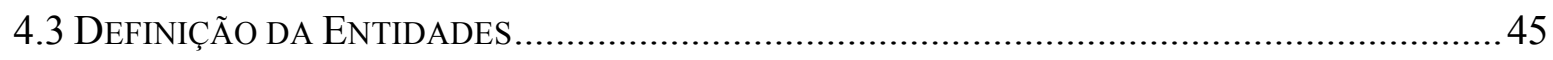

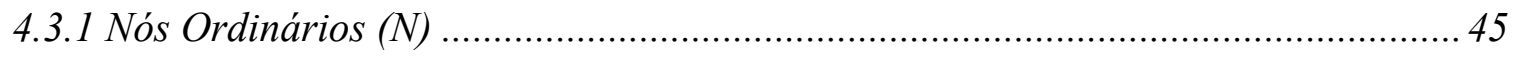




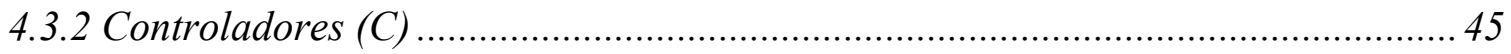

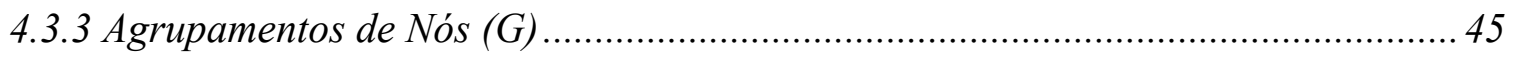

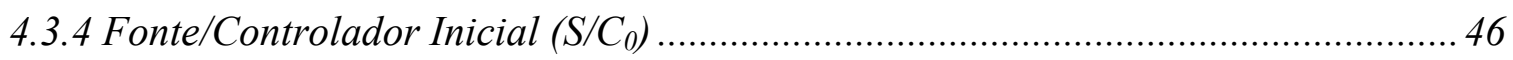

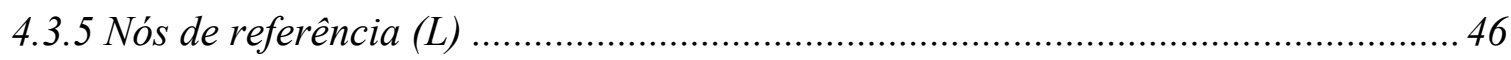

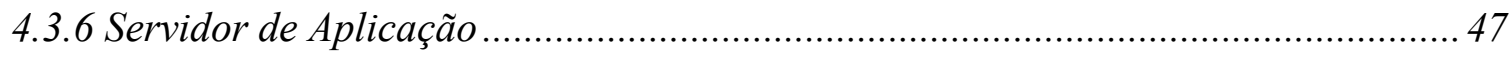

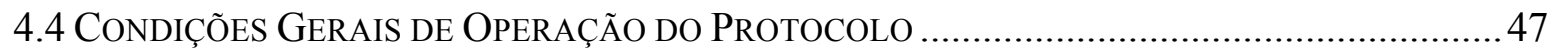

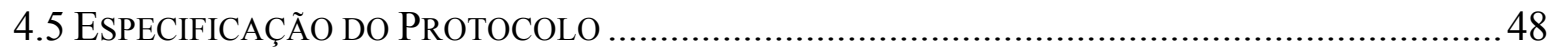

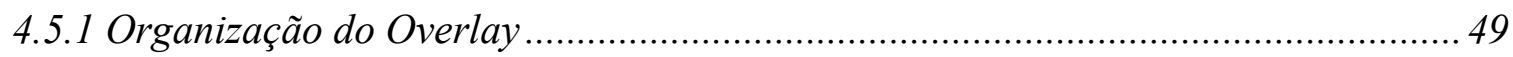

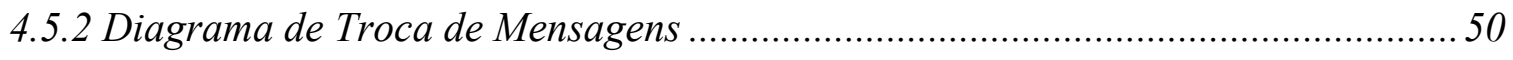

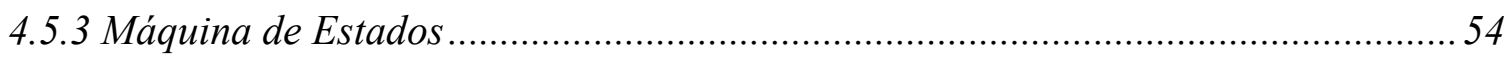

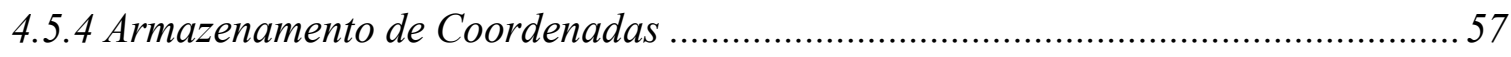

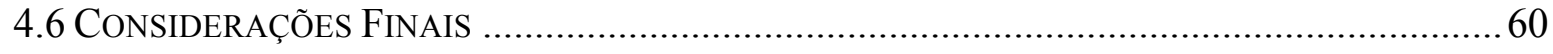

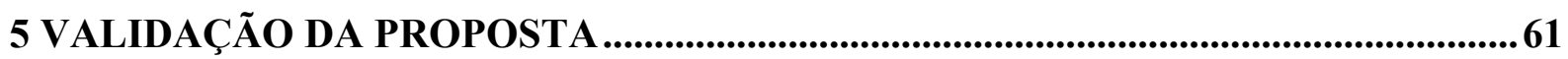

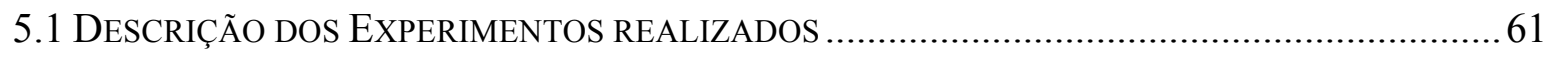

5.1.1 Validação do Método de Construção do Sistema de Coordenadas ........................... 64

5.1.1.1 Influência da Posição dos Nós de Referência.......................................................64

5.1.1.2 Influência do Período de Construção do Overlay.............................................66

5.1.1.3 Influência do Método de Medida Utilizado.......................................................67

5.1.2 Estimativa do Erro no Processo de Cálculo das Coordenadas ................................ 69

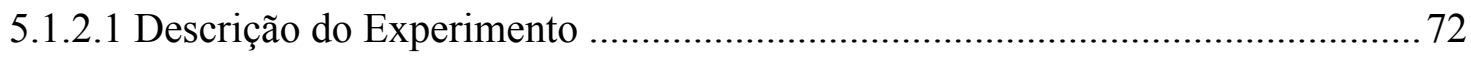

5.1.2.2 Tratamento para os Casos sem Solução para a Equação ................................... 73

5.2 ANÁliSE dos RESUltados PARA o ERRo de ESTIMATIVA .............................................76

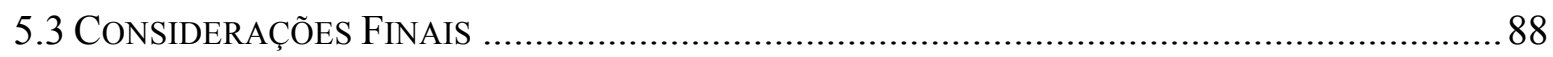

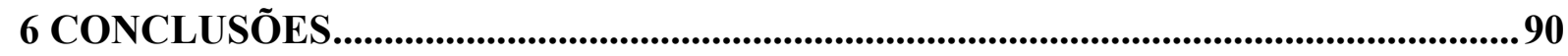

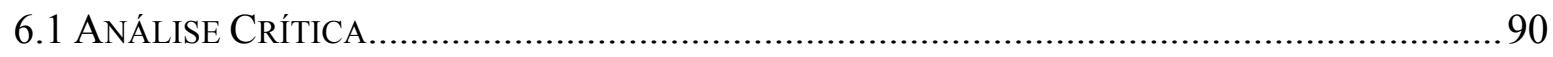

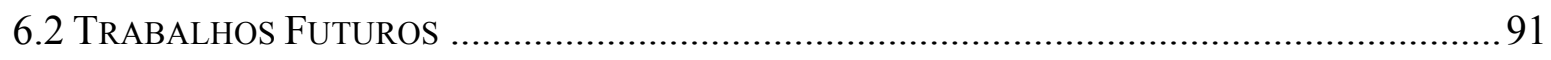

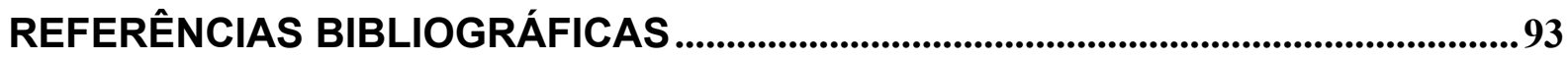




\section{INTRODUÇÃO}

O crescimento da Internet motivou o surgimento de inúmeras aplicações que utilizam sua infra-estrutura. Dentre elas destacam-se as aplicações de voz e vídeo, que podem ser consideradas "killer applications"1 para esse ambiente. Embora a Internet seja uma rede que funcione como meio de transmissão para tais aplicações, não existe a garantia de qualidade de serviço (QoS - Quality of Service) (WANG, 2001) (SUBRAMANIAN; STOICA; BALAKRISHNAN, 2004), (SUBRAMANIAN; STOICA; BALAKRISHNAN, 2004), característica esta que é inerente à natureza pública e altamente heterogênea desta rede. Entenda-se por qualidade de serviço o determinismo e constância no provimento dos mesmos (ex: alta disponibilidade e confiabilidade, largura de banda e latências determinísticos, entre outros).

Neste contexto, novos paradigmas de aplicações surgiram, como as aplicações P2P (Peer-to-Peer), em que um determinado serviço é provido por meio da somatória dos recursos de outros pares (Peers), ou seja, um par que faz parte de uma rede P2P recebe um serviço em troca do compartilhamento de uma parcela de seus próprios recursos (TANG et tal., 2007). Assim, por exemplo, em uma aplicação P2P para o compartilhamento de documentos, cada par tem à sua disposição um repertório de arquivos que poderão ser transferidos (serviço) em contrapartida ao armazenamento local de uma parcela do repertório de documentos existentes. Aplicações P2P utilizam redes P2P para a comunicação de seus pares. Entenda-se por redes P2P, overlays construídos sobre a camada de rede do modelo OSI (Open Systems Interconnection). Em uma rede P2P não são previstos elementos fixos de infraestrutura tais como roteadores e servidores, ou seja, os recursos necessários advém dos pares participantes.

Dentre as aplicações P2P existentes, destacam-se aquelas que transmitem streamings (fluxos) de voz/vídeo. Dentre estas, temos dois grandes grupos, as que não consideram interatividade dos pares, como a transmissão de um filme em

\footnotetext{
${ }^{1}$ É a designação dada às aplicações que alavancam o desenvolvimento de determinada tecnologia. Por exemplo: vídeo streaming pode ser considerada uma "killer application" para as infra-estruturas com alta disponibilidade de largura de banda.
} 
broadcast e as que consideram, como uma áudio/vídeo conferência. Ambas as categorias exigem que determinados requisitos sejam satisfeitos para que possa haver qualidade no serviço provido. Requisitos como, largura de banda, latência, atraso e variação de atraso (jitter) adequados, escalabilidade, disponibilidade, entre outros. Satisfazer a todos estes requisitos torna-se um grande desafio quando é utilizada a infra-estrutura da Internet para transmissão.

Nesse contexto, surge um paradoxo referente a como satisfazer todos os requisitos necessários para prover um serviço de streaming de voz/vídeo com qualidade, utilizando uma infra-estrutura de rede, a Internet, que não atende esses requisitos de forma determinística e nativa. Esse fato é o grande motivador da presente dissertação que tem por objetivo propor e analisar os limites de um protocolo para a construção de overlays escaláveis para a distribuição de streamings de vídeo em redes $\mathrm{P} 2 \mathrm{P}$ (Peer-to-Peer).

Dentro dessa proposta de trabalho, não há apenas a elaboração de um protocolo para a construção dos supracitados overlays, mas também a tentativa de validação e estabelecimento das limitações presentes no mesmo, de forma a estabelecer uma linha de base para futuros trabalhos.

\subsection{Motivação}

Conforme mencionado, garantir o nível de qualidade de serviço para uma aplicação P2P de streaming de voz/vídeo utilizando-se a Internet acaba por ser um paradoxo. As primeiras tentativas para isso consideravam protocolos multicast (LAO et al., 2005), no entanto, tal abordagem não se desenvolveu, uma vez que tais protocolos não são amplamente implementados na Internet (JIANGCHUAN et al., 2008), (YIU; XING; CHAN, 2007), o que implica em problemas de escalabilidade e viabilidade na prestação de serviço fim-a-fim com a QoS desejada. Além disso, pelo fato destes protocolos de multicast serem implementados na camada de rede, não oferecem 
suporte para funcionalidades de alto nível ${ }^{2}$. A falta de infra-estrutura na Internet para suportar IP multicast faz com que sejam necessárias redes controladas (de caráter privado) para sua implementação, o que impacta diretamente no custo das soluções que utilizam essa abordagem. Neste contexto, a abordagem P2P mostra-se extremamente atrativa, visto que não requer o suporte de roteadores e infraestrutura de rede com uma tecnologia específica, o que implica diretamente na redução de custos e facilidade de implementação. Adicionalmente, como na abordagem P2P, um par não só recebe um serviço (faz o download de um streaming de vídeo de outros pares), mas também compartilha parte de seus recursos com outros pares (faz o upload de um streaming para outros pares), quanto maior o número de membros participantes, maior será a quantidade de recursos disponível, o que permite a escalabilidade do serviço. Aliado a isso, a pluralidade de pares faz com que haja resiliência do serviço, ou seja, o sistema pode se adaptar à entrada e saída de pares e continuar garantindo o nível de serviço. Esta característica é um grande atrativo desse tipo de tecnologia, principalmente, em aplicações de voz/vídeo distribuídas em larga escala (broadcast).

Apesar de ser uma abordagem potencialmente muito promissora, o paradigma $\mathrm{P} 2 \mathrm{P}$ traz também muitos desafios. Há problemas de heterogeneidade de recursos entre os pares (diferenças de largura de banda, recursos computacionais, entre outros), problemas com o dinamismo dos pares no overlay (muitas entradas e saídas), principalmente quando ocorre uma grande quantidade de saída e/ou entrada de pares simultaneamente e problemas relacionados à falta de associação entre o overlay lógico e a rede física que o suporta. Há, também, questões relacionadas a incentivo, ou seja, como garantir, mesmo que minimamente, que os pares irão contribuir com recursos de forma equivalente ao serviço que estão recebendo. Outras questões, não menos importantes, referem-se à implementação, como problemas com pares que estão atrás de NAT e Firewalls. Além disso, há questões relacionadas ao atraso necessário para iniciar a recepção do streaming, ou ainda para mudar o streaming que está sendo recebido (uma mudança de canal, por exemplo), entre outras (YIU; XING; CHAN, 2007).

\footnotetext{
${ }^{2}$ Como exemplos de funcionalidades de alto nível não suportadas pelo IP multicast pode-se citar aquelas providas pela camada TCP, como o controle de fluxo e congestionamento
} 
Existem diversas soluções para distribuição de voz/vídeo que seguem o paradigma P2P. Muitas delas contemplam cenários de distribuição em larga escala (broadcast) sem considerar interatividade. Um estudo sobre diversos trabalhos, como os apresentados em (VENKATARAMAN; YOSHIDA; FRANCIS, 2006), (XINYAN et al., 2005), (PAl et al., 2005), (KOSTIC et al., 2003), (CASTRO; DRUSCHEL; LER,ARREC, 2003) e (WANG; XIONG; LIU, 2007), demonstra que, apesar de haver inúmeras abordagens para tentar construir um overlay escalável, viáveis em termos e custo, com garantia de qualidade de serviço, e que escale, a maioria desses trabalhos, muitas vezes utilizando técnicas de simulação, não consideram a falta de associação entre a rede overlay lógica construída e a rede física (Internet) que suporta esse overlay. Assim, apesar de muitas vezes tratarem-se de trabalhos inovadores, os resultados práticos acabam não sendo muito satisfatórios.

Deste modo, o grande motivador do presente trabalho, impulsionado pelo grande atrativo que existe no paradigma $\mathrm{P} 2 \mathrm{P}$, assim como todos os desafios por trás dessa abordagem, muitos deles ainda não solucionados, ou solucionados de forma parcial é o problema relativo às formas de construção do overlay para suportar a distribuição de streamings de vídeo, levando-se em consideração as características da rede física que o suporta.

\subsection{Objetivos e Escopo}

O objetivo principal deste trabalho é a proposta de um protocolo para a construção de overlays para a distribuição de streamings de vídeo em redes $\mathrm{P} 2 \mathrm{P}$. O protocolo proposto visa garantir que o overlay a ser empregado na distribuição de streamings seja construído, levando-se em consideração as características da rede física (nesse trabalho, a Internet) sob o mesmo. A idéia fundamental deste protocolo é organizar os pares de forma dinâmica, agrupando aqueles que estão mais próximos em termos de latência.

O segundo objetivo a ser alcançado neste trabalho é a validação do protocolo por meio de experimentos (prova de conceito) realizados com o PlanetLab (PLANETLAB, 2008), de modo a validar os mecanismos propostos. 


\subsection{Organização do Trabalho}

O próximo capítulo apresenta uma revisão bibliográfica que irá fornecer uma visão geral sobre P2P streaming. Serão explicados alguns conceitos e apresentada uma taxonomia para a distribuição de conteúdo. Ainda, nesse capítulo, serão descritas e comparadas as técnicas mais comumente utilizadas para a distribuição de vídeo em redes $\mathrm{P} 2 \mathrm{P}$, mais propriamente as técnicas utilizadas para a construção do overlay de distribuição, como as estruturas em árvore simples, as estruturas de múltiplas árvores, as técnicas orientadas a dados (não utilizam estruturas) e as técnicas híbridas. Em seguida serão apresentadas algumas das soluções existentes, comparando-as sempre que for possível ${ }^{3}$.

Em seguida, o capítulo três descreve técnicas para a construção de overlays para a distribuição de streamings, considerando aquelas baseadas em sistemas de coordenadas, aquelas baseadas em medidas sob demanda e as técnicas híbridas, evidenciando as vantagens e desvantagens de cada tipo de abordagem.

No capítulo quatro, é descrito o protocolo para a construção do overlay. São descritas as entidades presentes e o papel de cada uma. Em seguida, são apresentadas justificativas para algumas decisões tomadas, assim como uma visão detalhada do algoritmo para a construção do overlay, ressaltando o que está dentro e fora do seu escopo, identificando-se eventuais problemas não endereçados pelo mesmo. Por fim, é mostrada uma descrição mais formal do protocolo, o que compreende um diagrama de troca de mensagens, ainda que em alto nível, e uma máquina de estados.

No capítulo cinco são apresentadas as descrições e resultados dos experimentos realizados para a validação do protocolo, assim como uma discussão sobre os mesmos. O capítulo seis apresenta as conclusões do trabalho.

\footnotetext{
${ }^{3}$ Devido as grandes diferenças de abordagem e falta de uma metodologia comum para validação das soluções, muitas vezes torna-se extremamente difícil estabelecer uma comparação entre as mesmas considerando-se métricas objetivas.
} 


\section{VISÃO GERAL SOBRE P2P STREAMING}

Este capítulo tem por objetivo fornecer uma visão geral sobre P2P streaming e os conceitos envolvidos. Além disso, será descrita uma taxonomia que visa estabelecer uma classificação das arquiteturas existentes para a distribuição de conteúdo em larga escala (broadcast) na Internet. Em seguida, serão apresentadas abordagens de distribuição: baseados em estruturas em árvore (tree-based/Push - simples ou múltiplas), dirigidas por dados (data-driven/Pull) e híbridas. Por fim, serão descritas algumas soluções consideradas relevantes para esse trabalho.

\subsection{P2P Streaming}

Uma arquitetura P2P (Peer-to-Peer) considera que cada par (Peer) é um nó eqüipotente em termos de funcionalidade, ou melhor, estabelecendo-se um paralelo com as arquiteturas cliente/servidor, um par é tanto cliente, quanto servidor. Uma arquitetura P2P não prevê a existência de infra-estrutura fixa, ou seja, não há elementos fixos, como servidores ou roteadores com determinado protocolo implementado (como no caso do IP multicast). O fato de não ter infra-estrutura fixa, não significa que não possa haver hierarquias, ou funcionalidades diferenciadas entre os pares, contanto que qualquer par, em qualquer momento, possa assumir qualquer posição dentro da hierarquia definida, ou exercer quaisquer funcionalidades dentro do universo das possíveis. Em uma arquitetura P2P, não há qualquer tipo de restrição para a entrada e saída de pares, isto é, o sistema é dinâmico e deve ser resiliente aos eventos de entrada e saída de membros, mesmo que isto ocorra em intervalos de tempo curtos (eventos flash-crowd) (JIANGCHUAN et al., 2008). Além disso, apesar da eqüipotência em termos de funcionalidades, não há a necessidade dos pares serem eqüipotentes em termos de recursos como largura de banda e recursos computacionais. Contrariamente, em uma arquitetura P2P, há uma tendência dos pares serem extremamente heterogêneos. 
Uma das aplicações mais conhecidas que utiliza a abordagem P2P refere-se à distribuição de arquivos (file downloading), em que um arquivo é dividido em partes e as mesmas são enviadas aos pares conforme são requisitadas (POUWELSE et al., 2005). Nestes tipos de aplicação, não há requisitos rígidos de largura de banda e tempo de resposta determinístico. São tolerados atrasos na chegada das partes dos arquivos, assim como não há a necessidade de estabelecer qualquer ordem para a chegada das mesmas. Estes tipos de aplicações escalam na medida em que um maior número de pares acelera a distribuição de um determinado arquivo.

Contrariamente a estas aplicações, existem aquelas que tratam da distribuição de streaming de voz e vídeo. Streamings nada mais são do que fluxos contínuos de voz e vídeo que são gerados por uma ou mais fontes (pares) e distribuídos para um conjunto de pares. A diferença fundamental entre a distribuição de streamings de voz e vídeo e a distribuição de arquivos é que, ao contrário da distribuição de arquivos, streamings de voz e vídeo exigem largura de banda constante, atraso constante, e determinismo nos tempos de resposta, já que são inerentemente aplicações de tempo real. Em uma aplicação de voz, como por exemplo o Skype (ZENNSTRÖM; FRIIS, 2004) (BASET; SCHULZRINNE, 2004) há a necessidade de um atraso pequeno e constante, caso contrário a aplicação torna-se inviável. No caso de aplicações que envolvem streaming de vídeo, os requisitos de largura de banda e latência são ainda mais críticos, principalmente quando o número de participantes (pares) é elevado e extremamente dinâmico. Isso ocorre pela natureza dos streamings de vídeo, que inerentemente possuem o requisito de largura de banda elevada ${ }^{4}$.

\subsection{Taxonomia para a Distribuição de Vídeo em Larga Escala (Broadcast)}

Em razão da imensa quantidade de soluções e abordagens diferentes para a distribuição de vídeo em larga escala (broadcast), esta seção apresenta uma classificação, extraída de (JIANGCHUAN et al., 2008), para as diferentes soluções.

\footnotetext{
4 Um streaming de vídeo codificado em MPEG-4 necessita de 1.5Mbps para ser transmitido (JIANGCHUAN et al., 2008).
} 
O objetivo principal desta taxonomia é posicionar o presente trabalho dentro do universo de paradigmas existentes.

Dentre as arquiteturas existentes para a distribuição de streaming de vídeo (Figura 2.1), existem dois grandes grupos: i. arquiteturas baseadas em roteamento, como é o caso do IP multicast, e ii. arquiteturas sem suporte a roteamento. Dentro do segundo grupo (ii), existem três tipos de abordagens: iii. arquiteturas centradas em infra-estrutura, como exemplo pode-se citar o Akamai (AKAMAI, 2008), iv. arquiteturas baseadas em aplicação nos pares com infra-estrutura de suporte onde há disponibilidade e v. arquiteturas baseadas em aplicação nos pares, sem qualquer tipo de infra-estrutura de suporte. As soluções existentes para P2P streaming enquadram-se nos dois últimos tipos (iv. e v.). Um exemplo para o caso iv. refere-se ao Skype (BASET; SCHULZRINNE, 2006), aplicação P2P de voz cujo algoritmo elege alguns nós mais estáveis e com maior capacidade como sendo super-nodes. Neste caso, os nós comuns possuem uma lista de super-nodes aos quais podem se conectar de modo a receber os pacotes de voz.

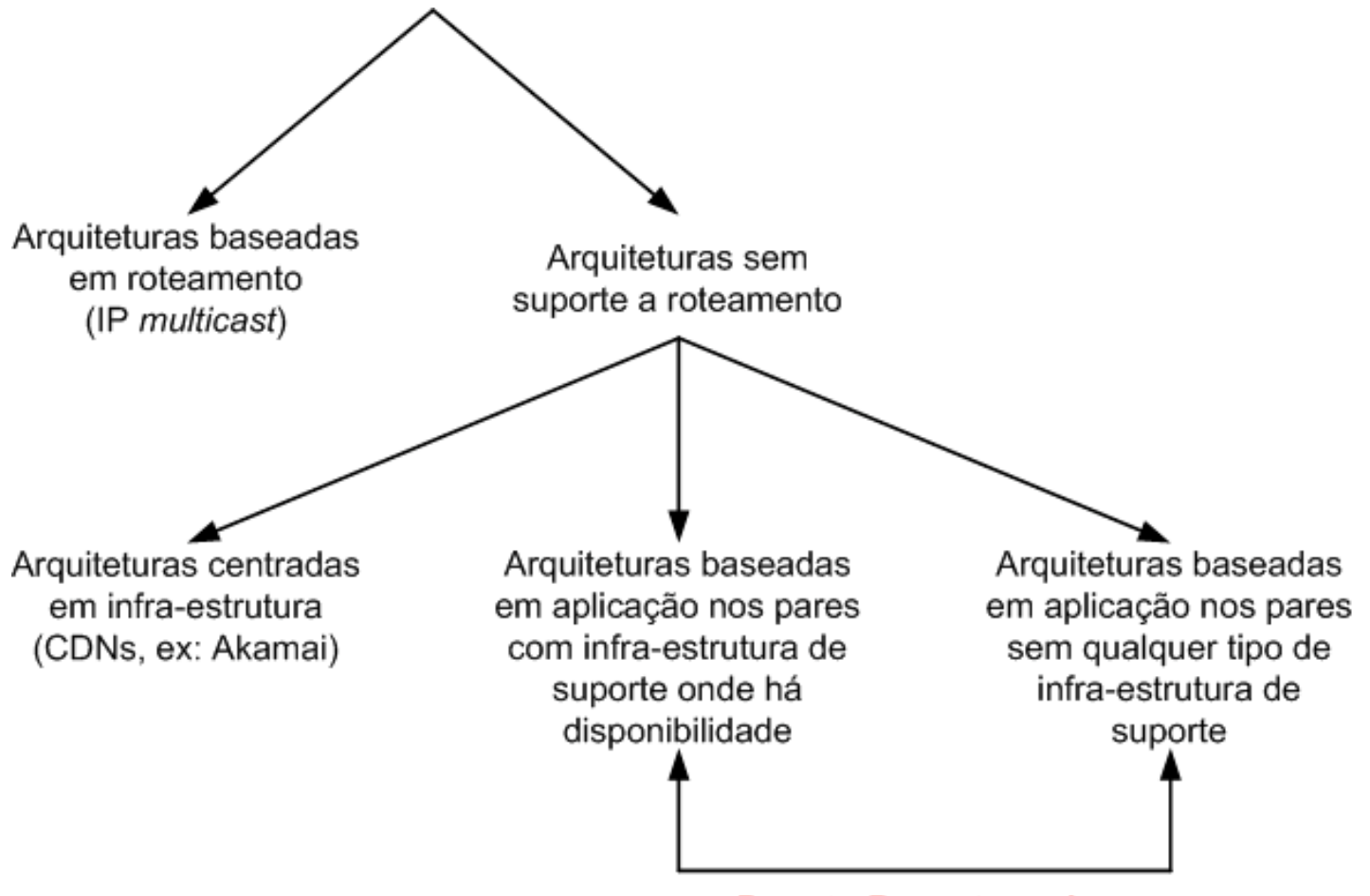

Peer-to-Peer streaming

Figura 2.1 - Taxonomia de arquiteturas para a distribuição de vídeo em larga escala (broadcast). Adaptado de (JIANGCHUAN et al., 2008). 
Cada uma destas arquiteturas possui vantagens e desvantagens. A grande vantagem das arquiteturas baseadas em roteamento (IP multicast) são as baixas latências e o baixo overhead dos protocolos. No entanto, apesar destas vantagens, protocolos multicast não são amplamente implementados nos roteadores. Dentre as razões para isso estão o custo elevado e o aumento da complexidade. Em suma, a falta de sucesso das arquiteturas multicast reside no fato de suas implementações dependerem de alterações estruturais da rede. Por sua vez, as arquiteturas centradas em infra-estrutura possuem como principal vantagem a confiabilidade e a robustez na entrega dos streamings visto que a infra-estrutura para entrega do conteúdo é controlada. Como desvantagens para esse tipo de arquitetura, podem ser citadas o custo ainda elevado, e a conseqüente falta de escalabilidade. Por fim, as arquiteturas baseadas em P2P, com ou sem algum tipo de infra-estrutura de suporte, possuem como vantagens o baixo custo, uma vez que não são necessárias alterações estruturais na rede e, os recursos necessários, advém dos próprios membros participantes, e o alto potencial de escalabilidade, já que um aumento do número de membros implica no aumento da quantidade de recursos disponíveis. No entanto, para que isso seja possível, as arquiteturas P2P necessitam endereçar uma série de desafios, como o grande overhead que poderá ser gerado para controle do overlay e o dinamismo na entrada e saída dos pares juntamente com a capacidade de se auto-organizar perante essas modificações (resiliência). Em resumo, a idéia central por trás das aplicações de streaming de vídeo baseadas em P2P é prover alta disponibilidade, escalabilidade e resiliência sem a necessidade de um ou mais servidores centrais e sem a necessidade de um elevado overhead de controle.

\subsection{Métodos de Distribuição de Vídeo em Redes P2P}

Nesta seção, serão descritas e comparadas as técnicas mais comumente utilizadas na distribuição de vídeo em redes $\mathrm{P} 2 \mathrm{P}$, mais propriamente as técnicas utilizadas na construção do overlay de distribuição, como as estruturas em árvore simples, as estruturas de múltiplas árvores, as técnicas orientadas a dados (não utilizam estruturas) e as abordagens híbridas. 


\subsubsection{Estruturas em Árvore Simples}

As técnicas de distribuição, que se baseiam em árvores simples, organizam o overlay de distribuição na forma de uma estrutura em árvore, em que o nó raiz é a fonte do streaming. Esta abordagem é uma extensão da idéia de sistemas multicast implementados na camada de aplicação, em que os streamings são transmitidos em unicast, mas a organização lógica dos pares segue uma estrutura em árvore. Este paradigma é, também, designado de push-based, ou seja, os segmentos de vídeo que são transmitidos em cada instante não precisam ser requisitados pelos pares que compõem o overlay, já que cada par conhece seu par pai e seus pares filhos.

A maior vantagem desta abordagem é o overhead reduzido, visto que não há a necessidade da troca de mensagens de requisição de segmentos de vídeo. Outra vantagem, embora fora do escopo desse trabalho, reside no fato desta técnica não requerer algoritmos de codificação de vídeo complexos, como aqueles que utilizam codificação em múltiplas camadas (TOSUN; FENG, 2000). Isso ocorre porque nessa técnica há apenas um streaming sendo distribuído (apenas uma árvore de distribuição). No entanto, o overhead reduzido e a simplicidade dos algoritmos de codificação não são suficientes para justificar o uso dessa técnica, uma vez que a mesma apresenta diversas desvantagens. A principal delas é o aproveitamento ineficiente dos recursos dos pares, já que a maior parte deles são nós folhas na estrutura, ou seja, a largura de banda de saída (outgoing bandwidth) destes pares não é utilizada. Além disso, a estrutura precisa ser mantida conforme os pares entram e saem do grupo, o que faz esta técnica não apresentar uma boa resiliência, sendo necessário reconectar as sub-árvores quando um nó falha, o que implica em problemas de desempenho. 


\subsubsection{Estruturas em Múltiplas Árvores}

De modo a mitigar o problema de balanceamento de carga existente na técnica de árvore simples, em que a maior parte dos nós são folhas, foi criada a técnica de múltiplas árvores, em que um streaming é dividido em múltiplos sub-streamings (descrições), e cada um deles é distribuído por meio de uma árvore separada. Desta maneira, os pares que são folhas em uma árvore serão nós (pares) internos à estrutura em outra árvore, aproveitando melhor a largura de banda de saída dos nós. Outra vantagem deste tipo de abordagem refere-se ao fato dos pares terem a opção de receber o streaming com uma qualidade degenerada caso não estejam disponíveis (devido a alguma instabilidade com a rede) todas as camadas necessárias para a reconstrução do mesmo. Apesar destas vantagens, esta técnica possui a desvantagem de necessitar que as estruturas em árvore sejam mantidas, além de necessitar que técnicas sofisticadas de codificação sejam adotadas e, como no caso das árvores simples, apresenta baixa resiliência.

\subsubsection{Estruturas Orientadas a Dados}

As técnicas de distribuição orientadas a dados (Data-Driven) não fazem uso de estruturas formais de distribuição, não sendo necessário construir e manter uma estrutura explícita para a entrega dos streamings. Neste paradigma, um dos pares é a fonte e baseando-se na chegada de requisições de outros pares, este nó (fonte) distribui os segmentos de vídeo requisitados. Neste esquema de distribuição, não só o nó fonte recebe as requisições, mas também todo e qualquer nó que esteja conectado ao overlay de distribuição, sendo necessário um algoritmo para escalonar como a organização dos pares será feita. Pode-se dizer que nesta técnica é a disponibilidade dos segmentos de vídeo que serve como guia para a distribuição. Esta abordagem é, também, designada de pull-based, ou seja, os segmentos de vídeo precisam ser requisitados entre os pares em cada instante. 
Esta abordagem apresenta muitas vantagens, a principal delas é a simplicidade se comparada com as técnicas que utilizam árvores. Trata-se, também, da abordagem que apresenta melhor resiliência, visto que a falha de uma par pode ser facilmente superada com a adoção de caminhos redundantes (um par pode por exemplo ter uma lista de outros pares para os quais pode requisitar os segmentos, caso um deles falhe, basta que a requisição seja enviada para outro par). Estes caminhos redundantes minimizam, também, o impacto da baixa largura de banda, uma vez que um dado par pode requisitar os segmentos de vários outros, inclusive de forma seletiva, de acordo com a banda disponível. Com relação aos algoritmos de codificação utilizados, não há a necessidade do uso de codificação em múltiplas camadas, o que contribui para a simplicidade da técnica.

Apesar de todas estas vantagens, este paradigma possui a grande desvantagem do alto overhead proveniente tanto da necessidade da troca constante de mensagens de requisição de segmentos entre os pares, quanto das informações necessárias para o controle do overlay. A existência deste elevado overhead impacta diretamente no aumento da latência, ou seja, quanto maior o overhead, maior será a latência e vice-versa. Desta maneira, é necessário estabelecer um ponto de equilíbrio entre o overhead e a latência, designado de latency-overhead trade-off. Por exemplo, uma solução, que necessite trocar mensagens de requisições para cada novo segmento, apresentará menor latência (segmentos unitários são trocados mais rapidamente) e maior overhead (necessidade de uma mensagem para cada novo segmento) que uma solução que necessite trocar essas mensagens de acordo com novos grupos de segmentos. Este problema cria espaço para outros tipos de soluções, inclusive no caso do protocolo proposto neste trabalho será endereçada a questão da manutenção e tráfego das informações de controle do overlay.

\subsubsection{Abordagens Híbridas}

O paradigma híbrido tenta tirar proveito das vantagens das técnicas que utilizam árvores e das técnicas orientadas a dados. Em suma, estas técnicas tentam resolver o problema da resiliência e do balanceamento de carga das estruturas em árvore por 
meio do uso de árvores costuradas (na verdade um grafo), em que um nó pode ter mais de um nó pai. Tipicamente as soluções que utilizam esta técnica apresentam melhor balanceamento de carga que aquelas que utilizam árvore, mas ainda pior que as técnicas orientadas a dados. A resiliência também é melhor que nos casos em que são utilizadas árvores, mas pior do que as abordagens orientadas a dados. Dentre as quatro abordagens apresentadas, a abordagem híbrida é também a mais complexa para implementar, o que implica em um overhead elevado (igual ou maior que nas técnicas orientadas a dados). Este fato faz com que este tipo de abordagem não seja atrativo.

\subsubsection{Sumário Comparativo entre as Abordagens}

Esta seção descreve um sumário comparativo, na forma de uma tabela (Tabela 2.1), entre as abordagens apresentadas, de modo a estabelecer um ponto de comparação, ainda que qualitativo entre elas. Estas comparações foram extraídas do conjunto de artigos investigados, e são baseadas principalmente em (MAGHAREI; REJAIE; PRIME, 2007), (MAGHAREI; REJAIE, 2006) e (SILVERSTON; FOURMAUX; DE PARIS, 2006).

Tabela 2.1 - Sumário comparativo das abordagens para distribuição de streaming de vídeo.

\begin{tabular}{|c|c|c|c|c|}
\hline \multirow[b]{2}{*}{ Critério } & \multicolumn{2}{|c|}{ Baseadas em Árvore (Push) } & \multirow{2}{*}{$\begin{array}{l}\text { Dirigidas por } \\
\text { dados Data- } \\
\text { driven/Pull }\end{array}$} & \multirow[b]{2}{*}{ Híbridas } \\
\hline & $\begin{array}{l}\text { Árvores } \\
\text { Simples }\end{array}$ & $\begin{array}{l}\text { Múltiplas } \\
\text { Árvores }\end{array}$ & & \\
\hline $\begin{array}{c}\text { Balanceamento } \\
\text { de carga }\end{array}$ & $\begin{array}{l}\text { A maioria dos } \\
\text { nós são folhas } \\
\text { na estrutura, e } \\
\text { a largura de } \\
\text { banda de } \\
\text { saída destes } \\
\text { nós não é } \\
\text { utilizada. }\end{array}$ & $\begin{array}{l}\text { Apresenta melhor } \\
\text { balanceamento } \\
\text { de carga do que } \\
\text { para caso com } \\
\text { árvores simples } \\
\text { (alguns nós são } \\
\text { folhas em uma } \\
\text { árvore e nós } \\
\text { internos em outra) }\end{array}$ & $\begin{array}{l}\text { Apresenta o } \\
\text { melhor } \\
\text { balanceamento } \\
\text { de carga entre } \\
\text { as abordagens }\end{array}$ & $\begin{array}{l}\text { Apresenta melhor } \\
\text { balanceamento de } \\
\text { carga que nas } \\
\text { técnicas que utilizam } \\
\text { árvores, mas } \\
\text { tipicamente pior que } \\
\text { nas abordagens data- } \\
\text { driven. }\end{array}$ \\
\hline
\end{tabular}




\begin{tabular}{|c|c|c|c|c|}
\hline \multirow[b]{2}{*}{ Critério } & \multicolumn{2}{|c|}{ Baseadas em Árvore (Push) } & \multirow{2}{*}{$\begin{array}{l}\text { Dirigidas por } \\
\text { dados Data- } \\
\text { driven/Pull }\end{array}$} & \multirow[b]{2}{*}{ Híbridas } \\
\hline & $\begin{array}{l}\text { Árvores } \\
\text { Simples }\end{array}$ & $\begin{array}{l}\text { Múltiplas } \\
\text { Árvores }\end{array}$ & & \\
\hline $\begin{array}{l}\text { Complexidade } \\
\text { para } \\
\text { Implementar }\end{array}$ & $\begin{array}{l}\text { Tipicamente é } \\
\text { mais complexa } \\
\text { que a } \\
\text { abordagem } \\
\text { orientada a } \\
\text { dados, mas } \\
\text { ainda assim é } \\
\text { muito mais } \\
\text { simples que o } \\
\text { caso de } \\
\text { múltiplas } \\
\text { árvores. }\end{array}$ & $\begin{array}{l}\text { Apresenta } \\
\text { grande } \\
\text { complexidade } \\
\text { devido a } \\
\text { necessidade de } \\
\text { algoritmos de } \\
\text { codificação que } \\
\text { utilizam } \\
\text { múltiplas } \\
\text { camadas (MDC } \\
\text { - Multiple } \\
\text { Description } \\
\text { Coding) }\end{array}$ & $\begin{array}{l}\text { É a mais } \\
\text { simples das } \\
\text { abordagens }\end{array}$ & $\begin{array}{l}\text { Tipicamente é a mais } \\
\text { complexa }\end{array}$ \\
\hline Overhead & \multicolumn{2}{|c|}{$\begin{array}{l}\text { Apresenta o menor overhead } \\
\text { entre as abordagens. Não sofre } \\
\text { do problema de balanceamento } \\
\text { entre latência e overhead. }\end{array}$} & $\begin{array}{l}\text { Apresenta o } \\
\text { maior dos } \\
\text { overheads }\end{array}$ & $\begin{array}{l}\text { Apresenta overhead } \\
\text { igual ou maior que } \\
\text { nas abordagens } \\
\text { orientadas a dados. }\end{array}$ \\
\hline Resiliência & $\begin{array}{l}\text { Apresenta a pio } \\
\text { as técnicas (É n } \\
\text { reconectar as S } \\
\text { quando um nó f }\end{array}$ & $\begin{array}{l}\text { resiliência entre } \\
\text { ecessário } \\
\text { ab-árvores } \\
\text { aha) }\end{array}$ & $\begin{array}{l}\text { Melhor } \\
\text { resiliência (há } \\
\text { redundância de } \\
\text { caminhos para a } \\
\text { entrega do } \\
\text { streaming) }\end{array}$ & $\begin{array}{l}\text { Apresenta melhor } \\
\text { resiliência que para o } \\
\text { caso que usa árvores } \\
\text { (simples/múltiplas) }\end{array}$ \\
\hline $\begin{array}{l}\text { Requisito de } \\
\text { buffer nos } \\
\text { pares }\end{array}$ & $\begin{array}{l}\text { Buffers são usa } \\
\text { acomodar as di } \\
\text { largura de band } \\
\text { diferentes camir } \\
\text { e os pares. }\end{array}$ & $\begin{array}{l}\text { los para } \\
\text { erenças de } \\
\text { a e latência nos } \\
\text { hos entre a fonte }\end{array}$ & $\begin{array}{l}\text { Buffers são } \\
\text { usados para } \\
\text { acomodar a } \\
\text { chegada fora de } \\
\text { ordem dos } \\
\text { segmentos } \\
\text { requisitados. }\end{array}$ & $\begin{array}{l}\text { Buffers são usados } \\
\text { tanto para acomodar } \\
\text { as diferenças de } \\
\text { largura de banda, } \\
\text { quando a chegada de } \\
\text { segmentos fora de } \\
\text { ordem. }\end{array}$ \\
\hline
\end{tabular}




\begin{tabular}{|c|c|c|c|c|}
\hline \multirow[b]{2}{*}{ Critério } & \multicolumn{2}{|c|}{ Baseadas em Árvore (Push) } & \multirow{2}{*}{$\begin{array}{l}\text { Dirigidas por } \\
\text { dados Data- } \\
\text { driven/Pull }\end{array}$} & \multirow[b]{2}{*}{ Híbridas } \\
\hline & $\begin{array}{l}\text { Árvores } \\
\text { Simples }\end{array}$ & $\begin{array}{l}\text { Múltiplas } \\
\text { Árvores }\end{array}$ & & \\
\hline $\begin{array}{l}\text { Largura de } \\
\text { banda }\end{array}$ & \multicolumn{2}{|c|}{$\begin{array}{l}\text { Como não há redundância de } \\
\text { caminhos (cada par tem um só } \\
\text { pai), as diferenças de largura de } \\
\text { banda nos diversos caminhos } \\
\text { impactam o streaming. Para as } \\
\text { múltiplas árvores, este efeito } \\
\text { ocorre somente na camada do } \\
\text { vídeo que está sendo distribuída } \\
\text { pela árvore que apresenta } \\
\text { problemas de banda. }\end{array}$} & \multicolumn{2}{|c|}{$\begin{array}{l}\text { Devido à existência de múltiplos } \\
\text { caminhos, o impacto de uma largura de } \\
\text { banda baixa é minimizado. }\end{array}$} \\
\hline
\end{tabular}

\subsection{Exemplos de Soluções Existentes para Streaming de Vídeo em Redes $P 2 P$}

\subsubsection{SplitStream}

SplitStream (CASTRO et al., 2003) é uma solução para distribuição de streamings em larga escala que utiliza a abordagem de múltiplas árvores (push-based). Conforme fora mencionado, a utilização de múltiplas árvores melhora a resiliência do overlay (a falha de um nó em um nível elevado da árvore não compromete todo o overlay) e mitiga o problema da sub-utilização da largura de banda dos nós folhas (problema existente nas técnicas que estruturam o overlay como uma árvore simples). No SplitStream a fonte codifica o streaming de vídeo em sub-streams e distribui cada um deles ao longo de uma árvore (cada árvore constitui um overlay). Um par recebe um conjunto de streamings provenientes de múltiplas árvores, sendo que a qualidade do vídeo depende da quantidade de streamings que são recebidos. O vídeo é codificado em múltiplas camadas e cada camada é distribuída por uma árvore. Caso um dado par não receba todos as camadas que compõem o vídeo, 
este ainda pode visualizá-lo com uma qualidade degradada. Essa solução apresenta como principais vantagens o aumento da resiliência do sistema e o melhor aproveitamento da largura de banda dos pares que compõem o overlay. Como principais desvantagens, há o aumento da latência em razão da necessidade de um dado par ter que se associar a múltiplos overlays para receber o streaming completo, e a necessidade do uso de algoritmos especiais para a codificação do vídeo, o que implica no aumento da complexidade.

\subsubsection{CoolStreaming/DONet}

CoolStreaming/DONet (XINYAN et al., 2005) é uma solução para a distribuição de vídeo orientada a dados (Data-driven/Pull-based). Nela, os nós (pares) mantêm um conjunto de nós parceiros e periodicamente trocam informações entre eles sobre a disponibilidade de dados (segmentos de vídeo). Como os segmentos de vídeo são trocados apenas quando são requisitados, não há o overhead de redundância de informações (um segmento nunca é recebido de dois pares distintos). Nessa abordagem, um streaming de vídeo é dividido em segmentos de tamanho uniforme e a disponibilidade dos segmentos ativos é representada por uma estrutura designada Buffer Map (BM). Cada nó continuamente troca seus Buffer Maps com seus parceiros e de acordo com os segmentos faltantes nesses BMs, requisita outros BMs de outros parceiros. A porção ativa do buffer é representada por uma janela deslizante (sliding window) de 120 segmentos, sendo que cada segmento representa 1 segundo de vídeo. Um BM consiste de uma string de 120 bits, cada um indicando a disponibilidade do segmento correspondente (Figura 2.2). Um número de seqüência é usado para localizar a janela deslizante no streaming. Nessa solução, um algoritmo de escalonamento precisa satisfazer duas restrições: cada segmento deve estar presente assim que for necessário à reprodução do streaming; e devem ser priorizadas requisições de segmentos de pares com menor largura de banda (um segmento pode estar no final da janela, faltando ainda 120 segundos para ser necessário na reprodução do streaming, mas se este segmento puder ser recebido apenas de um par com limitação de largura de banda, deverá ser requisitado primeiro que outros). As principais vantagens dessa solução são o baixo 
overhead de controle (cerca de $1 \%$ do tráfego de vídeo) e a maior resiliência quando comparado às técnicas baseadas em árvore. Como principal desvantagem há o atraso de 120 segundos (2 minutos) com relação à fonte, o que é inviável para aplicações de tempo real.

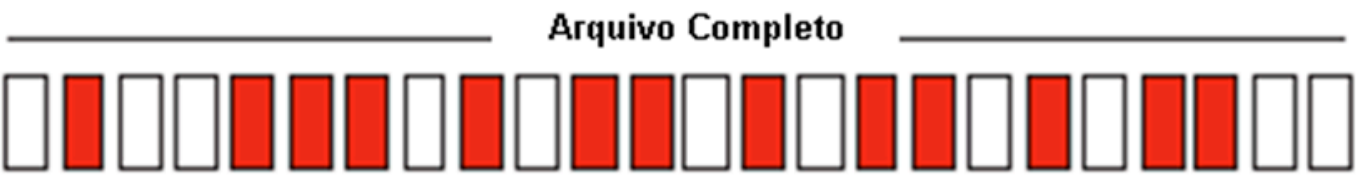

(a)

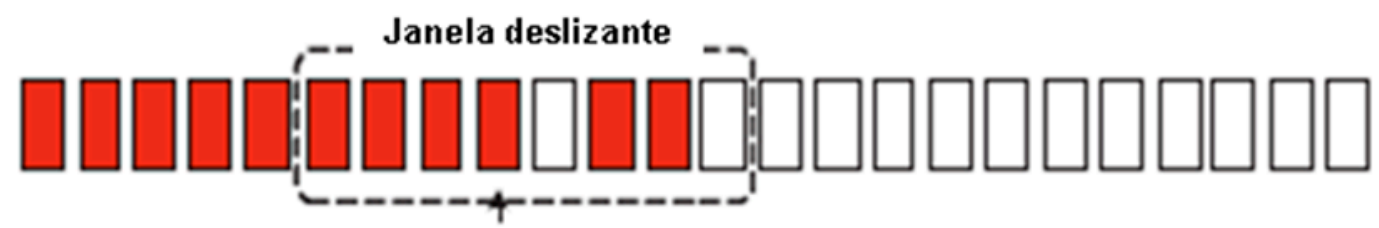

Ponto de reproduçäo do streaming

(b)

Figura 2.2 - Representação do buffer do BitTorrent (POUWELSE et al., 2005) (a) e CoolStreaming (b), onde os segmentos sombreados são os que estão disponíveis no buffer. Extraído de (XINYAN et al., 2005).

\subsubsection{ChunkySpread}

ChunkySpread (VENKATARAMAN; YOSHIDA; FRANCIS, 2006)utiliza a técnica de múltiplas árvores para a distribuição do streaming. Nessa solução, o streaming é dividido em partes distintas (slices) e transmitido por árvores separadas. Os pares são organizados na forma de grafos randômicos, os quais são construídos considerando-se a carga que será transmitida (o grau de um nó no grafo, ou seja, o número de conexões, é proporcional à carga que está transmitindo). O critério para encontrar o melhor par para o recebimento do streaming é a carga (número de conexões de saída de um dado par), e a latência. Desse modo cada nó permite que seus vizinhos conheçam a sua carga corrente (o número de slices que está transmitindo), a carga objetivo, ou seja, quantos slices deseja transmitir (pode ser maior ou menor que a carga corrente), carga máxima e os limiares superior e 
inferior de carga, ou seja, os limiares que determinam onde a carga objetivo deve estar contida. De posse dessas informações, cada nó periodicamente verifica se há nós sobrecarregados ou subcarregados, e de acordo com esse critério são remanejadas conexões no grafo, de modo a balancear a carga dos nós. Uma vez realizado o balanceamento de carga, cada nó mede o atraso relativo entre os streamings recebidos por meio da comparação entre os streamings provenientes das múltiplas árvores, e novamente conexões são remanejadas de modo a otimizar a latência. Apesar de considerar carga e latência para a escolha dos pares, essa solução apresenta um elevado atraso com relação à fonte (5s a 10s), não sendo adequada para aplicações interativas. Além isso, essa solução apresenta elevada complexidade, pois utiliza mecanismos sofisticados para efetuar o balanceamento de conexões.

\subsection{4 mTreebone}

mTreebone (WANG; XIONG; LIU, 2007) utiliza a abordagem híbrida para a distribuição do streaming. Essa solução organiza o overlay na forma de uma árvore (tronco principal de distribuição) constituída de nós estáveis (nós que estão a mais tempo no overlay). Agregados a esta árvore principal, estão os nós menos estáveis (transientes), formando um grafo. Quando um nó instável (nó A na Figura 2.3 (a)) falha ou sai do grupo, ele não afeta o streaming que está sendo distribuído pela árvore principal (tronco principal de distribuição). Ao passo que, quando um nó estável (nó B na Figura 2.3 (b)) sai do grupo, os nós afetados, tais como o nó $C$ podem facilmente requisitar o streaming de seus vizinhos antes de ser re-adicionado novamente à árvore principal. A grande desvantagem dessa solução é o método de classificação dos nós como sendo estáveis, que utiliza como métrica o tempo de permanência no overlay, deixando assim de aproveitar a capacidade de pares com grande disponibilidade de recursos (largura de banda) somente porque permanecem no overlay por um curto período. Além disso há o grande overhead de mensagens e a elevada complexidade inerente das técnicas híbridas. 


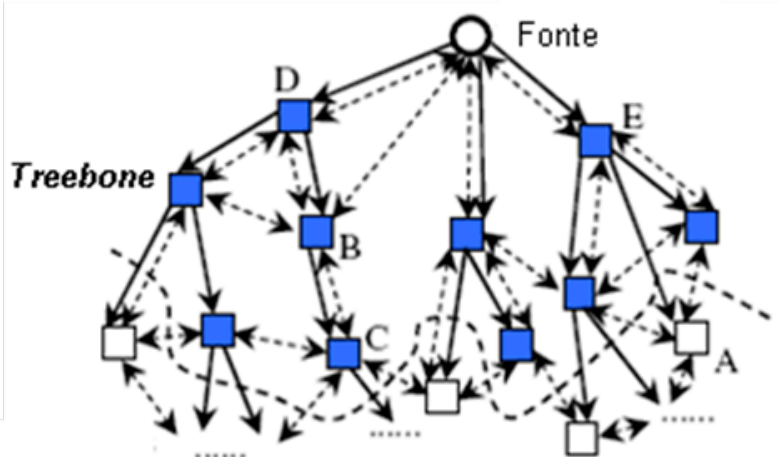

(a)

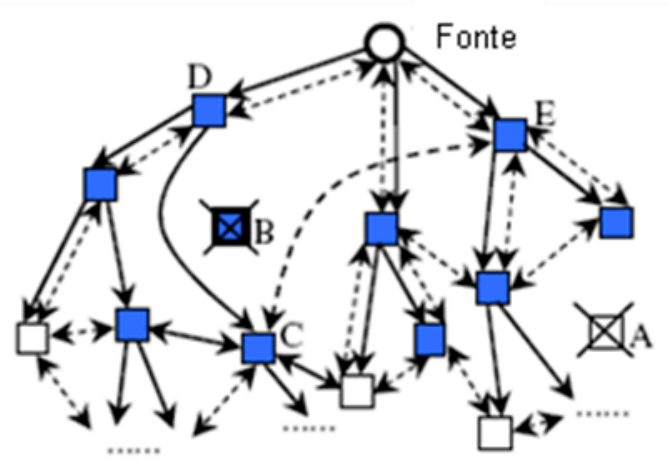

(b)

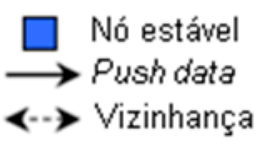

Nó instável

Pull data

Figura 2.3 - mTreebone - Saída e falha de um nó. Extraído de (WANG; XIONG; LIU, 2007).

\subsection{Considerações Finais}

Este capítulo apresentou uma visão geral sobre P2P streaming e os conceitos envolvidos, foi apresentada uma taxonomia para a distribuição de vídeo em larga escala, foram apresentados os métodos de distribuição de vídeo em redes $\mathrm{P} 2 \mathrm{P}$, os quais podem ser baseados em árvores simples, em múltiplas árvores, orientados a dados ou híbridos, e os mesmos foram exemplificados com soluções existentes. Cumpre ressaltar que foram escolhidos os exemplos considerados mais significativos para cada um dos métodos mostrados.

Este capítulo, assim como o próximo que irá descrever as técnicas para a construção de overlays, servirão de embasamento para a especificação detalhada do protocolo no capítulo quatro. 


\section{TÉCNICAS PARA A CONSTRUÇÃO DE OVERLAYS}

Este capítulo irá apresentar técnicas para a construção de overlays, mais especificamente aquelas baseadas em um sistema de coordenadas, aquelas baseadas na realização de medições sob-demanda e as híbridas que consideram tanto coordenadas como medidas sob-demanda.

Em um sistema P2P para distribuição de vídeo existe a necessidade da escolha dos pares de modo a formar um overlay lógico. Nesse processo, para alcançar os níveis necessários de latência, largura de banda e escalabilidade é necessário que essa escolha não seja completamente aleatória, ou seja, é necessário que seja utilizado algum critério de classificação que possibilite a escolha dos melhores pares para a recepção do streaming em cada instante de tempo. Uma das formas de escolher esses pares é selecionar os mais próximos considerando-se a latência entre eles. Para que isso seja possível pode-se optar por construir um sistema de coordenadas fixas, atribuir coordenadas para cada par que entrar no grupo ${ }^{5}$ e selecionar os pares aos quais o novo par se conectará por meio do cálculo da distância (latência) entre este novo par e os outros. Uma outra forma de se escolher os pares mais próximos em termos de latência seria efetuar algumas medidas para alguns pares e escolher aqueles que apresentarem as menores latências. Por fim, uma terceira forma de ser realizada esta escolha seria considerar um sistema de coordenadas para a escolha de um conjunto inicial de pares e em seguida realizar algumas medidas para confirmar quais pares estão realmente mais próximos em termos de latência. Nos três casos há uma série de questões que necessitam ser endereçadas: a necessidade de escolher um sistema adequado de coordenadas, a necessidade de escolher o método de medição que será utilizado, a necessidade de tratar a evolução do overlay na medida em que entram e saem pares, e, por último, a necessidade de manter um overhead de controle aceitável. Estas questões serão melhor tratadas nas próximas seções e servirão de embasamento para a definição do protocolo a ser proposto para a construção de overlays escaláveis para a distribuição de streaming de vídeo em redes $\mathrm{P} 2 \mathrm{P}$.

\footnotetext{
${ }^{5}$ Entenda-se por grupo o overlay lógico constituído por seus diversos pares em um dado instante de tempo.
} 


\subsection{Técnicas Baseadas em Coordenadas}

As técnicas que consideram um sistema de coordenadas para a construção de overlays como as apresentadas em (NG; HUI, 2002), (FRANCIS et al., 2001) e (HOTZ, 1994) defendem a idéia de que a escolha dos pares baseada puramente em medidas sob demanda, mesmo que seja efetuada apenas uma medida do tipo RTT (Round-trip time - ping), gera um alto e impraticável overhead. Em um sistema com $\mathrm{N}$ pares, seriam necessárias $\mathrm{N}^{*}(\mathrm{~N}-1) / 2$ medidas (complexidade $\mathrm{O}\left(\mathrm{N}^{2}\right)$ ) para que se obtenham todas as distâncias entre os pares e a partir deste ponto possa ser selecionado o conjunto de pares mais próximos de um dado par que acaba de entrar no grupo. Ao passo que um sistema de coordenadas para $\mathrm{N}$ pares, com $\mathrm{D}$ identificadores em cada coordenada resultaria em $N^{*} D$ coordenadas (complexidade $\mathrm{O}\left(\mathrm{N}^{*} \mathrm{D}\right)$ ) a serem armazenadas e mantidas. Deste modo é necessária, em primeiro lugar, uma estimativa de primeira ordem que irá localizar os pares mais próximos de um dado par a partir do cálculo de duas coordenadas, para depois ser realizada algum tipo de medida sob-demanda (ex: RTT), eliminando assim o overhead introduzido pelo processo de medição (NG; HUI, 2002). No entanto, há o grande problema de se construir e manter um sistema de coordenadas escalável que possa ser usado para estimar distâncias com precisão.

Um sistema de coordenadas simples pode ser construído da seguinte forma: primeiramente é necessário eleger alguns nós para serem os Nós de Referência (landmark nodes) e calcular suas coordenadas num dado espaço geométrico escolhido (por exemplo um espaço euclidiano de duas dimensões, sendo, portanto, necessários no mínimo três Nós de Referência). As coordenadas desses Nós de Referência devem ser difundidas para todos os pares que desejam participar do grupo. Em seguida, cada novo par que entra no grupo calcula suas coordenadas com base nas coordenadas dos Nós de Referência. Uma vez feito isso, o novo par, de posse de suas coordenadas e das coordenadas dos pares que já estão no overlay pode calcular as distâncias euclidianas entre os pares que já estão no grupo e obter um subconjunto de pares mais próximos. 
Apesar do uso de coordenadas reduzir o overhead de mensagens quando comparado com técnicas de medidas sob demanda, a grande desvantagem desta abordagem é o grande erro na estimativa das coordenadas. Isso ocorre pois as latências entre dois nós na Internet não é sempre a mesma e depende da infraestrutura de comunicação existente entre os mesmos. Por exemplo: dados três Nós de Referência ( $A, B$ e $C)$, com coordenadas sendo $A(x a, y a), B(x b, y b)$ e $C(x c, y c)$, considere a entrada consecutiva de dois pares no overlay: $\mathrm{K} \mathrm{e} \mathrm{L}$, cujas coordenadas estimadas são $\mathrm{K}(\mathrm{xk}, \mathrm{yk})$ e $\mathrm{L}(\mathrm{xl}, \mathrm{yl})$. A distância euclidiana entre $\mathrm{K}$ e $\mathrm{L}$ é dada por:

$$
d k I^{2}=(x k-x I)^{2}+(y k-y l)^{2}
$$

E considere agora a latência medida sob-demanda entre os pares $\mathrm{K}$ e $\mathrm{L}$ como sendo dkl', o erro relativo entre essas duas estimativas (dkl' e dkl) é elevado e apresenta elevada variabilidade.

\subsection{Técnicas Baseadas em Medidas Sob Demanda}

Conforme fora mencionado, escolher os pares mais próximos utilizando-se medidas sob-demanda implica em um elevado overhead caso seja necessário efetuar medições para todos os pares participantes do overlay. Este problema, conforme descrito na seção anterior, pode ser mitigado pelo uso de alguma estimativa de primeira ordem (ex: coordenadas). No entanto, mesmo que o universo de pares a ser considerado nas medições seja menor, ou seja, mesmo que seja praticável a realização de medidas sob demanda para alguns pares, a precisão desse tipo de abordagem está intimamente ligada com a precisão e representatividade do tipo de medida que é utilizada. Uma medida comumente utilizada é o Round-trip time (RTT) de uma mensagem ICMP (Internet Control Message Protocol) (Ping). No entanto, a primeira percepção no uso desse tipo de medida é a sua imprecisão, dado que em uma rede TCP/IP, o RTT depende da carga de trabalho, isto é, os valores de RTT obtidos por meio do envio de alguns bytes será diferente dos valores obtidos quando a carga enviada for maior. Estudos apresentados em (NG et al., 2003) fazem uma extensa análise comparativa entre técnicas para estimar quais são os melhores 
pares em termos de latência ou largura de banda. Nesse trabalho são comparados os resultados obtidos com a escolha aleatória de pares e com o uso de três técnicas de medidas: i. Round-trip time (RTT) - essa técnica consiste em se medir a latência entre o novo par e os outros pares presentes no grupo (candidatos à escolha) por meio do tempo gasto por um conjunto de pacotes ICMP (ex: com 32 bytes de dados) da origem até o destino, retornando em seguida para a origem (ping); ii. 10KB TCP - essa técnica consiste em se abrir uma conexão TCP com um par (candidato à escolha) e realizar o download de $10 \mathrm{~KB}$ de dados, medindo-se o tempo para essa operação; iii. Medida da largura de banda entre nós - essa técnica consiste em se medir a largura de banda entre o novo par e os pares presentes no grupo (candidatos) por meio de uma ferramenta específica para esta finalidade (ex: iperf (IPERF, 2008)). As principais conclusões apresentadas nesse trabalho e que servirão de base para justificar o uso de medidas do tipo RTT para seleção de pares no protocolo a ser proposto são:

- O uso de uma técnica básica, como o RTT, é suficiente para que mais de $30 \%$ dos pares convirjam para um nível adequado de desempenho dentro de um período de $5 \mathrm{~s}$, ou seja, usando-se RTT, $30 \%$ ou mais dos pares mais próximos em termos de latência podem ser identificados em um período de 5s. Entenda-se por convergência, o estado em que um par esteja recebendo o streaming com a melhor qualidade possível para uma dada configuração do overlay ${ }^{6}$.

- Definindo-se um Índice de Desempenho (ID) como sendo a razão entre a largura de banda entre um novo par e um par candidato à seleção e a largura de banda entre esse novo par e o melhor dos candidatos dentre o conjunto dos que estão sendo avaliados, de modo que, quanto mais alto for o valor desse índice, pode-se considerar mais próximo da escolha ótima e vice-versa. Para um conjunto de 10 candidatos, este trabalho aponta os seguintes resultados (para um intervalo de confiança de 95\%).

\footnotetext{
${ }^{6}$ Em (NG et al., 2003), o tempo de convergência é definido como o tempo necessário, após a entrada de um par no overlay, para que o mesmo receba mais de $95 \%$ da largura de banda estável (largura de banda necessária para acomodar a taxa de envio da fonte do streaming) por um período (janela de análise) de 30s.
} 
Tabela 3.1 - Índice de desempenho médio para a seleção do melhor par dentro de um conjunto de 10 candidatos (baseado em (NG et al., 2003)).

\begin{tabular}{|c|c|c|c|c|}
\hline $\begin{array}{c}\text { Tipo de } \\
\text { Seleção }\end{array}$ & Randômica & RTT com 36B & 10KB TCP & $\begin{array}{c}\text { Largura de } \\
\text { Banda }\end{array}$ \\
\hline ID & 0,46 & 0,86 & 0,91 & 0,95 \\
\hline
\end{tabular}

A partir desses resultados pode-se concluir que a seleção randômica conduz a resultados ruins (baixo índice de desempenho), ao passo que a utilização de qualquer uma das técnicas de medida apresentadas leva a uma escolha muito mais próxima da escolha ótima. Além disso, esses resultados apontam que, não há diferenças significativas entre o uso de uma medida simples, como o RTT e medidas mais acuradas, como o 10KB TCP e a largura de banda. Esse último resultado indica que selecionar pares por meio da latência medida por um ping é um método atrativo, visto que as outras duas opções de medidas precisam de um tempo significativamente maior para serem realizadas.

\subsection{Técnicas Híbridas}

Conforme fora mencionado, as técnicas para a seleção de pares baseadas em coordenadas apresentam um elevado erro de predição. Por outro lado, as técnicas baseadas em medidas sob demanda podem se tornar inviáveis dependendo do tamanho do grupo de pares candidatos que será analisado. Estudos apresentados em (ZHANG et al.,2006) indicam que a combinação de ambas as técnicas é muito efetiva para a melhoria do desempenho na seleção dos pares, na medida em que os erros de predição provenientes de uma estimativa baseada em coordenadas podem ser reduzidos a partir da confirmação dos pares que estão efetivamente mais próximos por meio de medidas sob-demanda. Além disso, o estudo analítico e experimental apresentado nesse trabalho, indica que o erro de predição das técnicas baseadas em coordenadas é tanto maior quanto menor o tamanho dos links entre os pares. 


\subsection{Considerações Finais}

Os resultados apresentados neste capítulo sugestionam que um overlay para a distribuição de streaming de vídeo pode ser construído levando-se em consideração o uso de um sistema de coordenadas para uma estimativa inicial dos pares que estão mais próximos em termos de latência de um dado par que acaba de entrar no grupo, e em seguida pode ser usada uma medida sob-demanda, para refinar a escolha. Esse fato servirá de base para o protocolo apresentado na próxima seção. 


\section{ESCOPO DA PROPOSTA}

Esse capítulo visa definir e descrever o protocolo para a construção de overlays para a distribuição de streamings de vídeo. Primeiramente serão definidos os requisitos funcionais do protocolo, em seguida será apresentada uma visão geral e serão definidas as entidades participantes do mesmo. Na seqüência, serão apresentadas as condições gerais de operação do protocolo e o mesmo será formalizado por meio de um diagrama de troca de mensagens e uma máquina de estados.

\subsection{Especificação de Requisitos do Protocolo}

Nesta seção serão especificados os requisitos que servirão como embasamento para a especificação do protocolo a ser proposto. Para fins de organização, os requisitos serão organizados em itens independentes.

R1 - O protocolo deverá construir um overlay para a distribuição de streamings de vídeo considerando as características da rede física que o suporta (o overlay deverá ser organizado considerando-se a latência da rede física que o suporta).

R2 - Deverá ser considerada a Internet como sendo a rede física que suportará a distribuição do streaming.

R3 - O streaming de vídeo deverá ser provido com qualidade de serviço (conforme definido em seções anteriores).

R4 - O protocolo deverá ser escalável, ou seja, independentemente do número de pares (carga), deverá manter o mesmo nível de qualidade para o streaming que está sendo distribuído.

R5 - O protocolo deverá ter a capacidade de adaptação a falhas (resiliência)

R6 - O protocolo deverá minimizar o overhead necessário para controle do overlay.

R7 - A largura de banda e latência deverão ser suficientes para manter o nível de qualidade do streaming.

R8 - Como cenário de aplicação será considerada uma vídeo conferência. 


\subsection{Visão Geral do Protocolo}

Conforme descrito na seção 1.2, o objetivo principal desse trabalho é a proposta de um protocolo para a construção de overlays para a distribuição de streamings de vídeo em redes P2P. A idéia básica será definir um protocolo que construa um overlay para a distribuição de streamings considerando-se as características da rede física que o suporta (nesse trabalho será considerada a Internet). O overlay será iniciado com um par (nó) inicial (também a fonte do streaming), e conforme forem ocorrendo a chegada e a saída de novos pares (operações de join e leave), estes serão organizados dinamicamente de modo a agrupar os que estão mais próximos em termos de latência.

Considerando a taxonomia apresentada na seção 2.2, a arquitetura desse protocolo será baseada apenas nos pares que compõem o overlay, sem qualquer tipo de infraestrutura de suporte nos pares. Esse tipo de abordagem foi escolhido pois há uma grande preocupação com a escalabilidade do sistema $^{7}$, ou seja, esse protocolo visa explorar o potencial de escalabilidade das redes $\mathrm{P} 2 \mathrm{P}$, em que o aumento do número de pares, implica não só no aumento de elementos que irão receber um dado serviço (aumento da necessidade de recursos), mas também no aumento dos recursos disponíveis para o provimento do serviço (streaming de vídeo) com qualidade (QoS).

Com relação ao método de distribuição, este protocolo seguirá a abordagem orientada a dados (Data-Driven/Pull), em razão da maior simplicidade quando comparada com as outras técnicas (árvores), da capacidade de adaptação (resiliência) conforme ocorrem as entradas e saídas (voluntárias ou devido a falhas dos nós) e da maior simplicidade dos algoritmos de codificação de vídeo utilizados. Embora as técnicas orientadas a dados apresentem maior overhead, nesse protocolo existirão pares diferenciados em termos de funcionalidade,

\footnotetext{
7 Entenda-se por sistema, o conjunto de pares organizados na forma de um overlay, recebendo o streaming originado em um par que também é a fonte.
} 
designados Controladores (definidos nas próximas seções) cuja função principal será auto-conter e gerenciar o overhead de controle do overlay.

A técnica de construção a ser usada será a híbrida, pois conforme a análise nas seções 3.1, 3.2 e 3.3, é a técnica mais promissora em termos de precisão (apresenta menor erro) no processo de seleção dos pares. Inicialmente o protocolo irá considerar três Nós de Referência (landmark nodes), em um sistema de coordenadas euclidiano bidimensional. As coordenadas dos Nós de Referência serão estimadas considerando-se a latência entre eles medida por meio de um ping, e serão difundidas para todos os pares que desejem participar do grupo. Em seguida, cada novo par que entrar no grupo calculará suas coordenadas com base nas coordenadas dos Nós de Referência. Uma vez feito isso, o novo par, de posse de suas coordenadas e das coordenadas dos pares que já estão no overlay poderá calcular as distâncias euclidianas entre os pares que já estão no grupo e obter um subconjunto de pares mais próximos. Esse primeiro subconjunto apresenta um elevado erro de estimativa. Sendo assim, de modo a refinar a escolha, serão disparados pings para esses nós, dando origem a outro subconjunto de pares efetivamente mais próximos (em termos de latência) do novo par.

O cenário de aplicação usado para guiar o projeto desse protocolo é uma vídeoconferência com uma pequena parcela (em torno de 10\%) de pares participando ativamente (falam e escutam) e uma grande parcela (o restante dos pares) participando passivamente (apenas escutam e visualizam os participantes ativos). Nesse tipo de cenário, os requisitos de largura de banda e principalmente latência são críticos, o que justifica a construção de um overlay otimizado em termos de latência. A largura de banda também é importante, no entanto, com uma análise um pouco mais detalhada do cenário, conclui-se que mesmo que a largura de banda não seja suficiente, pode-se utilizar técnicas de codificação de vídeo em camadas, de modo a possibilitar que os participantes visualizem uma imagem degradada de acordo com a banda disponível. Contrariamente, caso a latência atinja patamares elevados, a vídeo conferência torna-se inviável. Embora o cenário inicial visado seja uma conferência, de modo a simplificar o projeto do protocolo (seguindo o princípio "Dividir para Conquistar"), nesse trabalho foi considerado apenas uma fonte ativa, sendo os demais participantes passivos. 


\subsection{Definição da Entidades}

Nessa seção serão definidas as entidades participantes do protocolo proposto.

\subsubsection{Nós Ordinários $(\mathrm{N})$}

Nós Ordinários (N) são pares comuns, com as funcionalidades básicas de receber, enviar e reproduzir um streaming de vídeo. Esse tipo de nó pode a qualquer momento tornar-se um Nó de Referência ou um Controlador, seguindo a filosofia de que em um sistema P2P todos os pares são eqüipotentes.

\subsubsection{Controladores (C)}

Controladores (C) são Nós Ordinários com funcionalidades adicionais habilitadas. A principal função dos Controladores é gerenciar a distribuição de pares dentro de um agrupamento de nós. Dessa forma os Controladores agregam e auto-contêm o overhead de controle de um determinado agrupamento de nós. Um Controlador que recebe uma requisição para tratar a entrada de um novo par no overlay passa a ser

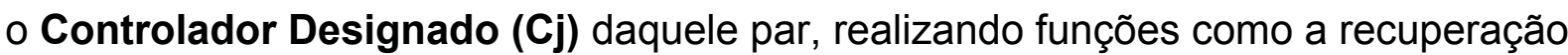
dos Controladores mais próximos do novo par com base em suas coordenadas. Esse processo encontra-se detalhado na seção 4.5.

\subsubsection{Agrupamentos de Nós (G)}


Agrupamentos de Nós (G) consistem de um conjunto de Nós Ordinários, gerenciados por um ou mais nós Controladores, cujo agrupamento é realizado considerando-se a distância entre os nós em termos de latência. Um Agrupamento de Nós pode ter um ou mais Controladores, cujas funções são balancear a carga dentro de um agrupamento (dependendo do número de nós), aumentar a disponibilidade/confiabilidade por meio de redundância e melhorar a resiliência na medida em que a saída de um dos controladores do overlay pode ser suprida automaticamente por meio de outro controlador. Os agrupamentos limitam o overhead e possibilitam a implementação de otimizações locais.

\subsubsection{Fonte/Controlador Inicial $\left(S / C_{0}\right)$}

A Fonte (S) do streaming é um nó Ordinário que inicia o overlay. É também o primeiro nó Controlador $\left(\mathbf{C}_{\mathbf{0}}\right)$.

\subsubsection{Nós de referência (L)}

Nós de Referência (L) são Nós Ordinários (N) cuja função é servir de referência para a construção de um sistema de coordenadas. Nesse protocolo serão considerados três nós de referência, necessários para a determinação de um espaço euclidiano bidimensional.

A escolha para os Nós de Referência ainda é um problema em aberto. Considerar que os Nós de Referência serão Nós Ordinários participantes do overlay, e que serão elegidos na seqüência (os Nós de Referência serão os três primeiros pares a entrarem no overlay - Fonte e os dois pares subseqüentes) pode implicar em um aumento no erro da estimativa das coordenadas caso a distância entre esses nós iniciais seja pequena. Para mitigar esse problema poderiam ser escolhidos elementos passivos da rede física, como roteadores, para servirem como Nós de Referência. No entanto, essa alternativa não é viável pois a maior parte dos 
roteadores na Internet não responde a ping. Uma possibilidade seria considerar nós de referência fixos, não obstante isso vai contra a premissa da ausência de infraestrutura fixa. Outra alternativa, viável, seria considerar que os nós de referência são nós que não necessariamente façam parte do overlay. Por exemplo: em um ambiente corporativo, em que é utilizada uma aplicação para comunicação interna, poderia ser desenvolvido algum tipo de extensão para esse aplicativo que agregasse a ele a função de nó de referência. Isso funcionaria pois muitas vezes os usuários de uma aplicação como um Instant Messenger corporativo deixam a aplicação em execução, mesmo que não estejam utilizando.

\subsubsection{Servidor de Aplicação}

O Servidor de Aplicação (AS) é a entidade responsável pelo armazenamento de informações sobre o evento de streaming, como a URL da Fonte, a data do evento, a duração do evento, entre outras. Além disso, é para o Servidor de Aplicação que são enviadas e armazenadas as coordenadas dos nós de referência, coordenadas estas que são calculadas pelo nó fonte. Esse processo encontra-se detalhado na seção 4.5 .

\subsection{Condições Gerais de Operação do Protocolo}

O protocolo proposto considera que algumas pré-condições sejam satisfeitas.

- Como está sendo utilizado um sistema de coordenadas euclidiano bidimensional, é necessário que existam três nós de referência com as respectivas distâncias entre os mesmos.

- Todos os Nós Controladores (C) devem possuir a lista dos Nós de Referência (L). Uma vez conhecidos, os endereços dos nós de referência serão publicados em um Servidor de Aplicação (AS) (ex: um Web Server), 
de modo que possam ser acessados pelos nós que desejarem entrar no grupo.

- O endereço IP da fonte também deve ser publicado em um Servidor de Aplicação (AS). Além do IP serão publicados a URL com o nome do evento, a data e a duração do evento. Cada URL com o nome do evento está relacionada com um conjunto de três Nós de Referência (endereço IP de cada um deles).

- A Fonte possui uma tabela com o endereço de um conjunto de nós para os quais irá encaminhar as mensagens de requisição de entrada no grupo (mensagens de request to join). Essa tabela será particionada em dois grupos: o grupo dos Nós Ordinários (N) internos ao Agrupamento (G) da Fonte (S) e o grupo dos nós Controladores (C) pertencentes a outros agrupamentos externos ao agrupamento da fonte. A prioridade de encaminhamento de requisições de entrada no grupo será em primeiro lugar para os nós pertencentes ao agrupamento da fonte e em seguida, dependendo da taxa de chegada de requisições, estas serão encaminhadas para Controladores externos ao agrupamento da fonte (Controladores designados para tratar a requisição de entrada no grupo). Esse processo visa balancear a carga de atendimento de requisições para entrada no grupo. Internamente ao agrupamento da fonte, os nós serão selecionados de acordo com um índice de recursos (IR), definido a seguir.

- Cada nó participante do overlay possui um Índice de Recursos (IR) definido como sendo uma função da largura de banda, do consumo de CPU, da utilização de memória e do número de conexões para outros pares do grupo.

\subsection{Especificação do Protocolo}

Esta seção irá detalhar o protocolo para a construção do overlay. Será apresentada sua forma de organização, um diagrama de troca de mensagens e a máquina de estados do protocolo. 


\subsubsection{Organização do Overlay}

A Figura 4.1 apresenta o aspecto geral do overlay construído pelo protocolo. Nessa figura podem ser observados os diversos Agrupamentos de Nós (representados pelos círculos) com seus respectivos Controladores. Cada Agrupamento possui uma quantidade de Nós Ordinários, sendo que alguns deles pertencem a mais de um Agrupamento. O tamanho dos agrupamentos são definidos em termos de um limiar de latência (LT - Latency Threshold) cujo valor inicial será da ordem de 50ms. Ainda nessa figura, pode-se observar que a origem do sistema de coordenadas é a fonte $\left(S / C_{0}\right)$ e que por razões de simplificação um dos Nós de Referência deve ser eleito o mais próximo possível da fonte, de modo a possuir coordenadas $\left(\mathrm{XL}_{1}, \mathrm{YL}_{1}\right)=$ $(0,0)$, um segundo nó de referência terá como coordenadas $\left(X L_{2}, Y L_{2}\right)=\left(X L_{2}, 0\right)$, e um terceiro nó de referência terá como coordenadas $\left(\mathrm{XL}_{3}, \mathrm{YL}_{3}\right)=\left(\mathrm{XL}_{3}, \mathrm{YL}_{3}\right)$, simplificando dessa forma a resolução do sistema de equações que irá determinar as coordenadas dos Nós de Referência ${ }^{8}$.

${ }^{8}$ Considerando-se que as coordenadas dos Nós de Referência sempre são da forma $L_{1}=\left(X L_{1}, Y L_{1}\right)=$ $(0,0), L_{2}=\left(X L_{2}, Y L_{2}\right)=\left(X L_{2}, 0\right)$ e $L_{3}=\left(X L_{3}, Y L_{3}\right)=\left(X L_{3}, Y L_{3}\right)$, e que é possível formular três equações a partir das distâncias entre os Nós de Referência, a determinação das coordenadas desses nós resume-se a determinar $\mathrm{XL}_{2}, \mathrm{XL}_{3}$ e $\mathrm{YL}_{3}$. 


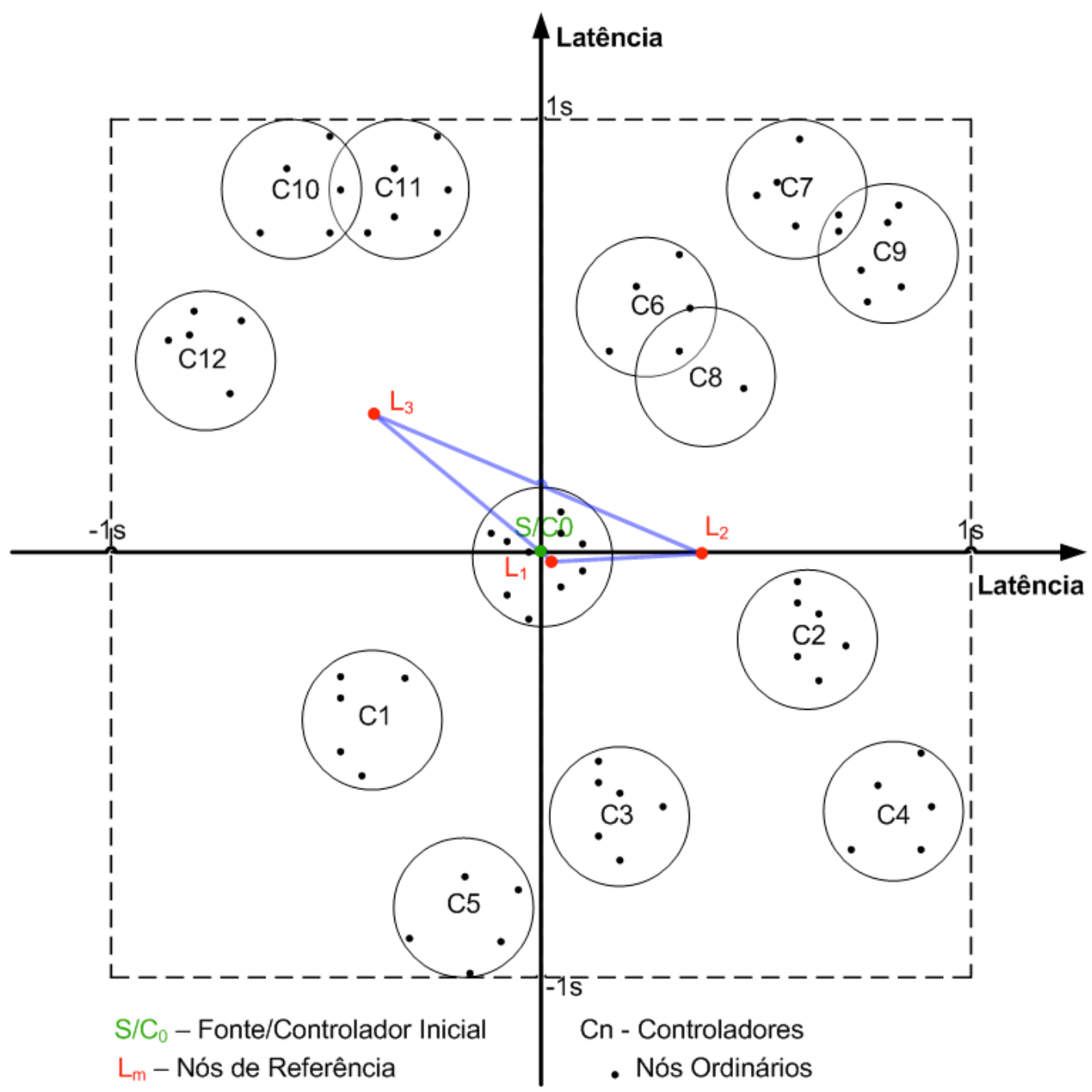

Figura 4.1 - Aspecto geral da organização do overlay.

\subsubsection{Diagrama de Troca de Mensagens}

Esta seção irá apresentar uma descrição da dinâmica do protocolo por meio da seqüência temporal de mensagens que são trocadas desde a entrada de um novo nó no overlay, até o início do processo de recebimento do streaming.

A entrada de novos pares no overlay funciona da seguinte maneira (Figura 4.2). Quando entra um novo nó ( $\mathrm{Nx}$ ), este envia uma mensagem de Request to Join para o Servidor de Aplicação (AS), o qual envia para o novo nó a URL da Fonte (S) e um mapa com os endereços IP e coordenadas dos Nós de Referência (L). Nesse ponto, a fonte do streaming já calculou e armazenou no Servidor de Aplicação o 
mapa com os endereços IP e as distâncias entre Nós de Referência. De posse do endereço da fonte, o novo nó envia uma mensagem de Request to Join para a fonte, a qual também é o Controlador inicial. De modo a balancear a carga para o tratamento de requisições de entrada no overlay, a fonte pode tratar a requisição, ou encaminhá-la para outro controlador, ou ainda encaminhar a requisição para um nó ordinário pertencente ao agrupamento da fonte. Esse último caso ocorre quando a fonte recebe um número elevado de requisições (necessita balancear a carga), mas nenhum outro Controlador ainda foi ativado em razão da proximidade entre os nós até então participantes do overlay. O Controlador/nó ordinário que recebe a requisição passa a ser o Controlador Designado (Cj) que irá tratar a entrada do novo nó no overlay, e envia uma mensagem de reconhecimento (ACK) para o novo nó com o seu endereço. De posse do endereço do Controlador designado, o novo nó (Nx) realiza medidas de RTT para os nós de referência e com base nesses valores, $\mathrm{Nx}$ calcula suas coordenadas $\mathrm{Nx}(\mathrm{x}, \mathrm{y})$, enviando-as para o Controlador designado. $\mathrm{O}$ Controlador designado recupera as coordenadas dos $\mathbf{n}$ Controladores mais próximos a Nx e envia essa lista (\{Ci\}) para o nó Nx. Essa lista é obtida pela comparação entre as coordenadas do novo nó $(\mathrm{Nx})$ com as coordenadas de cada um dos Controladores do overlay, uma vez que os nós Controladores conhecem uns aos outros (questões sobre o gerenciamento do mapa global de coordenadas serão discutidas nas próximas seções). De posse dessa lista $\{\mathrm{Ci}\}$, o nó $\mathrm{Nx}$ realiza medidas de RTT para cada um dos Controladores (Ci). Nesse ponto, o novo nó Nx conhece as distâncias até um conjunto de Controladores mais próximos. Desse ponto em diante é necessário que o novo nó realize uma auto-classificação, tornando-se ou não um novo Controlador. Se todas as latências até cada um dos Controladores medidos (Ci) for maior que um limiar (LT - Latency Threshold), o novo nó torna-se um Controlador. Nesse caso, para o recebimento da lista de pares, aos quais o novo nó irá se conectar, há duas possibilidades: i. se não houver intersecção entre o agrupamento do novo Controlador e os agrupamentos dos dois Controladores mais próximos (Ck1 e Ck2), cada um dos Ck's envia para o novo Controlador uma lista $L$ de pares aos quais o novo Controlador poderá se conectar de modo a iniciar o recebimento do streaming. ii. caso haja intersecção entre os agrupamentos dos dois Controladores mais próximos ( $\mathrm{Ck} 1$ e Ck2) e o agrupamento do novo Controlador, cada um dos Ck's cria uma lista de pares (L") pertencentes às intersecções entre os agrupamentos, envia essa lista para o novo Controlador, o qual se conecta a cada 
um desses pares e inicia o recebimento do streaming. Os pares nas intersecções podem ser identificados pelos Controladores a partir do mapa global de coordenadas de controladores e pelo mapa local das coordenadas dos pares pertencentes ao agrupamento. Por fim, caso o novo nó não seja eleito um novo Controlador pelo critério de comparação de latências, este deve apenas associar-se ao Controlador mais próximo, requisitar um lista de pares (L'), conectar-se a cada um desses pares e iniciar o recebimento do streaming. 


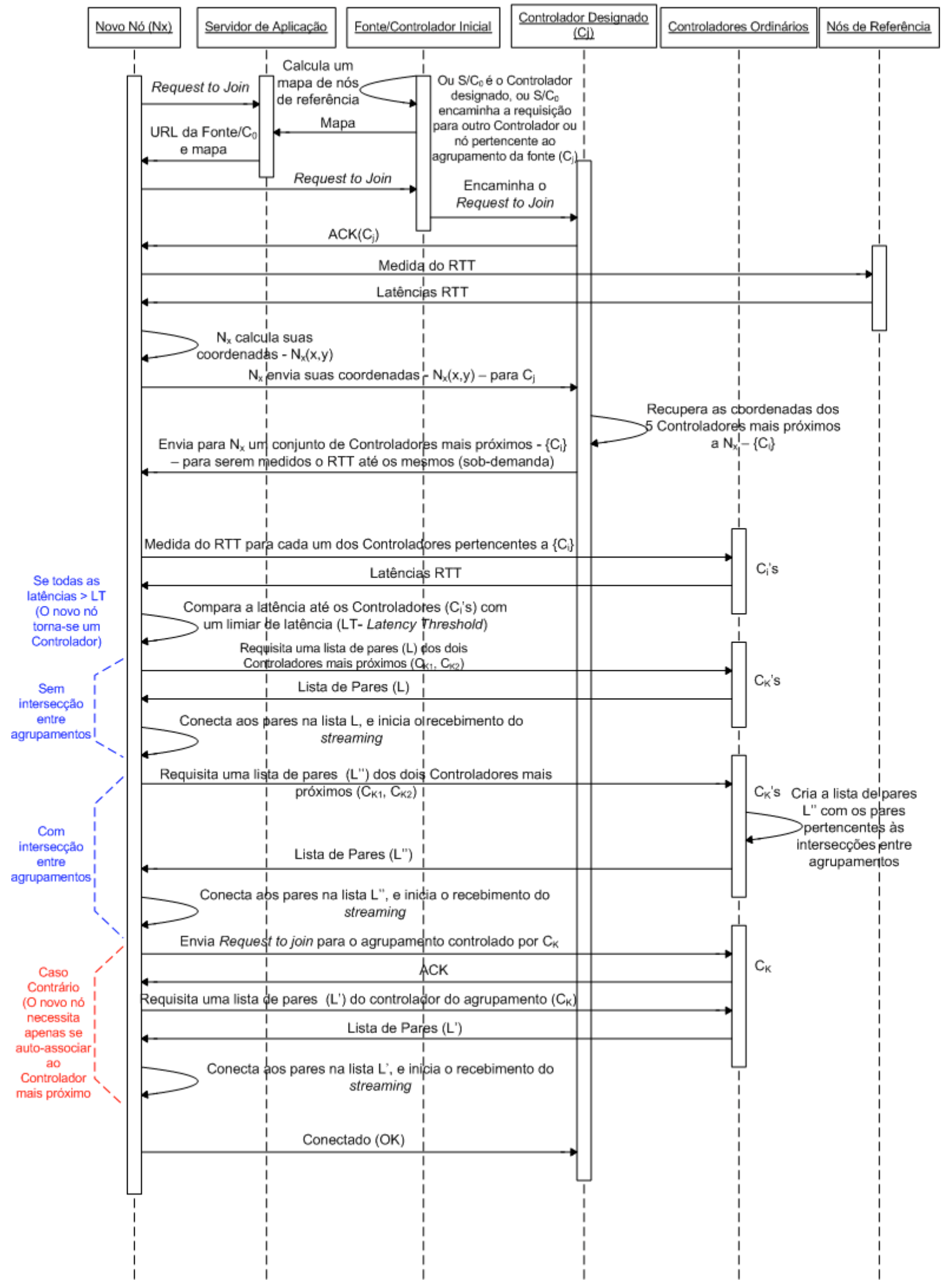

Figura 4.2 - Diagrama de troca de mensagens. 


\subsubsection{Máquina de Estados}

Essa seção irá descrever, por meio de máquinas de estados, o comportamento das entidades participantes do protocolo. Para cada uma das entidades participantes, há uma máquina dos estados possíveis de serem ocupados.

A Figura 4.3 (a) apresenta a máquina de estados para a Fonte/ $\mathrm{C}_{0}$. No estado inicial, considera-se que a fonte já possui o mapa com as distâncias entre os Nós de Referência. Estando no estado "Aguardando requisições do tipo Request to Join", ao receber uma mensagem de Request to Join de um novo nó $\mathrm{Nx}$, a máquina transita para o estado de "Forwarding" e envia uma mensagem de Request to Join para o Controlador Designado (Cj). No estado de "Forwarding", a máquina aguarda uma mensagem de reconhecimento (ACK) do Controlador Designado (Cj). Se esse reconhecimento for recebido pela Fonte, ela retorna para o estado inicial de modo a aguardar novas requisições, caso contrário, após um intervalo de tempo (timeout), a máquina transita para o estado inicial e envia uma mensagem de falha ao se conectar com o Controlador Designado para o novo nó (Nx).

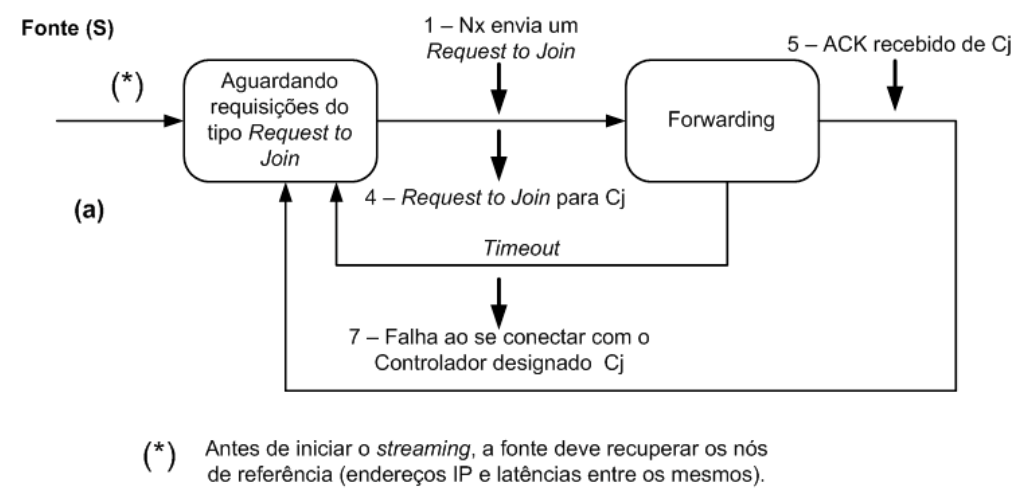

Controladores Designados $\left(\mathrm{C}_{\mathrm{j}}\right)$-> Nós pertencentes ao agrupamento da fonte, Controladores externos ao agrupamento da fonte ou o próprio Controlador inicial $\left(\mathrm{C}_{0}\right)$

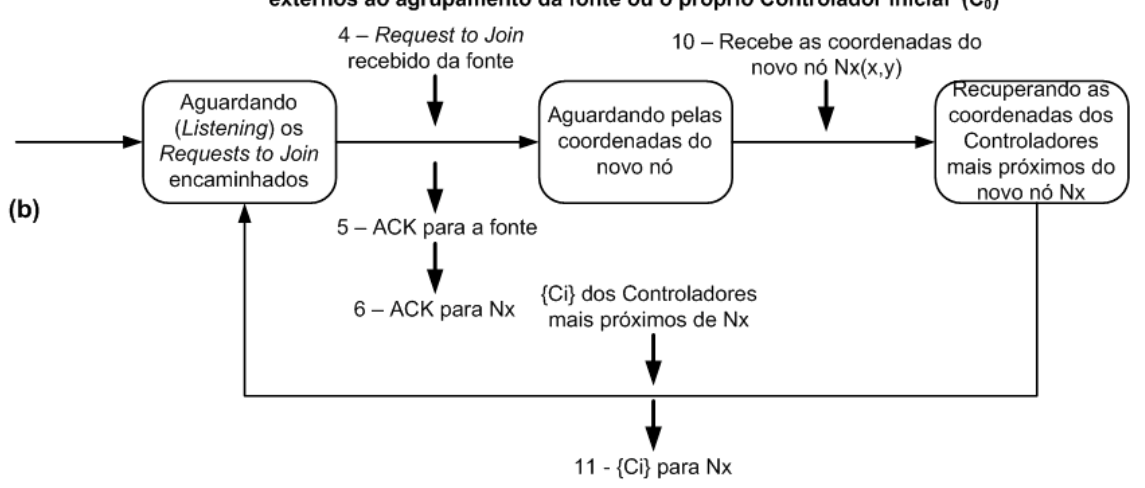

Figura 4.3 - Máquinas de estados para a Fonte (a) e para os Controladores Designados (b). 
Os Controladores Designados $(\mathrm{Cj})$ permanecem no estado "Aguardando (Listening) os Requests to Join encaminhados" pela Fonte - Figura 4.3 (b). A receberem esta requisição (Request to Join), disparam duas mensagens de reconhecimento (ACK), uma para a fonte e outra para o novo nó $\mathrm{Nx}$, transitando em seguida para o estado "Aguardando pelas coordenadas do novo nó". Ao receberem essas coordenadas $\mathrm{Nx}(\mathrm{x}, \mathrm{y})$ - os Controladores Designados iniciam o processo de recuperação das coordenadas dos Controladores mais próximos do novo nó Nx. De posse dessa lista de Controladores mais próximos $\{\mathrm{Ci}\}$, o Controlador Designado as envia para $\mathrm{Nx}$ e retorna para o estado "Aguardando (Listening) os Requests to Join encaminhados".

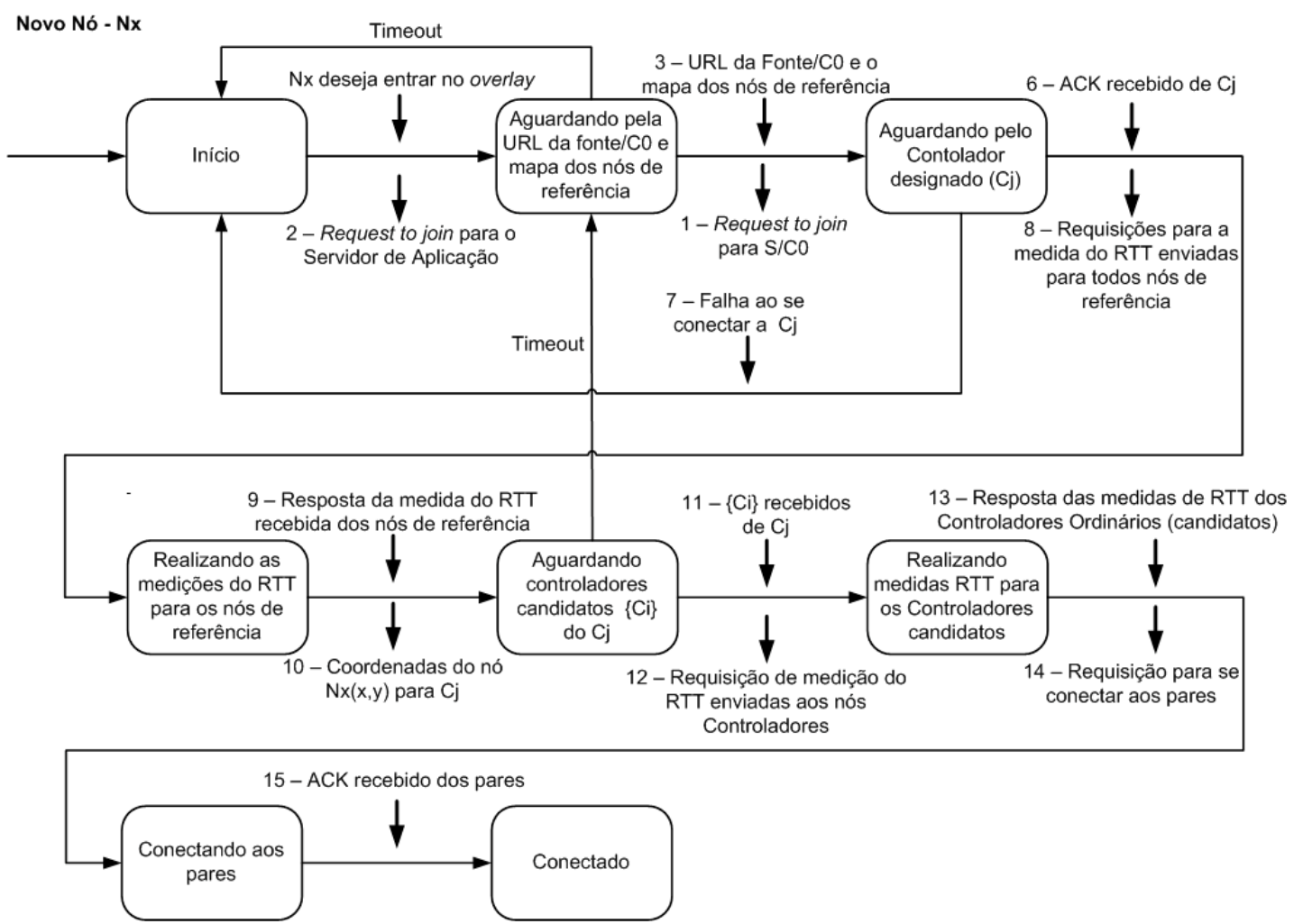

Figura 4.4 - Máquina de estados para um novo nó Nx.

A Figura 4.4 apresenta o comportamento de um novo nó $\mathrm{Nx}$. Estando no estado inicial "Início", o novo nó envia uma mensagem do tipo "Request to join para o Servidor de Aplicação" e passa para o estado "Aguardando pela URL da Fonte/ $\mathrm{C}_{0} \mathrm{e}$ mapa dos nós de referência". Caso o Servidor de Aplicação não retorne com essas informações, após um período (timeout), o novo nó retorna para o estado inicial. Caso contrário, ao receber a URL da Fonte/ $\mathrm{C}_{0}$ e o mapa dos nós de referência, o novo nó envia um "Request to Join para a Fonte/ $\mathrm{C}_{0}$ " e transita para o estado 
"Aguardando pelo Controlador Designado (Cj)". Neste estado, ao receber a mensagem de reconhecimento de Cj (ACK), o novo envia uma requisição para a medida do RTT (Round-Trip Time) para todos os nós de referência e transita para o estado "Realizando as medições do RTT para os nós de referência". Caso não seja recebido o ACK do Controlador Designado, o novo nó irá receber uma mensagem do tipo "Falha ao se conectar a Cj" da fonte e irá transitar para o estado inicial. Uma vez recebidas as medidas de RTT dos Nós de Referência, o novo nó calcula suas coordenadas - Nx(x,y) e as envia para $\mathrm{Cj}$, passando em seguida a aguardar a lista de Controladores candidatos $\{\mathrm{Ci}\}$ do Controlador $\mathrm{Cj}$. Caso $\mathrm{Cj}$ não retorne esta lista, após um período de tempo (timeout) o novo nó para novamente para o estado "Aguardando pela URL da fonte/C $\mathrm{C}_{0}$ e mapa dos nós de referência". Uma vez recebida esta lista $\{\mathrm{Ci}\}$, o novo nó $\mathrm{Nx}$ envia a cada um dos Controladores (Ci) requisições para a medição do RTT e passa a aguardar estas respostas permanecendo no estado "Realizando medidas RTT para os Controladores candidatos". Ao receber essas medidas de RTT para cada um dos Controladores pertencentes a $\{\mathrm{C} i\}$, o novo nó inicia a comunicação com os Controladores mais próximos, podendo tornar-se um novo Controlador, ou agregar-se ao grupo de um Controlador já existente, conforme descrito na seção 4.5.2. Desse modo, Nx envia requisições para se conectar aos pares recebidos de outros Controladores e, uma vez recebida a mensagem de reconhecimento (ACK) desses pares, o novo nó estará conectado ao overlay e poderá ser iniciado o recebimento do streaming. 

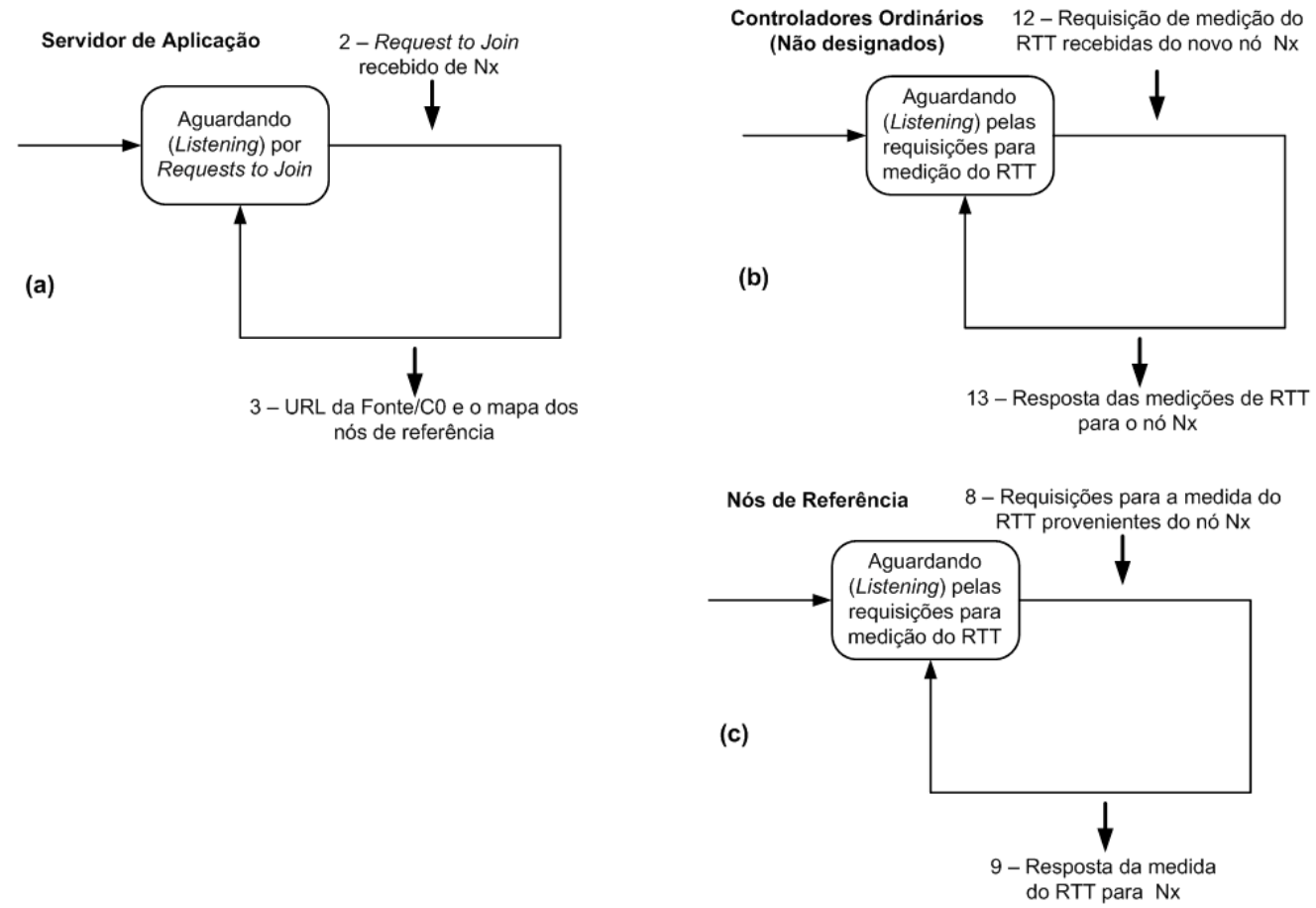

Figura 4.5 - Máquinas de estados para o Servidor de Aplicação (a), para os Controladores Ordinários (b) e para os Nós de Referência (c).

A Figura 4.5 apresenta as máquinas de estados para o Servidor de Aplicação (a), para os Controladores Ordinários (b) e para os nós de referência (c). O Servidor de Aplicação permanece constantemente no estado "Aguardando (Listening) por Requests to Join". Uma vez recebida uma requisição do novo nó Nx, o Servidor de Aplicação envia a URL da Fonte/ $\mathrm{C}_{0}$ e o mapa dos nós de referência para $\mathrm{Nx}$ e retorna ao estado inicial. Tanto os Controladores Ordinários, quanto os nós de referência possuem a funcionalidade de aguardar por requisições solicitando a medição do RTT. Uma vez recebidas essas requisições, estes nós enviam a resposta da medida do RTT para Nx e retornam para o estado inicial ("Aguardando (Listening) pelas requisições para a medição do RTT").

\subsubsection{Armazenamento de Coordenadas}

Conforme descrito anteriormente, uma das funções dos Controladores Designados (Cj) é recuperar as coordenadas de um grupo de Controladores mais próximos do nó que deseja entrar no overlay. Para isso, é necessário que cada Controlador 
Designado conheça as coordenadas de todos os Controladores existentes no overlay. No entanto, manter um mapa atualizado de coordenadas e ainda distribuir essas coordenadas por todos os Controladores do grupo gera um elevado overhead de mensagens, o que impacta diretamente na escalabilidade do overlay. De modo a mitigar esse problema, as coordenadas dos Controladores são armazenadas e atualizadas de forma distribuída, diminuindo o overhead em contrapartida ao aumento do número de consultas necessário para a recuperação das coordenadas de um determinado Controlador. A Figura 4.6 apresenta o esquema usado para o armazenamento e atualização do mapa de coordenadas. A idéia básica desse esquema é construir uma árvore de coordenadas e distribuir cada um dos seus níveis para um Controlador específico, de modo que cada Controlador (Cx) tenha condições de determinar se as coordenadas de um dado par (Nx) pertence ao nível que Cx está gerenciando, ou para qual Controlador deve ser enviada a requisição para a localização das coordenadas de outros Controladores mais próximos de Nx.

Nesse esquema, cada Controlador conhece uma tabela local de coordenadas (LCT - Local Coordinate Table) com as coordenadas dos nós pertencentes ao agrupamento do Controlador. Cada linha dessa tabela contém um identificador para o nó (NODE_ID), as coordenadas (X,Y) para esse nó, assim como seu endereço IP. A árvore de coordenadas é usada como uma estrutura hierárquica para armazenar as coordenadas dos nós Controladores (as coordenadas dos nós pertencentes ao agrupamento interno são armazenadas na LCT). Cada Controlador (Cx) que armazena parte da árvore global de coordenadas deve particionar sua subárvore e criar um nível adicional na hierarquia de armazenamento. Este processo (particionamento) ocorre no momento que o número de coordenadas armazenadas ultrapassa um determinado limiar. Nesse momento, o Controlador (Cx) elege um Controlador representativo do quadrante (QRC - Quadrant Representative Controller), sendo um QRC para cada quadrante (e subquadrante), e envia para cada QRC as raízes das subárvores que cada um irá gerenciar (cada raiz corresponde a um Controlador e está presente na subárvore original, assim como na subárvore que acaba de ser gerada pelo processo de particionamento). Desse modo são criados novos níveis na hierarquia de armazenamento. Por questões de redundância, cada $Q R C$ possui um $Q R C$ espelho $\left(Q R C_{B K}\right)$. A inserção de novos Controladores nessa estrutura e o cálculo da lista de Controladores mais próximos 


\section{\{Ci\} de um novo nó Nx segue o seguinte algoritmo (executado pelos Controladores} Designados - Cj):

i. $\mathrm{CX}<-$ Fonte $\mathrm{S} / \mathrm{CO}$

ii. Enquanto $\mathrm{Cx}$ não for uma folha na estrutura de armazenamento i. O Controlador Designado (Cj) envia as coordenadas do novo nó Nx para um Controlador Cx (ex: Fonte S/CO ou outro)

ii. Cx verifica se o quadrante que ele é responsável por armazenar as coordenadas (dos Controladores) já está particionado.

Se não estiver particionado então:

i. Cx inclui Nx na árvore e envia a Cj os Controladores mais próximos ( $\left.\left\{\mathrm{Ci}^{\prime}\right\}\right)$ de $\mathrm{Nx}$

senão (se particionado):

i. Cx detecta em qual quadrante $\mathrm{Nx}$ deveria ser inserido e envia a $\mathrm{Cj}$ o Controlador representativo do quadrante $(\mathrm{QRCn})$

ii. Cx envia a $\mathrm{Cj}$ as coordenadas (\{Cs\}, um conjunto de $\mathrm{K}$ coordenadas escolhidas randomicamente) dos irmãos de QRCn iii. $\left\{\mathrm{Ci} i^{\prime}<-\{\mathrm{Ci}\}\right.$ U $\{\mathrm{Cs}\}$

fim-se

iii. $C x<-Q R C n$

fim-enquanto

iii. Cj verifica a posição de $\mathrm{Nx}$ entre todos os nós em $\left\{\mathrm{C} i^{\prime}\right\}$ e envia para Nx um conjunto de controladores mais próximos\{Ci\} (inicialmente os experimentos serão realizados com 5 controladores na lista \{Ci\}). 


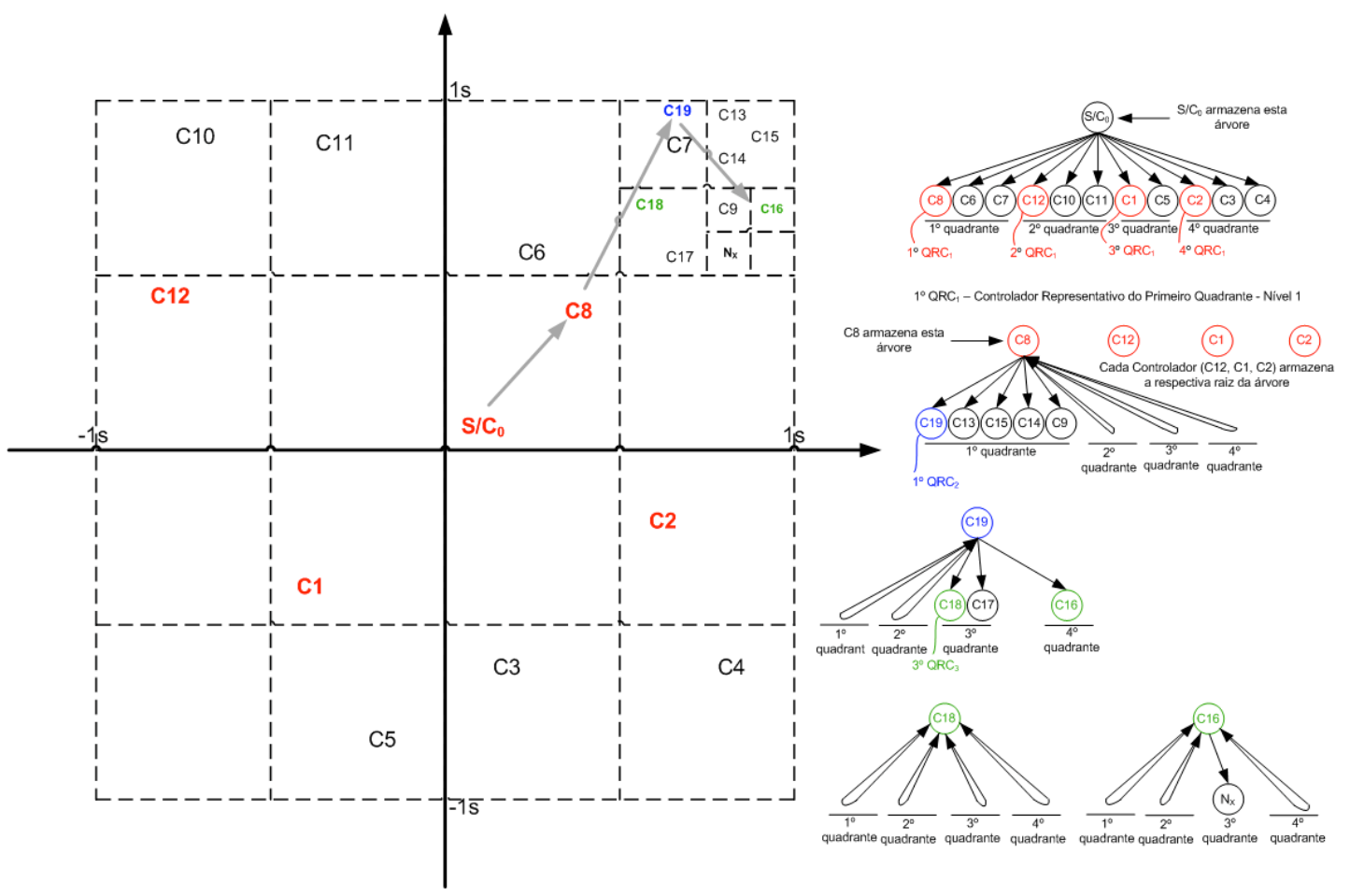

Figura 4.6 - Armazenamento de Coordenadas.

\subsection{Considerações Finais}

Este capítulo apresentou a especificação completa do protocolo proposto no presente trabalho, justificando cada decisão com base no que foi definido nas seções anteriores. Seguindo a linha proposta, o próximo passo será validar a proposta por meio de experimentos. Cumpre ressaltar que não serão validados todos os aspectos do protocolo, pois isso exigiria uma implementação completa do mesmo o que foge do escopo desse trabalho e não faria sentido antes que aspectos comportamentais mais básicos, como a eficiência do método para construção do overlay, sejam validados. O que de fato será validado é a eficácia do uso da técnica híbrida, baseada em coordenadas e medidas sob-demanda, para a seleção de pares dentro do overlay. 


\section{VALIDAÇÃO DA PROPOSTA}

Este capítulo descreve um conjunto de experimentos a serem realizados de modo a validar alguns aspectos do protocolo proposto. Validar a totalidade do protocolo exigiria uma implementação completa do mesmo o que foge do escopo desse trabalho e não faria sentido antes que aspectos comportamentais mais básicos, como a eficiência do método para construção do overlay, sejam validados. Desse modo, serão validados os aspectos referentes à utilização da técnica híbrida, baseada em coordenadas e medidas sob-demanda, para a seleção de pares dentro do overlay.

\subsection{Descrição dos Experimentos realizados}

Os experimentos foram realizados utilizando-se nós reais do PlanetLab (PATERSON; ROSCOE, 2006). O PlanetLab é uma plataforma para a execução de experimentos constituída por um conjunto de nós espalhados pelo mundo ${ }^{9} \mathrm{e}$ interconectados pela Internet. Essa plataforma foi escolhida para propiciar maior realismo aos experimentos. Conforme mencionado em seções anteriores, o uso de técnicas de simulação muitas vezes implicam em bons resultados, no entanto, na maior parte das vezes, as hipóteses assumidas e os dados de entrada no simulador não condizem com as condições reais em que o overlay será construído, o que torna os resultados simulados pouco aderentes à realidade.

Para o desenvolvimento dos scripts foi utilizado o Python (PYTHON, 2008), visto que é uma linguagem de scripts de fácil aprendizado, com recursos poderosos e disponível nos nós do PlanetLab. Isto facilitou a execução dos experimentos, uma

\footnotetext{
${ }^{9}$ Esses nós estão espalhados em universidades e corporações em diferentes continentes. Para fazer parte do PlanetLab (usar a infra-estrutura distribuída), universidades devem apenas ceder alguns nós e instalar o software necessário. Para o caso de corporações, há a necessidade do pagamento de uma taxa anual. Detalhes atualizados sobre os procedimentos para tornar-se um membro do PlanetLab podem ser encontrados no site http://www.planetlab.org.
} 
vez que não foi necessária a instalação de aplicações adicionais em cada um dos nós do slice ${ }^{10}$.

Foi criado um slice no PlanetLab com 121 nós espalhados pelo mundo. Como se tratam de nós reais, muitos dos nós escolhidos estavam inacessíveis, sendo necessária uma primeira filtragem no conjunto inicial, visto que, do mesmo modo que em condições reais, não é assegurada a alta disponibilidade dos nós participantes. Desse conjunto inicial foram extraídos três conjuntos de nós:

a) Um primeiro conjunto com nós próximos (latência $<=1 \mathrm{~ms}$ ). Esse conjunto possui 6 nós (Tabela 5.1) em um mesmo site. O objetivo desse conjunto é avaliar o protocolo proposto quando os nós participantes do grupo estão muito próximos, por exemplo, pertencem a uma mesma rede local. Para fins de referência no texto, esse conjunto será designado por NOS_PROXIMOS e o conjunto de Nós de Referência formados por estes nós será designado por RF_PROXIMOS.

Tabela 5.1 - Conjunto de nós próximos.

\begin{tabular}{|l|l|}
\hline \multicolumn{2}{|c|}{ Conjunto de nós próximos } \\
\hline planetlab6.millennium.berkeley.edu & planetlab8.millennium.berkeley.edu \\
\hline planetlab7.millennium.berkeley.edu & planet5.berkeley.intel-research.net \\
\hline planetlab4.millennium.berkeley.edu & planetlab1.millennium.berkeley.edu \\
\hline
\end{tabular}

b) Um segundo conjunto com nós confinados nos Estados Unidos (latência <= $100 \mathrm{~ms}$ ). Esse conjunto possui 10 nós (Tabela 5.2) estabelecidos no continente americano (a escolha dos Estados Unidos foi arbitrária). O objetivo desse conjunto é avaliar o protocolo proposto quando os nós participantes do grupo estão dentro de uma área intermediária em termos de latência, ou seja, nem muito próximos, nem muito distantes. Para fins de referência no texto, esse conjunto será designado por NOS_EUA e o conjunto de Nós de Referência formados por estes nós será designado por RF_EUA.

10 Slice é a designação usada no PlanetLab para um conjunto de nós que serão utilizados em um dado experimento. 
Tabela 5.2 - Conjunto de nós nos Estados Unidos.

\begin{tabular}{|l|l|}
\hline \multicolumn{2}{|c|}{ Conjunto de nós nos Estados Unidos } \\
\hline planetlab4.cs.duke.edu & lefthand.eecs.harvard.edu \\
\hline $\begin{array}{l}\text { planet3.pittsburgh.intel- } \\
\text { research.net }\end{array}$ & planetlab2.cs.uiuc.edu \\
\hline planetlab6.millennium.berkeley.edu & planetlab4.wail.wisc.edu \\
\hline planetlab1.csres.utexas.edu & planetlab3.csail.mit.edu \\
\hline planet4.cc.gt.atl.ga.us & righthand.eecs.harvard.edu \\
\hline
\end{tabular}

c) Um terceiro conjunto com nós distribuídos pelo mundo (latências <= $500 \mathrm{~ms}$ ). Esse conjunto possui 22 nós (Tabela 5.3) distribuídos pelo mundo. O objetivo desse conjunto é avaliar o protocolo proposto quando os nós participantes do grupo estão separados por grandes distâncias em termos de latência. Para fins de referência no texto, esse conjunto será designado por NOS_LONGE e o conjunto de Nós de Referência formados por estes nós será designado por RF_LONGE.

Tabela 5.3 - Conjunto de nós espalhados pelo mundo.

\begin{tabular}{|l|l|}
\hline \multicolumn{2}{|c|}{ Conjunto de nós espalhados pelo mundo } \\
\hline planetlab-europe-01.ipv6.lip6.fr & planetlab1.vtt.fi \\
\hline planetlab-1.imperial.ac.uk & planetlab2.cs.vu.nl \\
\hline & $\begin{array}{l}\text { planet3.pittsburgh.intel- } \\
\text { research.net }\end{array}$ \\
\hline planetlab4.cs.duke.edu & planetlab1.hiit.fi \\
\hline planetlab6.millennium.berkeley.edu & adam.ee.ntu.edu.tw \\
\hline planetlab1.csres.utexas.edu & lefthand.eecs.harvard.edu \\
\hline planet4.cc.gt.atl.ga.us & planetlab4.wail.wisc.edu \\
\hline planetlab2.cs.uiuc.edu & planetlab2.iis.sinica.edu.tw \\
\hline plab1.larc.usp.br & planetlab2.ie.cuhk.edu.hk \\
\hline eve.ee.ntu.edu.tw & planetlab2.csg.uzh.ch \\
\hline planetlab3.csail.mit.edu & planetlab2.cs.wisc.edu \\
\hline planetlab3.ie.cuhk.edu.hk &
\end{tabular}

Os limiares de latência (1ms, $100 \mathrm{~ms}$ e $500 \mathrm{~ms}$ ) para a escolha desses três conjuntos foram determinados de forma experimental por meio da utilização de pings com 36 bytes. Assim sendo, foi feito um experimento que consistiu em medir o RTT entre todos os nós iniciais do slice e a partir desses resultados foram criados os conjuntos de nós. Basicamente, o resultado desse experimento foi um conjunto de latências médias entre dois nós pertencentes ao conjunto inicial, o qual foi ordenado de modo que fosse possível estabelecer os limiares mencionados. Cumpre ressaltar que dos 121 nós iniciais, apenas 38 foram utilizados, sendo que uma parcela foi desconsiderada por estar inacessível e outra parcela foi desconsiderada por se 
tratarem de nós com a mesma localização física. A utilização destes últimos faria com que o tempo necessário para a execução dos experimentos tornar-se elevado, inviabilizando-os.

\subsubsection{Validação do Método de Construção do Sistema de Coordenadas}

De modo a avaliar se o erro obtido no processo de estimativa das coordenadas de um novo nó está diretamente relacionado à posição relativa dos Nós de Referência, ou seja, avaliar se Nós de Referência mais próximos implicarão em maiores erros, avaliar se existe influência do período em que o overlay é construído (se as latências entre nós na Internet variam de acordo com o tráfego na rede, o que está diretamente relacionado ao horário em que as medições estão sendo efetuadas) e avaliar a influência do método de medida utilizado (apesar desse protocolo considerar a utilização do RTT como medida de latência entre os nós, para o caso dos Nós de Referência foram realizados experimentos utilizando-se o netperf (NETPERF, 2008), foram definidos e executados os três experimentos descritos a seguir, cujo objetivo é avaliar os aspectos mencionados e gerar um conjunto de Nós de Referência a serem utilizados no processo de estimativa do erro $(\varepsilon)$ no processo de cálculo das coordenadas.

\subsubsection{Influência da Posição dos Nós de Referência}

Neste experimento, a partir de cada um dos três conjuntos de nós mencionados, foram geradas todas as combinações possíveis de 3 nós. Basicamente, o script para a geração dos Nós de Referência realiza os seguintes passos (o script utilizado para a geração dos Nós de Referência encontra-se anexado ao final do trabalho):

a) Gera todas as combinações de 3 nós. 
b) Para cada uma das combinações, a partir do primeiro nó, é medido o RTT para o segundo e terceiro nós por meio de um ping com 3 pacotes de 36 bytes. Em seguida, a partir do segundo nó, é medido o RTT para o terceiro nó.

C) De posse das distâncias (latências) entre os três nós, $d_{A B}-R T T$ entre os nós $A$ e $B, d_{A C}-R T T$ entre os nós $A$ e $C$ e $d_{C B}-R T T$ entre os nós $C$ e $B$, as coordenadas de cada um deles é estimada da seguinte forma:

Para o primeiro nó $(A):\left(X_{A}, Y_{A}\right)=(0,0)$.

Para o segundo nó $(B):\left(X_{B}, Y_{B}\right)=\left(d_{A B}, 0\right)$.

Para o terceiro nó $(C):\left(X_{C}, Y_{C}\right)=\left(\left(d_{A C}{ }^{2}+d_{A B}{ }^{2}-d_{C B}{ }^{2}\right) /\left(2 d_{A B}\right), \operatorname{sqrt}\left(d_{C B}{ }^{2}-\left(X_{C}-d_{A B}\right)^{2}\right)\right)$.

O número de pacotes para a medida do RTT ( 3 pacotes de 36 bytes) foi escolhido de modo a obter uma medida com boa precisão (foi considerada a latência média), mas sem aumentar muito o tempo de execução dos experimentos, o que inviabilizaria o trabalho.

Os Nós de Referência obtidos para cada um dos três conjuntos de nós geraram arquivos de saída no seguinte formato:

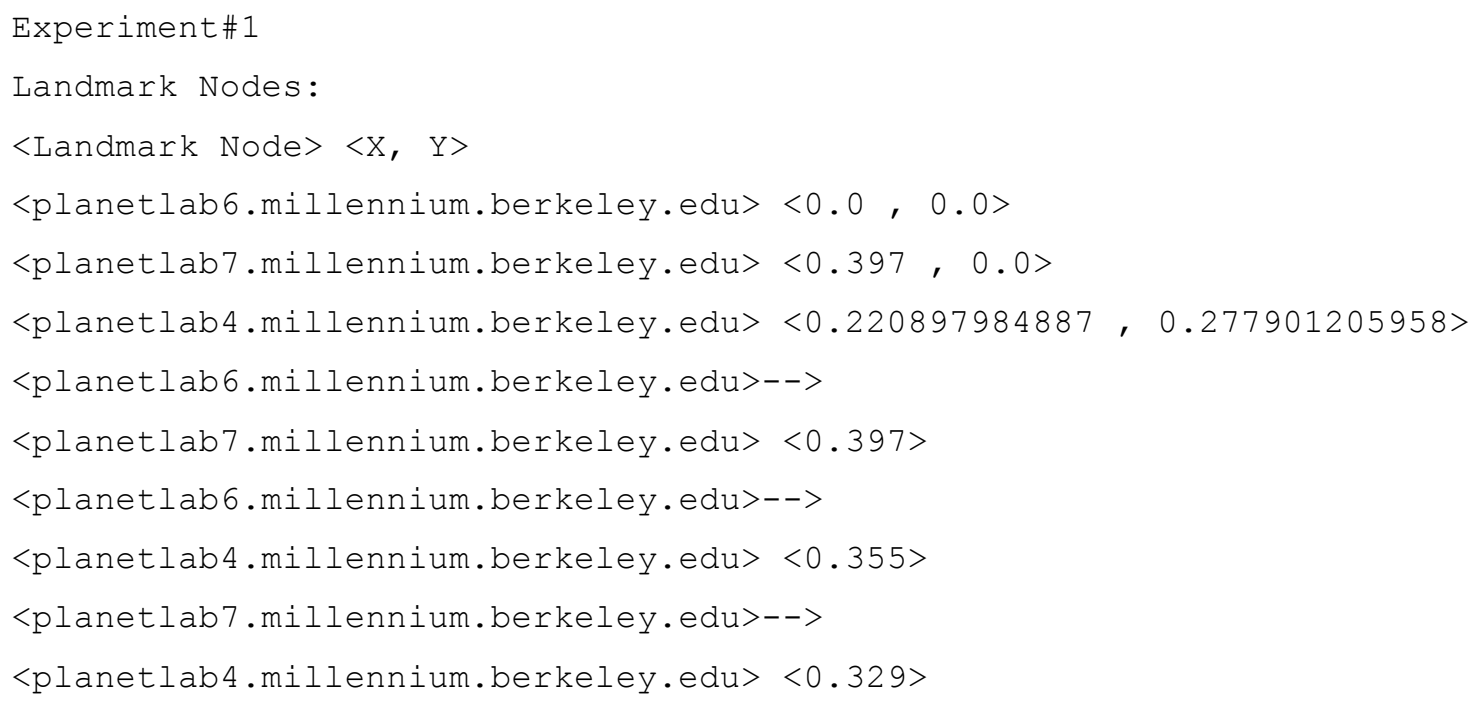

Os resultados da geração dos Nós de Referência encontram-se sumarizados na (Tabela 5.4). 
Tabela 5.4 - Sumário dos resultados na geração dos Nós de Referência.

\begin{tabular}{|c|c|c|c|}
\hline $\begin{array}{c}\text { Conjunto de Nós de } \\
\text { Referência }\end{array}$ & $\begin{array}{c}\text { Número teórico de } \\
\text { combinações de 3 } \\
\text { nós }\end{array}$ & $\begin{array}{c}\text { Número de } \\
\text { combinações } \\
\text { obtido }\end{array}$ & $\begin{array}{c}\text { Distância entre os } \\
\text { Nós de Referência }\end{array}$ \\
\hline RF_PROXIMOS & 20 & 19 & $<1 \mathrm{~ms}$ \\
\hline RF_EUA & 120 & 88 & $<100 \mathrm{~ms}$ \\
\hline RF_LONGE & 1540 & 318 & $<362 \mathrm{~ms}$ \\
\hline
\end{tabular}

Pelos resultados da Tabela 5.4 verifica-se que o número de combinações teórico difere do número de combinações obtidos pelo script. Essa diferença reside no fato de nem sempre ser possível calcular a coordenada $Y_{C}$ do nó $C$ (casos de raiz quadrada de número negativo). Isso ocorre pois existem situações em que não é possível obter o triângulo com vértices nos nós $A, B$ e C (lei de formação do triângulo não é satisfeita em razão das diferenças encontradas nas diferentes partes da infraestrutura de comunicação - Internet).

\subsubsection{Influência do Período de Construção do Overlay}

Neste experimento foram realizados os mesmos procedimentos do experimento descrito na seção 5.1.1.1, porém o mesmo foi repetido em diferentes períodos, de modo a verificar qual a variação de latências em função da utilização da Internet. Os períodos de análise foram: das 00:00h as 06:00h, das 06:00h as 12:00h, das 12:00h as $18: 00 \mathrm{~h}$ e das $18: 00 \mathrm{~h}$ as $24: 00 \mathrm{~h}$. Os resultados encontram-se sumarizados na Tabela 5.5. 
Tabela 5.5 - Sumário dos resultados na geração dos Nós de Referência por período de execução.

\begin{tabular}{|c|l|l|l|l|}
\hline \multirow{2}{*}{$\begin{array}{c}\text { Conjunto de Nós } \\
\text { de Referência }\end{array}$} & \multicolumn{5}{|c|}{ Distância entre os Nós de Referência/Número de combinações } \\
obtido \\
\cline { 2 - 6 } & $\begin{array}{l}00: 00 \mathrm{~h} \text { as } \\
06: 00 \mathrm{~h}\end{array}$ & $\begin{array}{l}06: 00 \mathrm{~h} \\
12: 00 \mathrm{~h}\end{array}$ & $\begin{array}{l}12: 00 \mathrm{~h} \\
18: 00 \mathrm{~h}\end{array}$ & $\begin{array}{l}18: 00 \mathrm{~h} \\
24: 00 \mathrm{~h}\end{array}$ \\
\hline RF_PROXIMOS & $<1 \mathrm{~ms} / 19$ & $<1 \mathrm{~ms} / 19$ & $<1 \mathrm{~ms} / 19$ & $<1 \mathrm{~ms} / 19$ \\
\hline RF_EUA & $<80 \mathrm{~ms} / 110$ & $<100 \mathrm{~ms} / 95$ & $<100 \mathrm{~ms} / 88$ & $<90 \mathrm{~ms} / 100$ \\
\hline RF_LONGE & $<400 \mathrm{~ms} / 450$ & $<350 \mathrm{~ms} / 340$ & $<362 \mathrm{~ms} / 318$ & $<500 \mathrm{~ms} / 385$ \\
\hline
\end{tabular}

Os resultados da tabela acima indicam que para o conjunto RF_PROXIMOS não há variações na distância entre os Nós de Referência visto que estão em uma mesma rede local. O número de combinações obtido também não varia em função do horário. Esses resultados indicam o determinismo das latências quando é usada uma rede de caráter privado. Para o caso dos RF_EUA e RF_LONGE pode-se observar que houve uma variação de 12 a $20 \%$ entre os valores obtidos durante o dia e durante a noite. Embora essas variações tenham sido constatadas, não se pode considerar que ocorreram em razão do volume maior de tráfego na rede durante o dia, visto que a carga de trabalho utilizada nos experimentos foram pings com 36 bytes por pacote, ou seja, uma carga de trabalho pouco influenciada por congestionamentos na rede. Nessa análise também não foi considerada a influência dos fuso-horários nas medições.

\subsubsection{Influência do Método de Medida Utilizado}

Neste experimento foram realizadas medidas de latência entre todos os nós constituintes do conjunto RF_EUA. Foram escolhidos os nós do conjunto RF_EUA pois para o caso do RF_PROXIMOS não seriam percebidas variações significativas, 
dada a pequena distância entre os nós, e para os RF_LONGE seria inviável considerar os efeitos relativos ao fuso horário (a análise seria muito complexa). No entanto, ao invés de ser utilizado o RTT para estimativa de latências, nesse experimento foi utilizada uma carga de trabalho mais significativa gerada pelo netperf (NETPERF, 2008), de modo a verificar a influência do método de medida de latência no cálculo das coordenadas dos Nós de Referência. Cumpre ressaltar que o netperf mede largura de banda, sendo que as medidas de latência foram estimadas a partir da largura de banda medida. Uma carga de trabalho maior faz com que os efeitos referentes a perda de pacotes, congestionamento na rede, saturação de buffers e chegada de pacotes fora de ordem influenciem mais nas medidas de latência.

O netperf permite que sejam variados o tamanho do buffer da aplicação (message size - opção $-\mathrm{m}$ ), e o tamanho do buffer de sistema (socket size - opção $-\mathrm{s}$ ). As iterações dentro de cada caso de teste foram executadas por no mínimo 21s, correspondentes a 3 medidas, e por no máximo 70s, correspondentes a 10 medidas, encerrando a execução de uma iteração assim que for atingido um valor dentro do intervalo de confiança de $95 \%$. Nesse experimento o buffer de sistema foi fixado em 256KB, o buffer de aplicação fixado em 96KB e o MTU (Maximum Transmission Unit) foi fixado em 1500 bytes. Esses valores foram escolhidos de modo a maximizar a carga de trabalho, estando fora do escopo deste trabalho avaliar o impacto da variação desses parâmetros na latência obtida. O Gráfico 5.1 sumariza os resultados desse experimento por meio das funções de distribuição cumulativa de probabilidades para cada um dos quatro períodos medidos. Nesse gráfico pode-se verificar que entre o período das 0-6h e 12-18h há uma variação de $53 \%$ a $73 \%$, entre o período das $6-12 \mathrm{~h}$ e $12-18 \mathrm{~h}$ há uma variação de $86 \%$ a $94 \%$ e entre o período das $18-24 \mathrm{~h}$ e $12-18 \mathrm{~h}$ há uma variação de $10 \%$ a $19 \%$. Essas medidas indicam que ocorre uma maior utilização da Internet durante o período da tarde e começo da noite, indicando que dependendo do método de medida utilizado, as coordenadas dos Nós de Referência sofrem alterações. Embora isso ocorra, estimar as coordenadas dos Nós de Referência por meio de medidas mais acuradas pode acarretar em um overhead de controle elevado para o protocolo, o que não é viável, uma vez que o sistema de coordenadas é apenas para uma estimativa inicial da posição dos pares dentro do overlay, sendo necessárias, conforme descrito em 
seções anteriores, medidas sob demanda para a averiguação dos pares que efetivamente estão mais próximos de um dado par $(\mathrm{Nx})$ que entra no grupo para a recepção do streaming de vídeo.

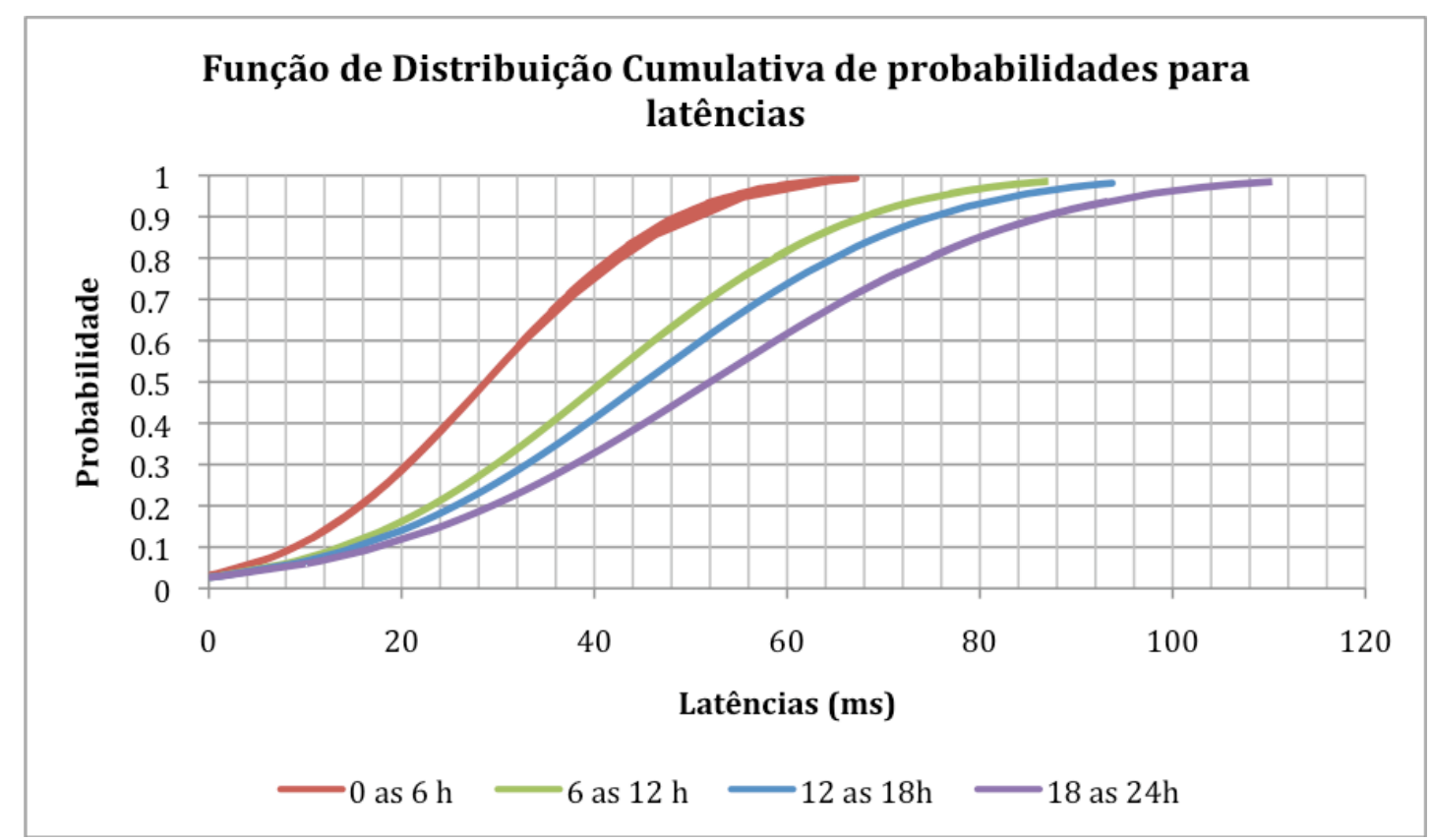

Gráfico 5.1 - Resultado da análise das distâncias (latências) entre os Nós de Referência nos diferentes períodos.

\subsubsection{Estimativa do Erro no Processo de Cálculo das Coordenadas}

Conforme fora mencionado na seção 4.2, o objetivo do presente trabalho é propor e validar um protocolo para a construção de overlays para a distribuição de streamings de vídeo em redes P2P utilizando para isso a técnica híbrida (descrita na seção 3.3). Não faz parte do escopo dessa proposta implementar uma aplicação que utilize esse protocolo. Dessa forma, é fundamental que se avalie a eficiência na construção do overlay utilizando a técnica proposta. Para validar o mesmo, a métrica que será analisada é o erro obtido $(\varepsilon)$ ao se estimar as coordenadas de cada novo nó que entra no overlay.

Para validar o método de construção foram definidos nove cenários experimentais, considerando que existem três possibilidades para os Nós de Referência 
(RF_PROXIMOS, RF_EUA e RF_LONGE) e três possibilidades para os nós que entrarão no overlay (NOS_PROXIMOS, NOS_EUA e NOS_LONGE). Cada um dos cenários possui correlação direta com situações que podem ocorrer na realidade durante o processo de construção do overlay. Seguem a descrições dos cenários:

Cenário 1: Nós de Referência pertencentes ao conjunto RF_PROXIMOS.

Cenário 1.1 (RF_PROXIMOS_NOS_PROXIMOS): Nós de Referência pertencentes ao conjunto RF_PROXIMOS e nós que entrarão no overlay próximos (NOS_PROXIMOS). Este cenário visa emular os casos em que tanto os Nós de Referência, como os nós subseqüentes que entram no overlay estão próximos em termos de latência $(<1 \mathrm{~ms})$. Por exemplo, a fonte e os participantes de uma vídeo-conferência confinados em um mesmo site corporativo, sendo os Nós de Referência pertencentes a este mesmo site.

Cenário 1.2 (RF_PROXIMOS_NOS_EUA): Nós de Referência pertencentes ao conjunto RF_PROXIMOS e nós que entram no overlay distribuídos confinados nos Estados Unidos (NOS_EUA).

Cenário 1.3 (RF_PROXIMOS_NOS_LONGE): Nós de Referência pertencentes ao conjunto RF_PROXIMOS e nós que entram no overlay distribuídos pelo mundo (NOS_LONGE).

Os Cenários 1.2 e 1.3 ilustram a situação em que os Nós de Referência estão próximos e os nós subseqüentes que entram no overlay estão distantes (latência entre eles $<100 \mathrm{~ms}$ ou $<500 \mathrm{~ms}$ ). Para esses casos, os Nós de Referência podem ser considerados como sendo um só para efeito da estimativa das coordenadas dos nós que entram no overlay.

Cenário 2: Nós de Referência pertencentes ao conjunto RF_EUA.

Cenário 2.1 (RF_EUA_NOS_PROXIMOS): Nós de Referência pertencentes ao conjunto RF_EUA e nós que entram no overlay próximos (NOS_PROXIMOS). Esse cenário visa emular os casos em que os Nós de 
Referência estão confinados nos Estados Unidos (latência entre eles < 100 ms) e os nós que entram no overlay estão confinados em um mesmo site. Para esse cenário espera-se um comportamento parecido (mesma ordem de grandeza do erro estimado) para todos os nós que entram no overlay. Esse experimento em particular permite isolar o efeito da variação da posição dos nós que entram no overlay, considerando apenas os efeitos relativos à posição dos Nós de Referência.

Cenário 2.2 (RF_EUA_NOS_EUA): Nós de Referência pertencentes ao conjunto RF_EUA e nós que entrarão no overlay distribuídos pelos Estados Unidos (NOS_EUA). Esse cenário visa emular os casos em que tanto os Nós de Referência, quando os nós subseqüentes que entram no overlay estão confinados e distribuídos nos Estados Unidos (latência entre eles < $100 \mathrm{~ms}$ ).

Cenário 2.3 (RF_EUA_NOS_LONGE): Nós de Referência pertencentes ao conjunto RF_EUA e nós que entrarão no overlay distribuídos pelo mundo (NOS_LONGE). Este cenário emula a mesma situação do cenário 2.2, com a diferença que os nós que entrarão no overlay estão distantes (latências entre os mesmos $<500 \mathrm{~ms}$ ).

Cenário 3: Nós de Referência pertencentes ao conjunto RF_LONGE.

Cenário 3.1 (RF_LONGE_NOS_PROXIMOS): Nós de Referência pertencentes ao conjunto RF_LONGE e nós que entram no overlay próximos (NOS_PROXIMOS). Esse cenário visa emular os casos em que os Nós de Referência estão distribuídos pelo mundo (latência entre eles $<500 \mathrm{~ms}$ ) e os nós que entram no overlay estão confinados em um mesmo site. Assim como para o cenário 2.1, para esse cenário espera-se um comportamento parecido (mesma ordem de grandeza do erro estimado) para todos os nós que entram no overlay. Esse experimento também permite isolar o efeito da variação da posição dos nós que entram no overlay, considerando apenas os efeitos relativos à posição dos Nós de Referência.

Cenário 3.2 (RF_LONGE_NOS_EUA): Nós de Referência pertencentes ao conjunto RF_LONGE e nós que entram no overlay distribuídos pelos Estados Unidos (NOS_EUA). Este cenário emula a mesma situação que o cenário 2.3, 
com a diferença que os Nós de Referência estão distribuídos pelo mundo e os nós que entram no overlay estão confinados nos Estados Unidos.

Cenário 3.3 (RF_LONGE_NOS_LONGE): Nós de Referência pertencentes ao conjunto RF_LONGE e nós que entrarão no overlay distribuídos pelo mundo (NOS_LONGE). Esse cenário visa emular os casos em que tanto os Nós de Referência, quanto os nós subseqüentes que entram no overlay estão distribuídos pelo mundo (latência entre eles $<500$ ms).

Embora existam equivalências entre os cenários definidos, as mesmas foram propositalmente mantidas de modo a avaliar as variações entre experimentos que numa primeira análise deveriam levar a resultados similares. A Tabela 5.6 consolida os experimentos realizados. O código de cores utilizado indica a possibilidade de equivalência entre cenários.

Tabela 5.6 - Sumário dos cenários experimentais avaliados.

\begin{tabular}{|c|c|c|c|}
\hline \multirow{2}{*}{$\begin{array}{c}\text { Nós de } \\
\text { Referência }\end{array}$} & \multicolumn{3}{|c|}{ Nós } \\
\cline { 2 - 4 } & NOS_PROXIMOS & NOS_EUA & NOS_LONGE \\
\hline RF_PROXIMOS & 1.1 & 1.2 & 1.3 \\
\hline RF_EUA & 2.1 & 2.2 & 2.3 \\
\hline RF_LONGE & 3.1 & 3.2 & 3.3 \\
\hline
\end{tabular}

\subsubsection{Descrição do Experimento}

A idéia básica desse experimento é fixar três nós como sendo os de Referência para cada um dos conjuntos gerados na etapa anterior (seção 5.1.1 - RF_PROXIMOS, RF_EUA e RF_LONGE) e para cada um dos nós pertencentes aos conjuntos NOS_PROXIMOS, ou NOS_EUA, ou NOS_LONGE), estimar suas coordenadas, e comparar, dois a dois, a distância (d) obtida pela fórmula que calcula a distância entre dois pontos com a distância (d') obtida por meio do RTT. Por exemplo, dados 
três Nós de Referência ( $A, B$ e $C)$, com coordenadas sendo $A(x a, y a), B(x b, y b)$ e $\mathrm{C}(\mathrm{xc}, \mathrm{yc})$, considere a entrada consecutiva de dois pares no overlay: $\mathrm{Ke} \mathrm{L}$, cujas coordenadas estimadas são $K(x k$, yk) e $L(x l, y l)$. A distância euclidiana entre $K$ e $L$ é dada por:

$$
d k I^{2}=(x k-x l)^{2}+(y k-y l)^{2}
$$

Considere agora a latência medida sob-demanda (RTT) entre os pares $\mathrm{K}$ e L como sendo dkl'. O erro relativo $(\varepsilon)$ entre essas duas estimativas (dkl' e dkl) é a variável que será analisada nesse experimento.

\subsubsection{Tratamento para os Casos sem Solução para a Equação}

No processo de cálculo das coordenadas do novo nó, existem situações em que não é possível estimar essas coordenadas, ou seja, situações em que não há solução para o sistema de equações:

$$
\begin{aligned}
d_{A N x}{ }^{2} & =\left(x^{\prime}-x_{A}\right)^{2}+\left(y^{\prime}-y_{A}\right)^{2}(2 a) \\
d_{C N x}{ }^{2} & =\left(x^{\prime \prime}-x_{C}\right)^{2}+\left(y^{\prime \prime}-y_{C}\right)^{2}(2 b) \\
d_{B N x}{ }^{2} & =\left(x^{\prime \prime \prime}-x_{B}\right)^{2}+\left(y^{\prime \prime \prime}-y_{B}\right)^{2}(2 c)
\end{aligned}
$$

Com $x_{B}=0, y_{C}=0, x_{A}=y_{A}=0$. Sendo $\left(x^{\prime}, y^{\prime}\right),\left(x^{\prime \prime}, y^{\prime \prime}\right),\left(x^{\prime \prime \prime}, y^{\prime \prime \prime}\right)$ as estimativas possíveis para as coordenadas do novo nó $\mathrm{Nx}(\mathrm{x}, \mathrm{y})$. Quando este sistema (2) apresenta soluções (Figura 5.1), as coordenadas do novo nó $\mathrm{Nx}(\mathrm{x}, \mathrm{y})$ podem ser estimadas como sendo o baricentro do triângulo com vértices $N\left(x^{\prime}, y^{\prime}\right), N\left(x^{\prime \prime}, y^{\prime \prime}\right)$ e $N\left(x^{\prime \prime \prime}, y^{\prime \prime \prime}\right)$. 


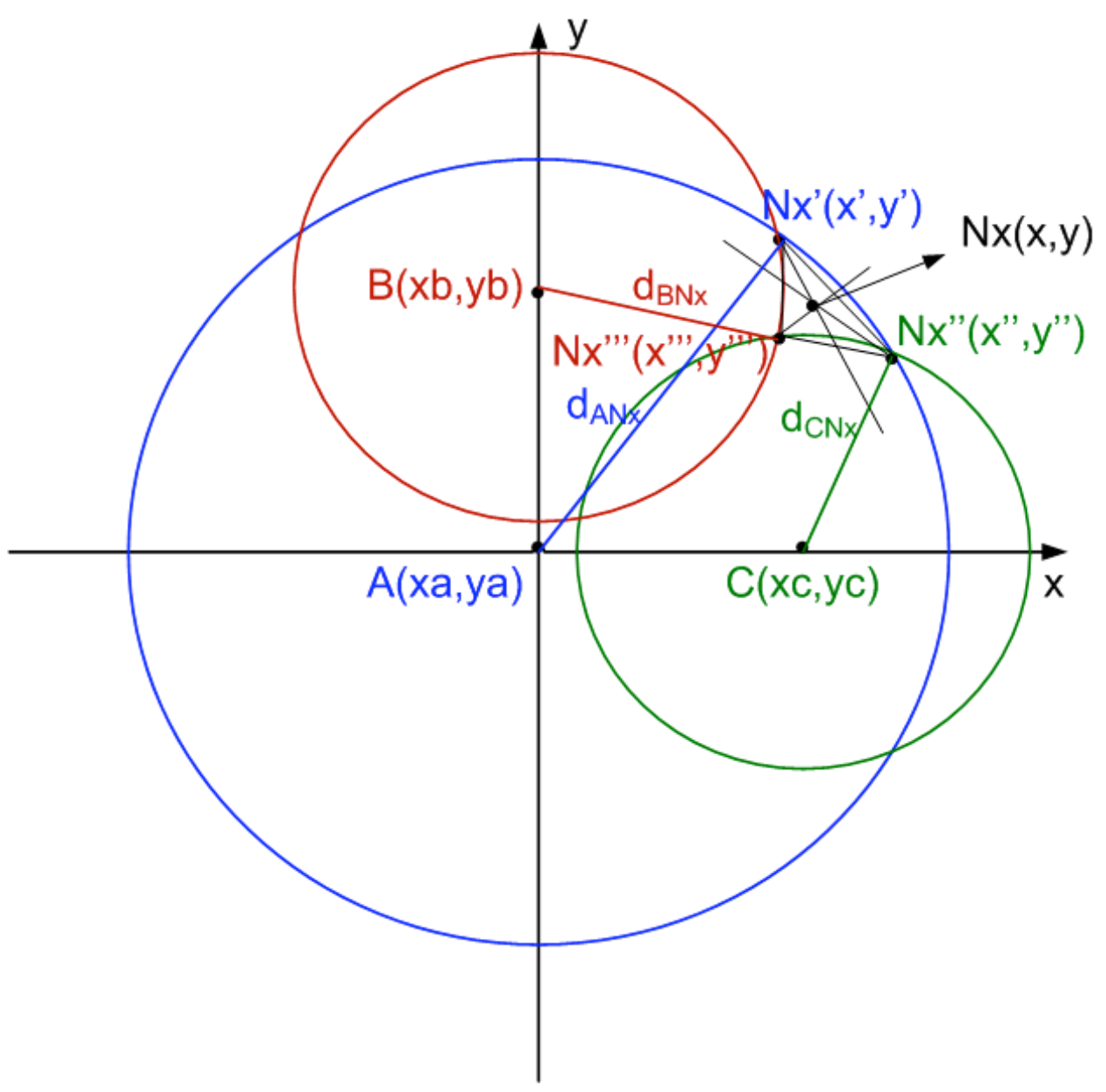

Figura 5.1 - Estimativa das coordenadas quando há solução para as equações.

Quando este sistema apresenta solução parcial (Figura 5.2) ou não apresenta solução (Figura 5.3), uma heurística deve ser aplicada para estimar as coordenadas do novo nó $\mathrm{Nx}(\mathrm{x}, \mathrm{y})$. No caso de não haver solução, as coordenadas de $\mathrm{Nx}$ podem ser estimadas como sendo o baricentro do triângulo cujos vértices são $A(x a, y a)$, $\mathrm{B}(\mathrm{xb}, \mathrm{Yb})$ ou $\mathrm{C}(\mathrm{xc}, \mathrm{yc})$. Desse modo, esse experimento visa analisar a proporção de casos em que há solução, ou em que há solução parcial, ou ainda em que não há solução. 


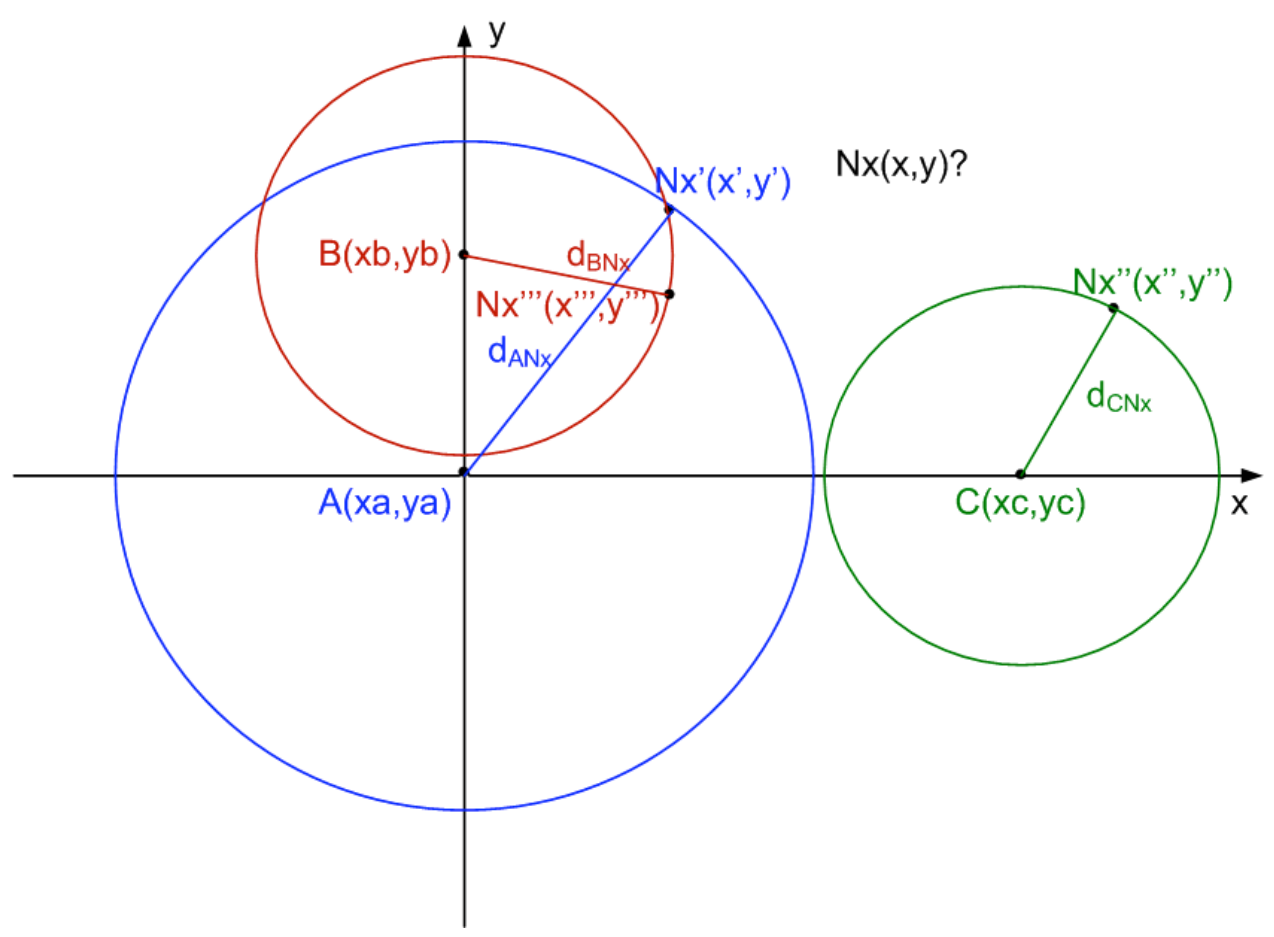

Figura 5.2 - Estimativa das coordenadas quando há solução parcial para as equações.

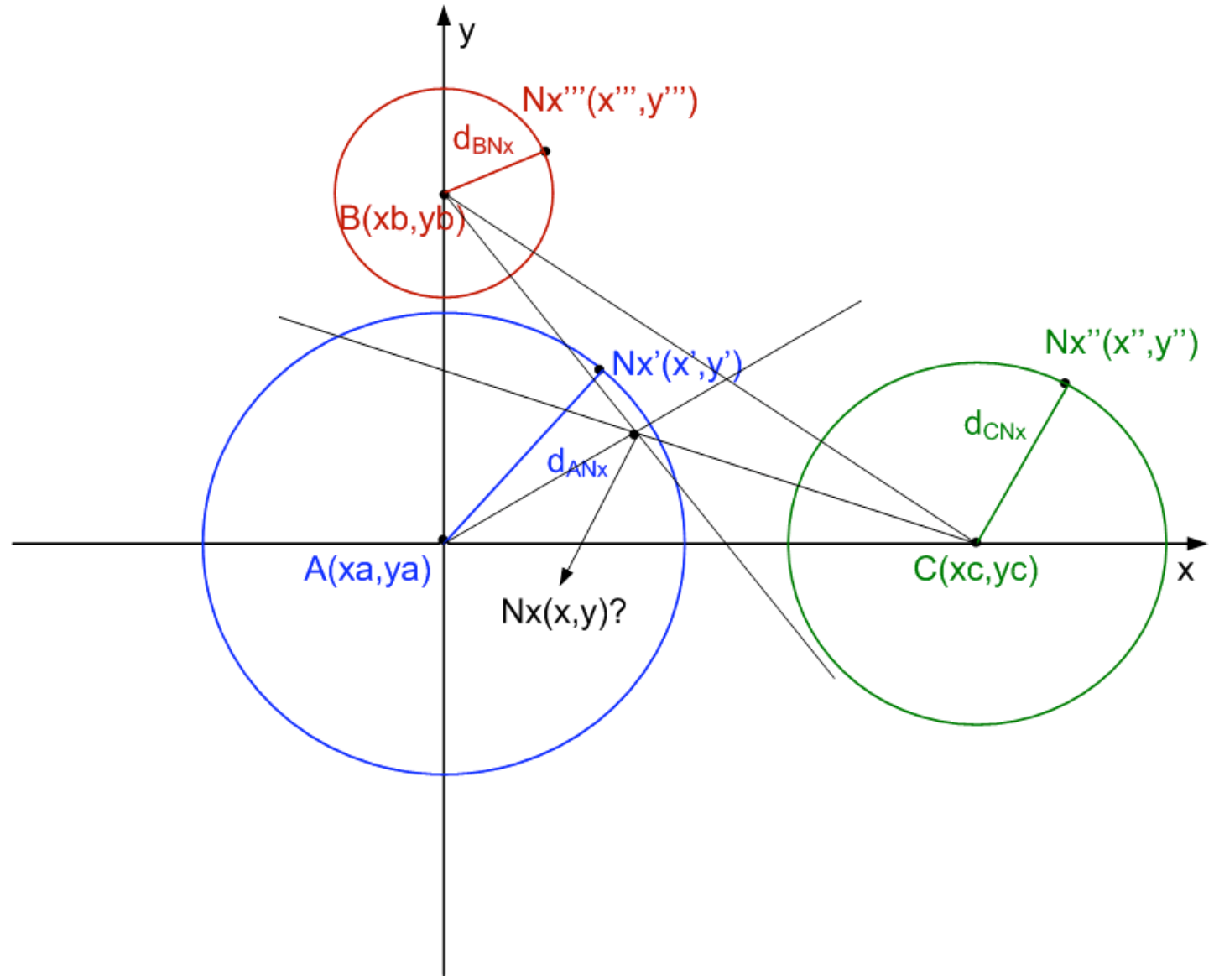

Figura 5.3 - Estimativa das coordenadas quando não há solução para as equações. 
O script em Python do experimento executado encontra-se no CD com a cópia da dissertação.

\subsection{Análise dos Resultados para o Erro de Estimativa}

A análise os resultados experimentais está organizada de modo a considerar as possíveis equivalências entre os cenários conforme descrito na Tabela 5.6. Para cada grupo de cenários, são apresentadas a porcentagem de casos em que foi possível estimar as coordenadas, ou seja, houve solução para o sistema de equações (2) e o comportamento da porcentagem de erro $(\varepsilon)$ obtida na estimativa.

Cenário 1.1 - Nós de Referência próximos e nós que entram no overlay próximos RF_PROXIMOS_NOS_PROXIMOS.

Para este cenário, a porcentagem de casos em que foi possível estimar as coordenadas foi em torno de 90\% (Gráfico 5.2).

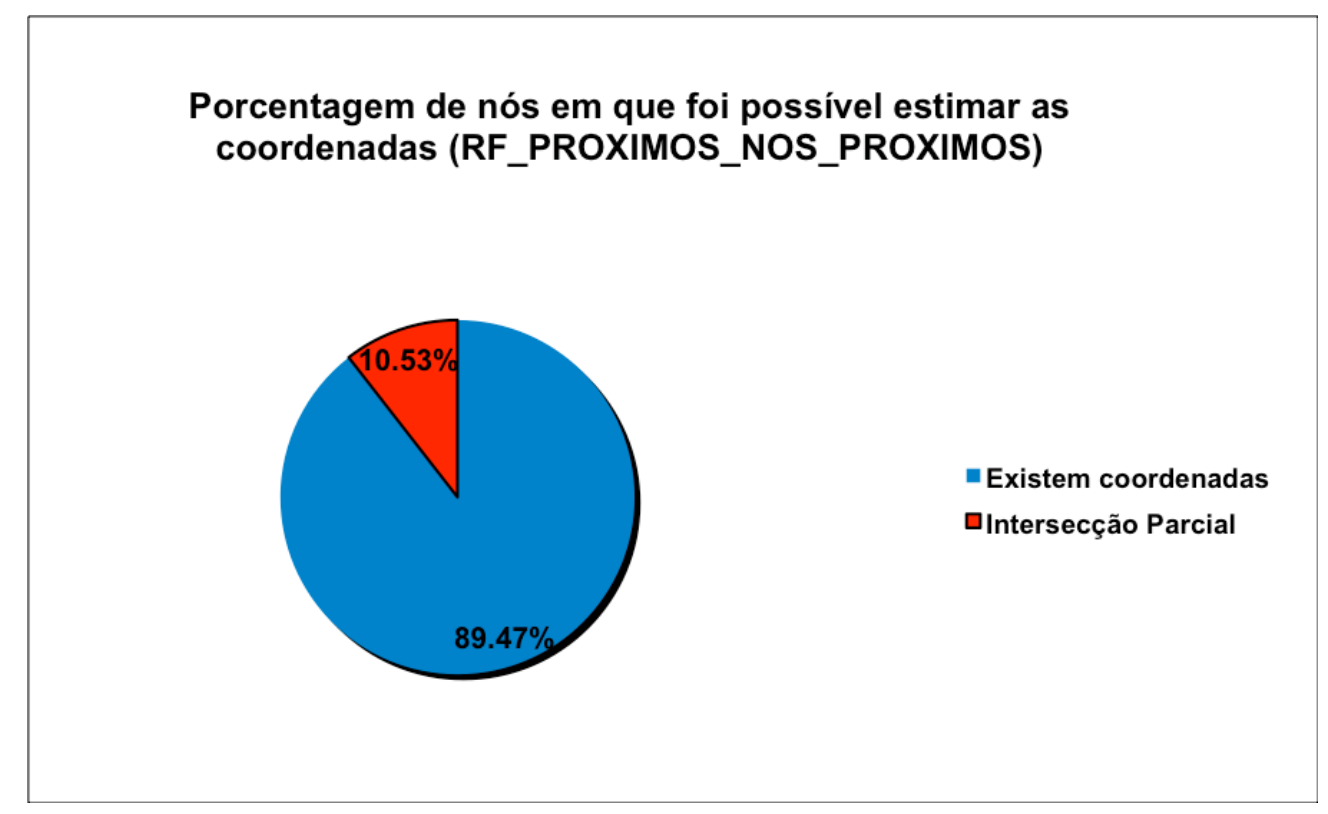

Gráfico 5.2 - Porcentagem de casos em que foi possível estimas as coordenadas - cenário RF_PROXIMOS_NOS_PROXIMOS. 
O erro de estimativa $(\varepsilon)$ teve comportamento conforme o Gráfico 5.3 . Para $55 \%$ dos casos foi maior que $60 \%$, no entanto, não ocorreram situações em que o erro é muitas ordens de grandeza maior que 100\% ( $\varepsilon \gg>100 \%$ ). Embora a porcentagem de casos em que foi possível estimar as coordenadas tenha sido elevada, o erro de estimativa mostrou-se elevado, indicando que a situação em que os Nós de Referência e os nós que entram no overlay são próximos faz com que o comportamento do protocolo seja anômalo, isto é, nessa situação o erro de estimativa das coordenadas será elevado e muitos nós tornar-se-ão erroneamente controladores, independentemente do limiar de latência (50 ms como definido no protocolo ou um valor da mesma ordem de grandeza da distância entre os nós - $<1$ $\mathrm{ms})$. Esses resultados indicam que para nós muito próximos, estimar a posição dos pares por meio de coordenadas não é eficiente. Para estes casos, é mais interessante selecionar os pares de forma randômica.

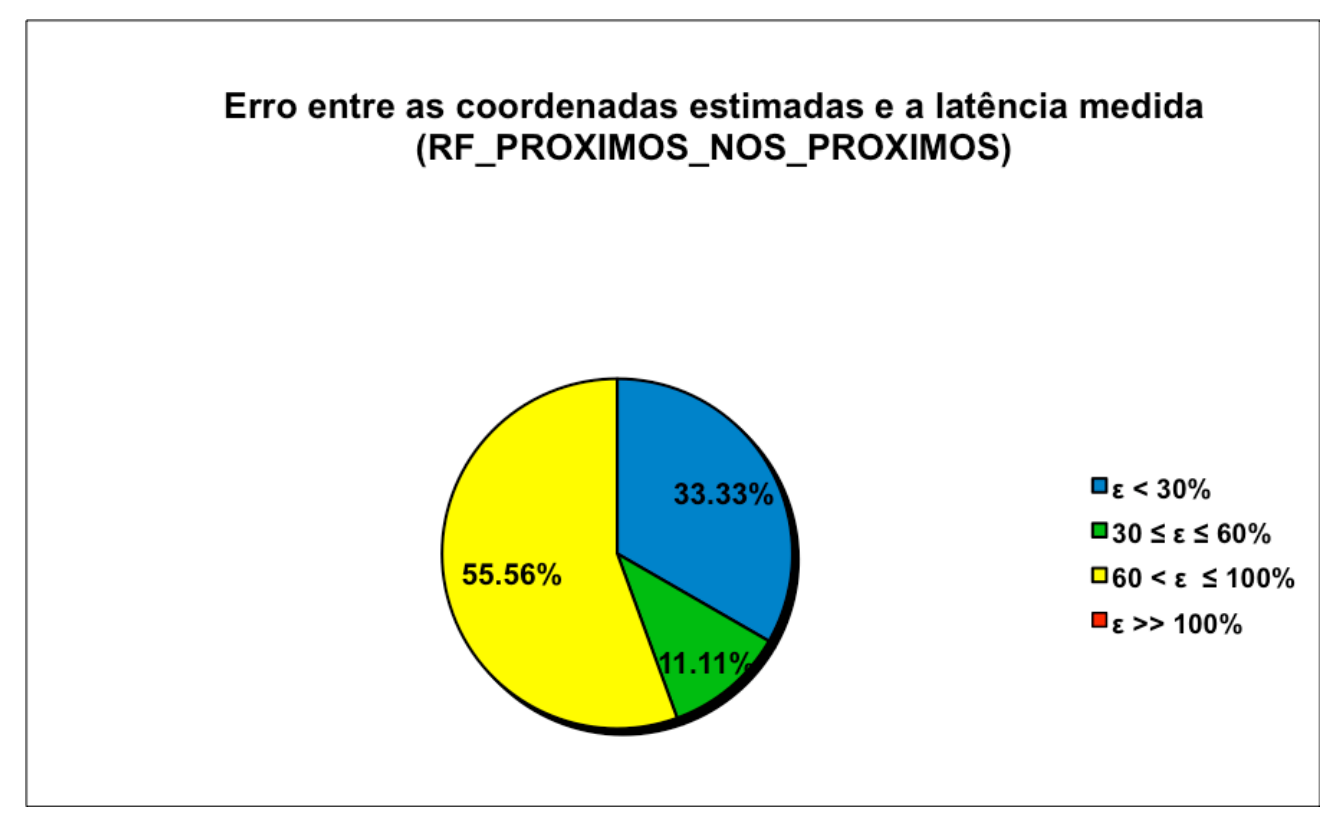

Gráfico 5.3 - Comportamento do erro de estimativa das coordenadas $(\varepsilon)$ - Cenário RF_PROXIMOS_NOS_PROXIMOS.

Cenário 1.2 e Cenário 1.3 - Nós de Referência próximos e nós que entram no overlay nos Estados Unidos ou distribuídos pelo mundo RF_PROXIMOS_NOS_EUA e RF_PROXIMOS_NOS_LONGE. 
Para estes cenários, a porcentagem de casos em que foi possível estimar as coordenadas foi em torno de 20\% (Gráfico 5.4 e Gráfico 5.5), o que representa um índice muito baixo. Isso ocorre pois na medida em que os Nós de Referência estão distantes entre si algumas ordens de grandeza a menos que os nós que entram no overlay (1ms $\ll 500 \mathrm{~ms}$ ), para o processo de estimativa de coordenadas essa situação passa a equivaler ao caso que há apenas um Nó de Referência, o que faz com que existam muitas situações em que não há solução para o sistema de equações apresentado (2).

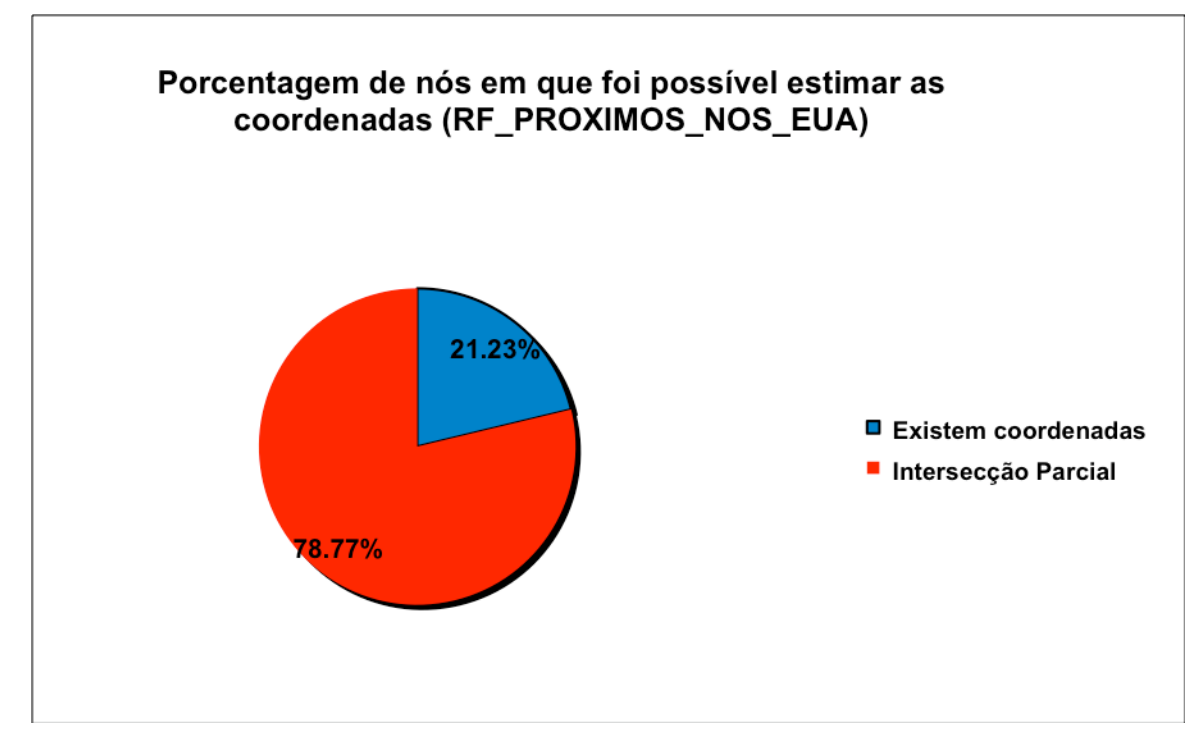

Gráfico 5.4 - Porcentagem de casos em que foi possível estimas as coordenadas - cenário RF_PROXIMOS_NOS_EUA.

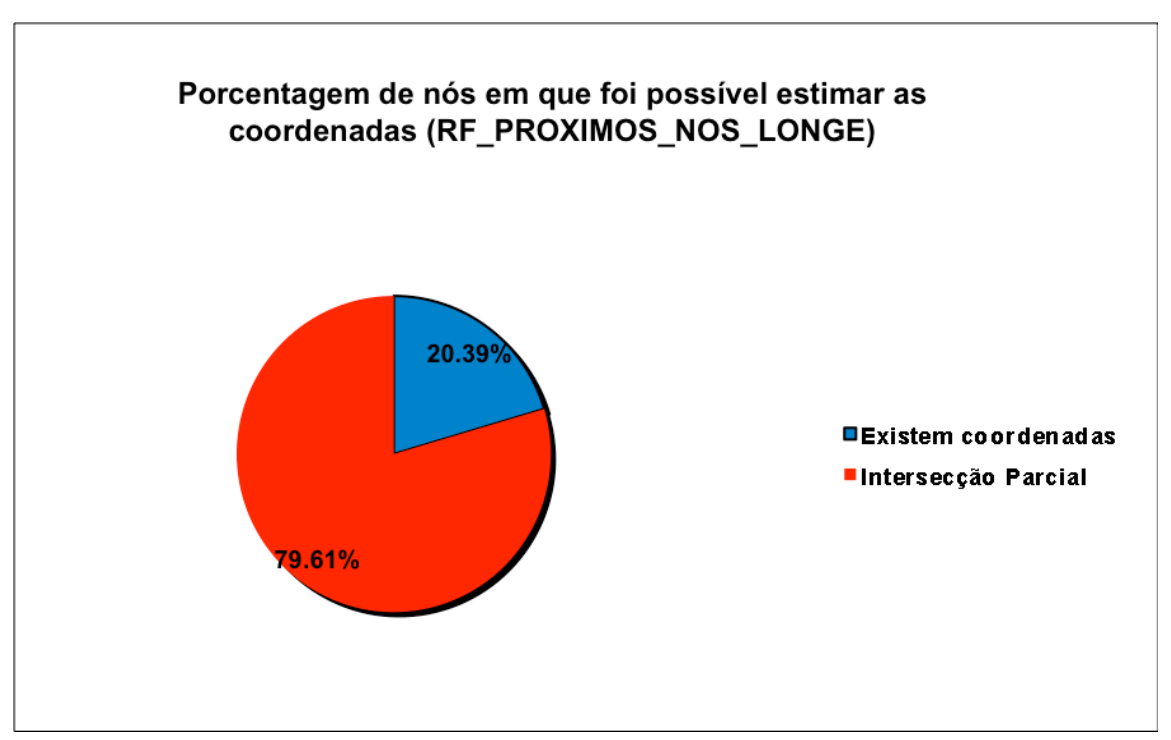

Gráfico 5.5 - Porcentagem de casos em que foi possível estimas as coordenadas - cenário RF_PROXIMOS_NOS_LONGE. 
Com relação ao erro de estimativa $(\varepsilon), 30$ a $50 \%$ dos casos apresentaram erros várias ordens de grandeza maior que $100 \%$, ao passo que 20 a $50 \%$ dos casos apresentaram erros menores que 30\% (Gráfico 5.6 e Gráfico 5.7). Esses resultados indicam que para esses cenários, a distribuição dos erros é aleatória e uniforme. Assim como no cenário 1.1, nesses cenários muitos nós tornar-se-ão erroneamente controladores, e da mesma forma que no cenário anterior, fica evidente que quando os Nós de Referência estão muito próximos, a seleção de pares de forma randômica passa a ser uma alternativa melhor do que a seleção híbrida usando coordenadas e medidas sob demanda, pois apesar de apresentar erros significativos, esta forma de seleção elimina o overhead introduzido pelo processo de estimativa de coordenadas. Em outras palavras, não é viável aumentar o overhead na seleção de pares, se os erros introduzidos pelo processo de estimativa de coordenadas são elevados.

\section{Erro entre as coordenadas estimadas e a latência medida}

(RF_PROXIMOS_NOS_EUA)

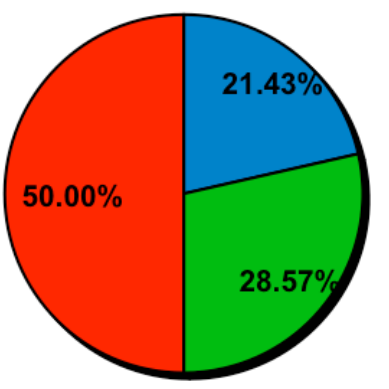

$\square_{\varepsilon}<30 \%$

$\square 30 \leq \varepsilon \leq 60 \%$

$\square 60<\varepsilon \leq 100 \%$

$\square \varepsilon \gg 100 \%$

Gráfico 5.6 - Comportamento do erro de estimativa das coordenadas $(\varepsilon)-$ Cenário RF_PROXIMOS_NOS_EUA. 


\section{Erro entre as coordenadas estimadas e a latência medida}

(RF_PROXIMOS_NOS_LONGE)

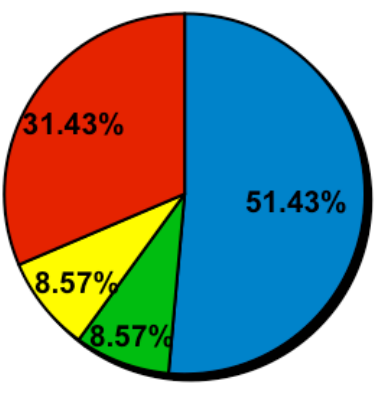

$\square_{\varepsilon}<30 \%$

$\square 30 \leq \varepsilon \leq 60 \%$

$\square 60<\varepsilon \leq 100 \%$

$\square_{\varepsilon} \gg 100 \%$

Gráfico 5.7 - Comportamento do erro de estimativa das coordenadas $(\varepsilon)$ - Cenário RF_PROXIMOS_NOS_LONGE.

Cenário 2.1 e Cenário 3.1 - Nós de Referência nos Estados Unidos ou distribuídos pelo mundo e nós que entram no overlay próximos - RF_EUA_NOS_PROXIMOS e RF_LONGE_NOS_PROXIMOS.

No caso desses cenários, a porcentagem de casos em que foi possível estimar as coordenadas foi elevada, variando entre 74 a $84 \%$ (Gráfico 5.8 e Gráfico 5.9). Este fato ocorreu, pois Nós de Referência distantes aumentam as chances de existir intersecção entre as três circunferências mencionadas na seção 5.1.2.2, ou seja, as distâncias entre cada novo nó que entra no overlay e os Nós de Referência é grande o suficiente para que exista um ponto (coordenada) que satisfaça o sistema de equações com o menor erro possível (baricentro do triângulo cujos vértices são dos pontos de intersecção das circunferências). Embora a porcentagem de casos em que foi constatada intersecção tenha sido elevada, os erros foram elevados (Gráfico 5.10 e Gráfico 5.11), com 54 a 94\% dos casos apresentando erro muitas ordens de grandeza maior que $100 \%$. Isso ocorreu em razão do método de estimativa de erro utilizado, o qual não é eficiente para os casos em que a latência medida entre os pares é pequena. O erro de estimativa $(\varepsilon)$ é calculado como sendo a relação entre a diferença da distância calculada por meio das coordenadas estimadas e a distância medida, e a distância medida. Dessa forma, quando a distância medida entre os nós 
é pequena ( $<1 \mathrm{~ms}$ ), o erro obtido na distância estimada, mesmo que seja pequeno, irá acarretar em um elevado erro de estimativa $(\varepsilon)$.

$\varepsilon=($ distância estimada - distância medida) / (distância medida) (3)

\section{Porcentagem de nós em que foi possível estimar as} coordenadas (RF_EUA_NOS_PROXIMOS)

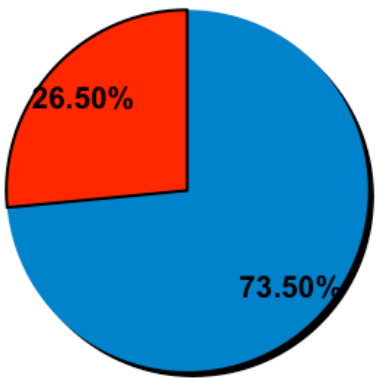

Existem coordenadas

口Intersecção Parcial

Gráfico 5.8 - Porcentagem de casos em que foi possível estimas as coordenadas - cenário RF_EUA_NOS_PROXIMOS

Porcentagem de nós em que foi possível estimar as coordenadas (RF_LONGE_NOS_PROXIMOS)

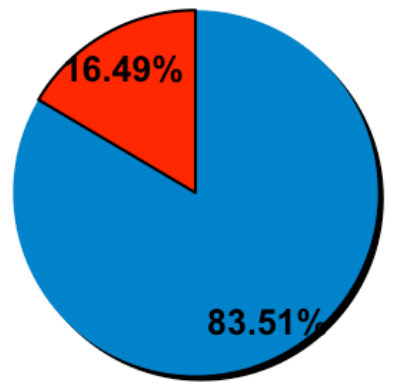

- Existem coordenadas

- Intersecção Parcial

Gráfico 5.9 - Porcentagem de casos em que foi possível estimas as coordenadas - cenário RF_LONGE_NOS_PROXIMOS. 
Erro entre as coordenadas estimadas e a latência medida (RF_EUA_NOS_PROXIMOS)

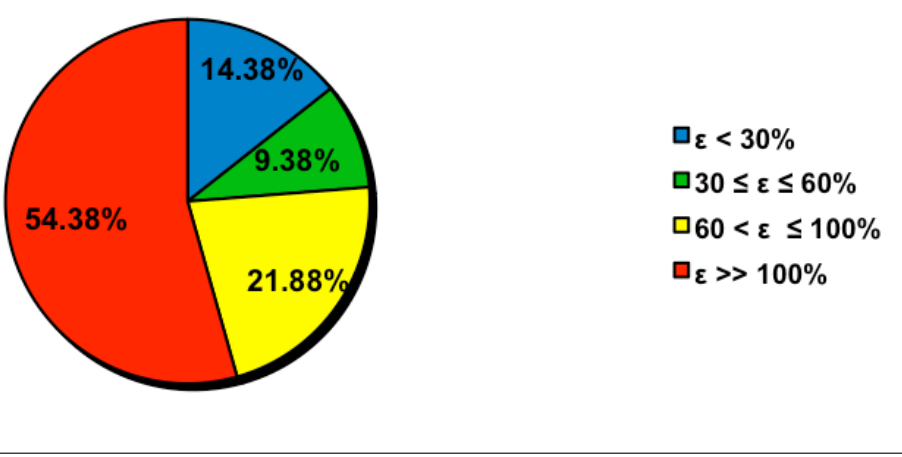

Gráfico 5.10 - Comportamento do erro de estimativa das coordenadas $(\varepsilon)$ - Cenário RF_EUA_NOS_PROXIMOS.

Erro entre as coordenadas estimadas e a latência medida (RF_LONGE_NOS_PROXIMOS)

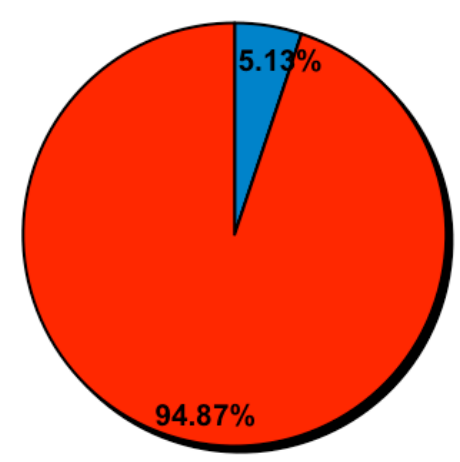

$\square_{\varepsilon}<30 \%$

$\square 30 \leq \varepsilon \leq 60 \%$

$\square 60<\varepsilon \leq 100 \%$

$\square_{\varepsilon} \gg 100 \%$

Gráfico 5.11 - Comportamento do erro de estimativa das coordenadas $(\varepsilon)$ - Cenário RF_LONGE_NOS_PROXIMOS. 
Cenário 2.2, Cenário 2.3, Cenário 3.2 e Cenário 3.3 - Nós de Referência nos Estados Unidos ou distribuídos pelo mundo e nós que entram no overlay nos Estados Unidos ou distribuídos pelo mundo - RF_EUA_NOS_EUA, RF_EUA_NOS_LONGE, RF_LONGE_NOS_EUA, RF_LONGE_NOS_LONGE.

Para esses cenários, a porcentagem de casos em que foi possível estimar as coordenadas foi elevada, variando de 70 a 80\% (Gráfico 5.12, Gráfico 5.13, Gráfico 5.14 e Gráfico 5.15). Esses resultados evidenciam que o protocolo comporta-se de forma satisfatória quando as latências entre os Nós de Referência e os nós que entram no overlay são elevadas e da mesma ordem de grandeza (de 100 a 500 ms). Nesses casos é vantajosa a utilização da técnica híbrida para escolha dos pares, ou seja, utilizar um sistema de coordenadas para uma estimativa inicial dos pares que estão mais próximos em termos de latência de um dado par que acaba de entrar no grupo, e em seguida usar a técnica de medida sob-demanda para refinar a escolha.

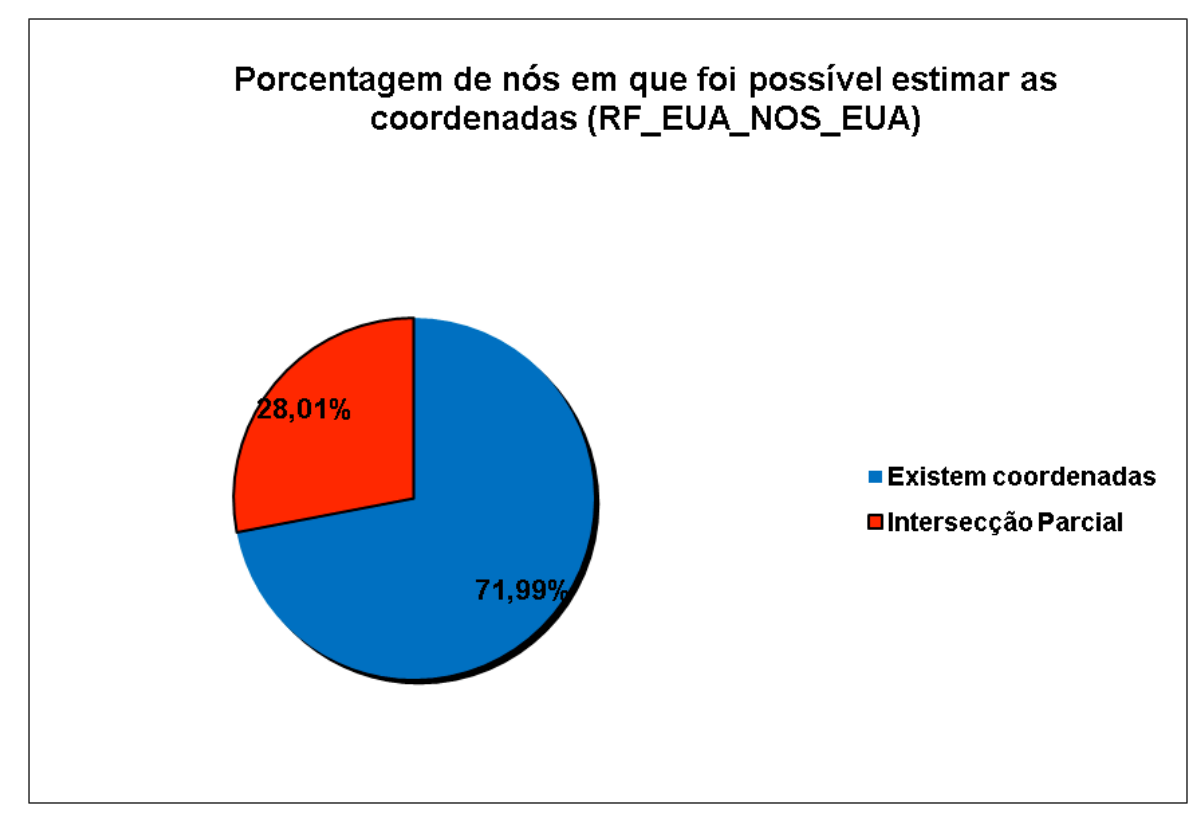

Gráfico 5.12 - Porcentagem de casos em que foi possível estimas as coordenadas - cenário RF_EUA_NOS_EUA. 
Porcentagem de nós em que foi possível estimar as coordenadas (RF_EUA_NOS_LONGE)

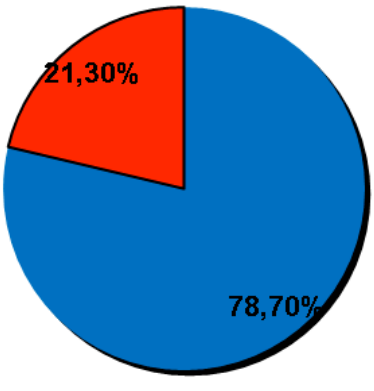

Existem coordenadas

口Intersecção Parcial

Gráfico 5.13 - Porcentagem de casos em que foi possível estimas as coordenadas - cenário RF_EUA_NOS_LONGE.

Porcentagem de nós em que foi possível estimar as coordenadas (RF_LONGE_NOS_EUA)

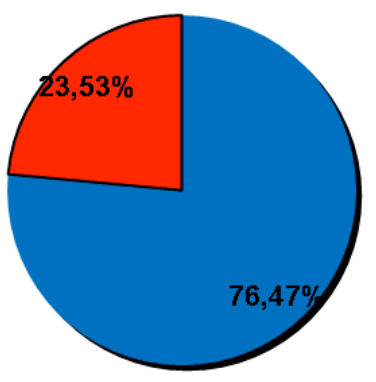

- Existem coordenadas

uIntersecção Parcial

Gráfico 5.14 - Porcentagem de casos em que foi possível estimas as coordenadas - cenário RF_LONGE_NOS_EUA. 


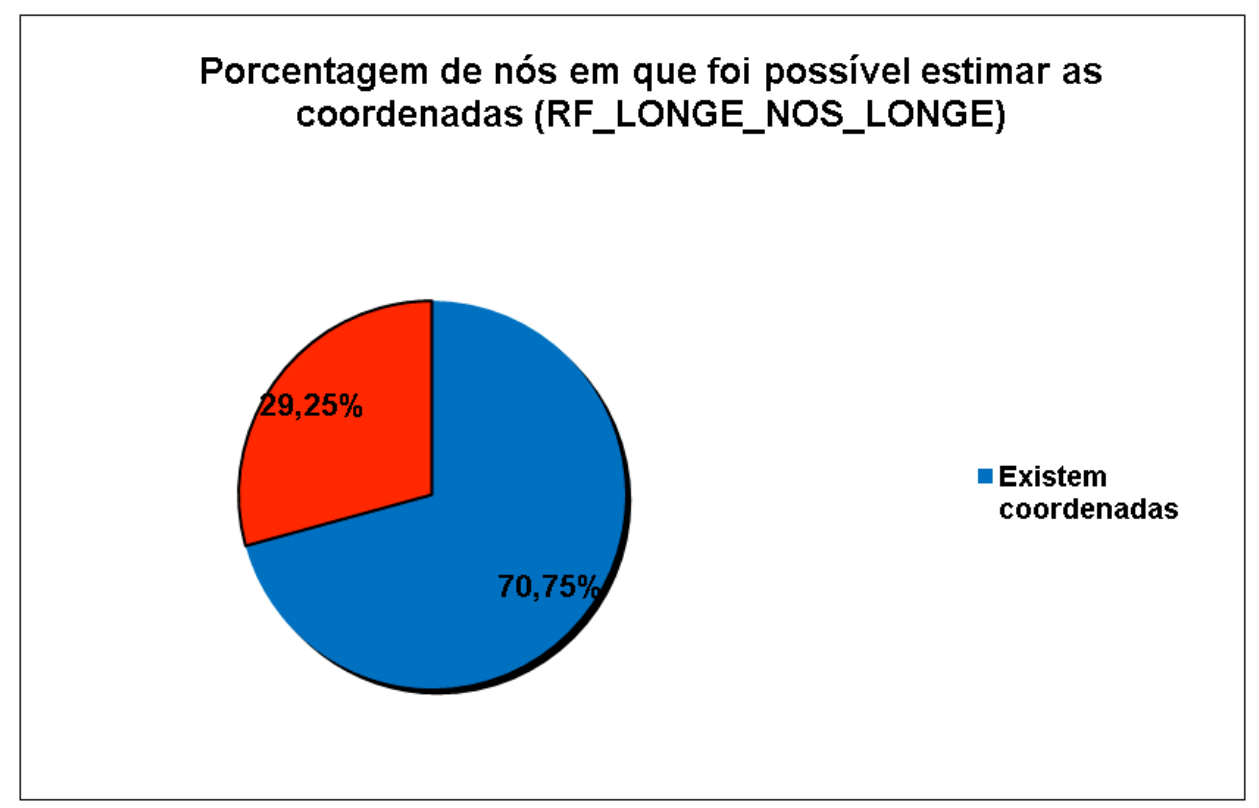

Gráfico 5.15 - Porcentagem de casos em que foi possível estimas as coordenadas - cenário RF_LONGE_NOS_LONGE.

Com relação ao erro de estimativa $(\varepsilon)$, estes cenários foram os que apresentaram melhor comportamento. Em 40 a $60 \%$ dos casos apresentaram erro menor que $30 \%$, sendo que em apenas 6 a $13 \%$ dos casos o erro foi muito maior que $100 \%$ (Gráfico 5.16, Gráfico 5.17, Gráfico 5.18 e Gráfico 5.19 ).

\section{Erro entre as coordenadas estimadas e a latência medida (RF_EUA_NOS_EUA)}

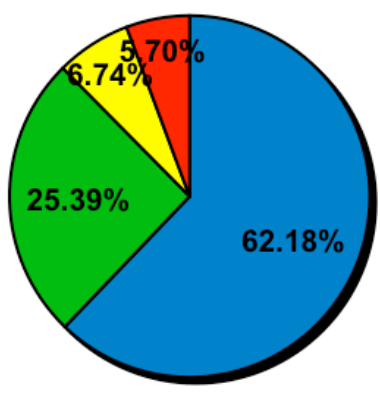

$\square \varepsilon<30 \%$

$\square 30 \leq \varepsilon \leq 60 \%$

$\square 60<\varepsilon \leq 100 \%$

$\square \varepsilon \gg 100 \%$

Gráfico 5.16 - Comportamento do erro de estimativa das coordenadas $(\varepsilon)$ - Cenário RF_EUA_NOS_EUA. 
Erro entre as coordenadas estimadas e a latência medida (RF_EUA_NOS_LONGE)

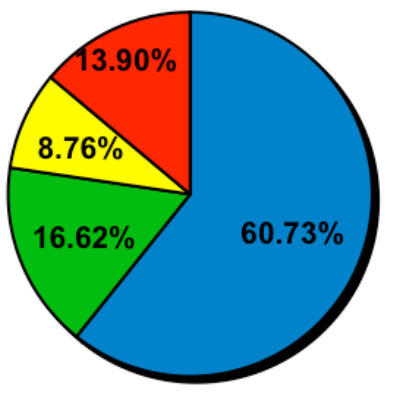

$\square_{\varepsilon}<30 \%$

$\square 30 \leq \varepsilon \leq 60 \%$

$\square 60<\varepsilon \leq 100 \%$

$\square \varepsilon \gg 100 \%$

Gráfico 5.17 - Comportamento do erro de estimativa das coordenadas $(\varepsilon)$ - Cenário RF_EUA_NOS_LONGE.

Erro entre as coordenadas estimadas e a latência medida (RF_LONGE_NOS_EUA)

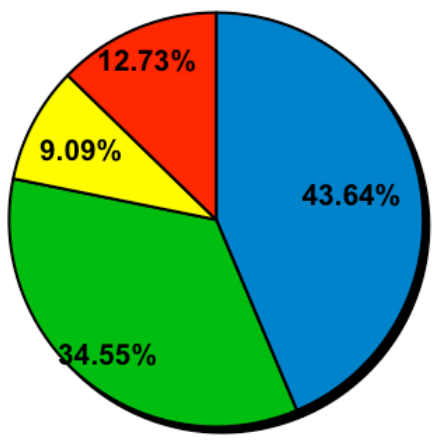

$\square_{\varepsilon}<30 \%$

$\square 30 \leq \varepsilon \leq 60 \%$

$\square_{60}<\varepsilon \leq 100 \%$

$\square_{\varepsilon} \gg 100 \%$

Gráfico 5.18 - Comportamento do erro de estimativa das coordenadas $(\varepsilon)$ - Cenário RF_LONGE_NOS_EUA. 


\section{Erro entre as coordenadas estimadas e a latência medida} (RF_LONGE_NOS_LONGE)

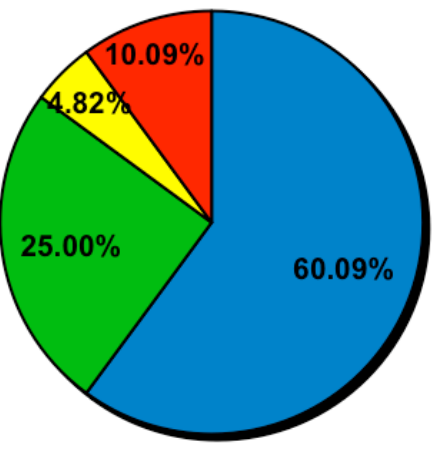

$\square_{\varepsilon}<30 \%$

$\square 30 \leq \varepsilon \leq 60 \%$

$\square 60<\varepsilon \leq 100 \%$

$\square_{\varepsilon} \gg 100 \%$

Gráfico 5.19 - Comportamento do erro de estimativa das coordenadas $(\varepsilon)$ - Cenário RF_LONGE_NOS_LONGE.

Considerando que o número de casos em que o erro de estimativa foi muito menor que $100 \%$ foi pequeno, foram traçadas as funções de distribuição cumulativa de probabilidades para o erro estimado de modo a comparar o comportamento do erro entres esses quatro últimos cenários (Gráfico 5.20). Analisando as curvas, verifica-se a equivalência existente entre estes cenários, sendo que a variação do erro comportou-se de forma similar. Esse resultado reforça as vantagens da utilização da técnica híbrida para a seleção de pares dentro do overlay, indicando que o protocolo comporta-se de forma satisfatória quando a diferença entre as distâncias entre os Nós de Referência e os nós que entram no overlay são da mesma ordem de grandeza. 


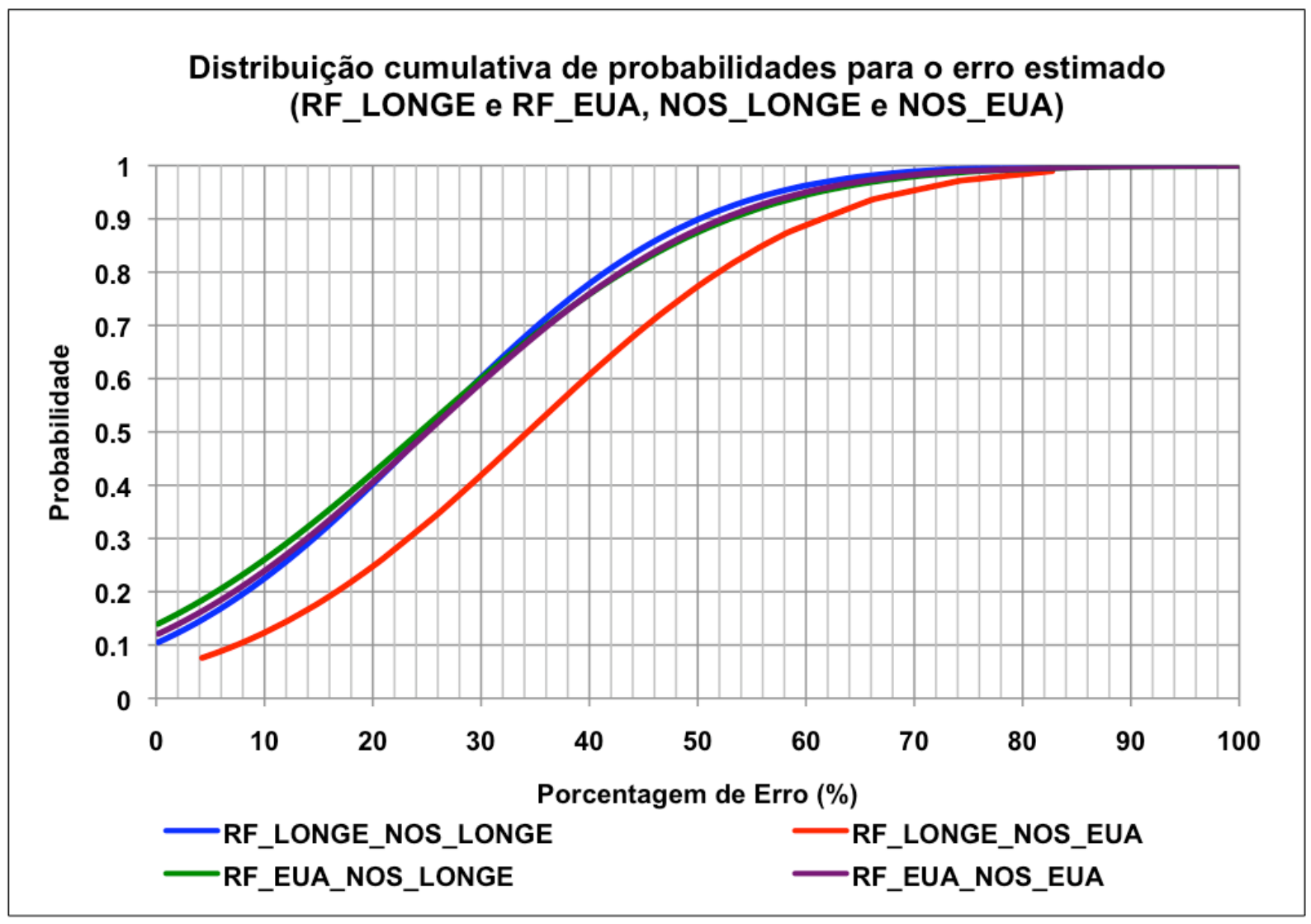

Gráfico 5.20 - Distribuição cumulativa de probabilidades para o erro estimado.

\subsection{Considerações Finais}

As análises apresentadas nas seções anteriores demonstram o grande desafio que existe ao se tentar estimar a posição dos nós que entram no overlay considerandose um sistema de coordenadas formado por Nós de Referência, principalmente quando as latências entre os mesmos são pequenas. Conforme fora mencionado na seção 4.3.5, a escolha dos Nós de Referência ainda é um problema em aberto, principalmente se for considerado que os mesmos serão pares que participam do overlay de distribuição (Controladores ou Nós Ordinários), seguindo o requisito da inexistência de infra-estrutura de suporte. Diante desses aspectos, fica mais evidente que uma das alternativas viáveis para a escolha destes nós é considerar elementos que não necessariamente façam parte do grupo de distribuição (overlay), como no caso da utilização de outras aplicações que possam também assumir a funcionalidade de Nós de Referência. Por exemplo: em um ambiente corporativo, 
onde é utilizada uma aplicação para comunicação interna, poderia ser desenvolvido algum tipo de extensão para esse aplicativo que agregasse a ele a função de Nó de Referência. Isso funcionaria, pois muitas vezes os usuários de uma aplicação como um Instant Messenger corporativo deixam a aplicação em execução, mesmo que não estejam utilizando. Este exemplo reforça a idéia de que não há uma solução geral para a escolha desses nós e sim que cada tipo de cenário exige que sejam considerados os Nós de Referência adequados.

Os resultados dos experimentos também demonstraram que, uma vez escolhidos os Nós de Referência adequados (no caso, distantes em termos de latência), torna-se viável a utilização de um sistema de coordenadas para uma estimativa inicial dos pares candidatos $\{\mathrm{Ci}\}$ a se conectarem a um dado par (Nx) que entra no overlay, reduzindo, desta forma, o overhead que existiria se a seleção dos pares mais próximos em termos de latência fosse feita após a realização de medidas de latências para todos os pares do grupo de distribuição. Ou, por outro lado, a inexistência de qualquer associação entre o overlay lógico e a rede física que o suporta faria com que a seleção fosse completamente randômica. Essa independência entre o overlay e a rede física impactaria na disponibilidade do streaming de vídeo, na escalabilidade do overlay e no nível de qualidade do serviço provido, podendo até mesmo inviabilizar o cenário de aplicação proposto (vídeoconferência). Ainda com relação à utilização de um sistema de coordenadas, ficou evidente que um sistema de coordenadas euclidiano bi-dimensional, extremamente simples, implicou em bons resultados para a estimativa da posição relativa entre os pares do overlay. Pela simplicidade, este sistema de coordenadas conduz a um baixo overhead, reforçando um dos mais importantes princípios diretores levados em consideração no projeto desse protocolo, o qual corresponde à construção do overlay lógico para a distribuição de streamings de vídeo considerando as características da rede física que o suporta, mas sem aumentar demasiadamente o overhead de controle (latency-overhead tradeoff), o que nitidamente tornaria a proposta inviável. Outro fator determinante para o não aumento do overhead de controle foi a constatação de que a utilização de técnicas de medida simples como pings, implica em boas estimativas para posição relativa entre os pares que entram no overlay. 


\section{CONCLUSÕES}

\subsection{Análise Crítica}

O protocolo proposto neste trabalho foi concebido de modo a construir um overlay para a distribuição de streamings de vídeo considerando as características da rede física que o suporta. Desse modo, o principal princípio diretor utilizado na definição do mesmo refere-se à organização dos pares por meio do agrupamento daqueles que estão mais próximos em termos de latência. Para isso foi utilizada uma técnica de construção híbrida que considera um sistema de coordenadas euclidiano bidimensional formado por três Nós de Referência, usado para uma estimativa inicial da posição dos pares. Após esta estimativa inicial, medidas sob demanda (RTT Round-Trip Time) são realizadas para confirmar quais são os pares efetivamente mais próximos de um novo par que entra no overlay. Os resultados dos experimentos demonstraram que não é viável utilizar um sistema de coordenadas como o que foi proposto se as distâncias entre os Nós de Referência forem muito menores (uma ou duas ordens de grandeza) com relação às distâncias entre os pares que se associam ao overlay e estes Nós de Referência. Com isso, não se pode considerar que os Nós de Referência serão os pares (no caso os três primeiros), que se associam inicialmente ao grupo de distribuição do streaming. Uma solução para este problema seria eleger nós que não necessariamente façam parte do grupo de distribuição (overlay) como sendo Nós de Referência conforme fora exemplificado em seções anteriores. Além da distância entre os nós de referência foi constatado também que o período em que as latências entre os mesmos são medidas, assim como o método de medida utilizado não influenciam significativamente na posição dos nós, o que não justifica o acréscimo no overhead pela utilização de técnicas de medidas sofisticadas. Por outro lado, uma vez escolhidos os Nós de Referência adequados (no caso, distantes em termos de latência), torna-se viável a utilização de um sistema de coordenadas para uma estimativa inicial dos pares candidatos $\{\mathrm{Ci}\}$ a se conectarem a um dado par $(\mathrm{Nx})$ que 
entra no overlay, reduzindo, desta forma, o overhead que existiria se a seleção dos pares mais próximos em termos de latência fosse feita após a realização de medidas de latências para todos os pares do grupo de distribuição. Esta última constatação valida o supracitado principio diretor usado no projeto deste protocolo: construir um overlay considerando-se as características da rede física.

Outro princípio diretor utilizado na definição deste protocolo refere-se ao tratamento do overhead de controle. Para reduzir e melhor gerenciar o overhead foram definidos os nós Controladores. A existência desses nós, a utilização de um sistema de coordenadas simples e a utilização de pings para medida de latência são os elementos responsáveis pela redução do overhead e a conseqüente melhoria da escalabilidade do protocolo. Outro fator determinante para o não aumento do overhead de controle foi a constatação de que a utilização de técnicas de medida simples como pings, implica em boas estimativas para posição relativa entre os pares que entram no overlay.

\subsection{Trabalhos Futuros}

O principal foco deste trabalho foi a definição do protocolo e a validação dos aspectos relativos à utilização do sistema de coordenadas. Uma evolução natural seria validar o método proposto para o armazenamento distribuído de coordenadas entre os nós Controladores. Isso poderia ser feito implementando-se o algoritmo de armazenamento de coordenadas com o uso de alguma linguagem de programação (por exemplo, C) e em seguida, simulando-se o comportamento do tempo de recuperação das coordenadas dos nós controladores conforme fosse aumentando o número de nós no overlay.

Após a validação do método de armazenamento de coordenadas, o próximo passo seria a implementação de um protótipo do protocolo proposto. Nesse caso, poderiam ser validados outros aspectos do mesmo, como o comportamento em caso de falha de um ou mais nós (resiliência do protocolo), o tempo de resposta para iniciar a recepção de um streaming e as questões relativas ao balanceamento de carga entre 
os Controladores durante eventos em que ocorrem muitas entradas e saídas de pares (flash-crowd). 


\section{REFERÊNCIAS BIBLIOGRÁFICAS}

AKAMAI. Web Application Acceleration and Performance Management, Streaming Media Services, and Content Delivery. Disponível em: <http://www.akamai.com/>. Acesso em 20 de jun. 2008.

AMAD, M.; MEDDAHI, A. A Scalable Approach for Application Layer Multicast in P2P Networks. In: Pervasive Computing and Communications, 2008. PerCom 2008. Sixth Annual IEEE International Conference on. p. 498-503, 2008.

ARMAND, M.; MEDDAHI, A.. A Scalable Approach for Application Layer Multicast in P2P Networks. Pervasive Computing and Communications, pp. 498-503, 2008 Apresentado em: PerCom 2008. Sixth Annual IEEE International Conference. Hong Kong, 2008.

BASET, S. A.; SCHULZRINNE, H. An Analysis of the Skype Peer-to-Peer Internel Telephony Protocol. In: , In: IEEE INFOCOM 2006. 25th IEEE International Conference on Computer Communications. IEEE Computer Society Press, Los Alamitos, CA. 2006.

BISHOP, M.; RAO, S.; SRIPANIDKULCHAI, K. Considering Priority in Overlay Multicast Protocols Under Heterogeneous Environments. In: IEEE INFOCOM 2006. 25th IEEE International Conference on Computer Communications. IEEE Computer Society Press, Los Alamitos, CA. 2006. p. 1-13.

CASTRO, M.; DRUSCHEL, P.; KERMARREC, A. M.; ET AL. SplitStream: highbandwidth multicast in cooperative environments. ACM Press New York, NY, USA, 2003. p. 298-313.

CHAO, Z.; HAI, J.; DAFU, D.; ET AL. Anysee: Multicast-based Peer-to-Peer Media Streaming Service System. In: COMMUNICATIONS, 2005. Asia-Pacific Conference, 2005. p. 274-278.

FRANCIS, P.; JAMIN, S.; JIN, C.; ET AL. IDMaps: a global internet host distance estimation service. ACM Press New York, NY, USA, 2001. p. 525-540.

GUOQIANG, Z.; GUOQING, Z. Agent Selection And P2P Overlay Construction Using Global Locality Knowledge. In: Networking, Sensing and Control, 2007 IEEE International Conference, 2007.. p. 519-524. 
HOTZ, S. Routing information organization to support scalable interdomain routing with heterogeneous path requirements. Tese de doutorado da Universidade da Califórnia do Sul, 1994.

IPERF. A tool to measure the maximum TCP bandwidth between two points on the internet. 2008.

JIANGCHUAN, L.; RAO, S. G.; BO, L.; HUI, Z. Opportunities and Challenges of Peer-to-Peer Internet Video Broadcast. Proceedings of the IEEE, v. 96, n. 1, p. 1124, 2008.

KOSTIC, D.; RODRIGUEZ, A.; ALBRECHT, J.; VAHDAT, A. Bullet: high bandwidth data dissemination using an overlay mesh. ACM Press New York, NY, USA, 2003. P. 282-297.

LAO, L.; CUI, J. H.; GERLA, M.; MAGGIORINI, D. A Comparative Study of Multicast Protocols: Top, Bottom, or In the Middle? .2005.

LIAO, X.; JIN, H.; LIU, Y.; NI, L. M. Scalable Live Streaming Service Based on Interoverlay Optimization. Parallel and Distributed Systems, IEEE Transactions on, v. 18, n. 12, p. 1663-1674, 2007.

LUTZ, M. Programming Python. O'Reilly Media, Inc., 2006.

MAGHAREI, N.; REJAIE, R. PRIME: Peer-to-Peer Receiver-drlven MEsh-based Streaming. In: , INFOCOM 2007. 26th IEEE International Conference on Computer Communications, 2007. p. 1415-1423.

MAGHAREI, N.; REJAIE, R. Understanding Mesh-based Peer-to-Peer Streaming. ACM Press New York, NY, USA, 2006.

MAGHAREI, N.; REJAIE, R.; GUO, Y. Mesh or Multiple-Tree: A Comparative Study of Live P2P Streaming Approaches. In: INFOCOM 2007. 26th IEEE International Conference on Computer Communications, 2007. ACM Press New York, NY, USA, 2007. p.127-136.

NETPERF. Disponível em: <http://www.netperf.org/netperf/>. Acesso em 7 ago. 2008. 
NG, T. S. E.; CHU, Y. H.; RAO, S. G.; SRIPANIDKULCHAI, K.; ZHANG, H. Measurement-based optimization techniques for bandwidth-demanding peerto-peer systems. In: INFOCOM 2003. Twenty-Second Annual Joint Conference of the IEEE Computer and Communications Societies. IEEE. v. 3, 2003. p. 2199-2209.

NG, T. S. E.; HUI, Z. Predicting Internet network distance with coordinates-based approaches. In: INFOCOM 2002. Twenty-First Annual Joint Conference of the IEEE Computer and Communications Societies. Proceedings. IEEE. v. 1, 2002. p. 170179.

PAI, V.; KUMAR, K.; TAMILMANI, K.; SAMBAMURTHY, V.; MOHR, A. E. Chainsaw: Eliminating trees from overlay multicast. Springer, 2005. p. 127-140.

PATERSON, L.; ROSCOE, T. The Design Principles of PlanetLab. Operating Systems Review, v. 40, n. 1, 2006. p. 11-16.

PLANETLAB. PlanetLab Services Page. Disponível em: <http://www.planetlab.org/services>. Acesso em 17 fev. 2008.

POUWELSE, J.; GARBACKI, P.; EPEMA, D.; SIPS, H. The Bittorrent P2P FileSharing System: Measurements and Analysis. In: 4th International Workshop on Peer-to-Peer Systems (IPTPS). Ithaca, New York, USA, 2005.

PYTHON. Python Programming Language - The Official WebSite. Disponível em: <http://www.python.org>. Acesso em: 30 out. 2008.

SILVERSTON, T.; FOURMAUX, O.; DE PARIS, L. I. Source vs Data-driven Approach for Live P2P Streaming. In: . IEEE Computer Society Washington, DC, USA, 2006.

SKYPE. Disponível em: <http://www.skype.com/intl/pt/products/skypeout/>. Acesso em: 24 jun. 2008.

SUBRAMANIAN, L.; BALAKRISHNAN, H.; STOICA, I.. OverQoS: An Overlay based Architecture for Enhancing Internet QoS. In: FIRS SYMPOSIUM ON NEWORKED SYSTEMS DESIGN AND IMPLEMENTATION (NSDI '04)., 2004 San Francisco, California, USA: ACM Press, 2004

TANG, Y.; LUO, J. G.; ZHANG, Q.; ZHANG, M.; YANG, S. Q. Deploying P2P networks for large-scale live video-streaming service. 2007. p. 100-106. 
TOSUN, A. S.; FENG, W. C. Efficient multi-layer coding and encryption of MPEG video streams. 2000.

TU, X.; JIN, H.; DENG, D.; ZHANG, C.; YUAN, Q. Design and Deployment of Locality-Aware Overlay Multicast Protocol for Live Streaming Services. Springer, 2005.

VENKATARAMAN, V.; YOSHIDA, K.; FRANCIS, P. Chunkyspread: Heterogeneous Unstructured Tree-Based Peer-to-Peer Multicast. In: Network Protocols, 2006. ICNP '06. Proceedings of the 2006 14th IEEE International Conference on 2006. p. 2-11.

WANG, F.; XIONG, Y.; LIU, J. mTreebone: A Hybrid Tree/Mesh Overlay for Application-Layer Live Video Multicast. In: Distributed Computing Systems, 2007. ICDCS '07. 27th International Conference on 2007. p. 49-49.

WANG, Z. Internet QoS: Architectures and Mechanisms for Quality of Service. Academic Press, 2001.

WANG, Z.; Internet QoS: Architectures and Mechanisms for Quality of Service: Morgan Kaufmann Publishers, 2001. 239 p.

XHAFA, F.; BAROLLI, L.; FERNANDEZ, R.; DARADOUMIS, T. An Experimental Study on Peer Selection in a P2P Network over PlanetLab. In: Parallel Processing Workshops, 2007. ICPPW 2007. International Conference on 2007. p. 3-3.

XINYAN, Z.; JIANGCHUAN, L.; BO, L.; YUM, Y. S. P. CoolStreaming/DONet: a data-driven overlay network for peer-to-peer live media streaming. In: INFOCOM 2005. 24th Annual Joint Conference of the IEEE Computer and Communications Societies. Proceedings IEEE. v. 3, p. 2102-2111 vol. 3, 2005.

YANG, C.; BEI-XING, D.; XING, L. Canicula: An Improved Hybrid Overlay Networks. In: Networks, 2006. ICON '06. 14th IEEE International Conference on 2006. v. 2, p. 1-6.

YIU, W. P.; XING, J.; CHAN, S. H. G. Challenges and Approaches in Large-Scale P2P Media Streaming. Multimedia, IEEE 2007, v. 14, n. 2, p. 50-59.

ZENNSTRÖM, N.; FRIIS, J. Skype. . Disponível em: <http://www.skype.com>. Acesso em 14 ago. 2008. 
ZHANG, R.; TANG, C.; HU, Y. C.; FAHMY, S.; LIN, X. Impact of the Inaccuracy of Distance Prediction Algorithms on Internet Applications - an Analytical and Comparative Study. In: INFOCOM 2006. 25th IEEE International Conference on Computer Communications. Proceedings, 2006. p. 1-12. 